
prevention in clinical practice: executive summary

\title{
Fourth Joint Task Force of the European Society of Cardiology and Other Societies on Cardiovascular Disease Prevention in Clinical Practice (Constituted by representatives of nine societies and by invited experts)
}

Online publish-ahead-of-print 28 August 2007

Authors/Task Force Members: Ian Graham ${ }^{1 *}$, Chairperson, Dan Atar ${ }^{1}$, Oslo (Norway), Knut Borch-Johnsen ${ }^{2,3}$, Gentofte (Denmark), Gudrun Boysen ${ }^{4}$, Copenhagen (Denmark), Gunilla Burell ${ }^{5}$, Uppsala (Sweden), Renata Cifkova ${ }^{6}$, Praha (Czech Republic), Jean Dallongeville ${ }^{1}$, Lille (France), Guy De Backer ${ }^{1}$, Gent (Belgium), Shah Ebrahim ${ }^{1}$, London (UK), Bjørn Gjelsvik ${ }^{7}$, Oslo (Norway), Christoph Herrmann-Lingen ${ }^{5}$, Marburg (Germany), Arno Hoes ${ }^{7}$, Utrecht (The Netherlands), Steve Humphries ${ }^{1}$, London (UK), Mike Knapton ${ }^{8}$, London (UK), Joep Perk ${ }^{1}$, Oskarshamn (Sweden), Silvia G. Priori ${ }^{1}$, Pavia (Italy), Kalevi Pyorala ${ }^{1}$, Kuopio (Finland), Zeljko Reiner ${ }^{9}$, Zagreb (Croatia), Luis Ruilope ${ }^{1}$, Madrid (Spain), Susana Sans-Menendez ${ }^{1}$, Barcelona (Spain), Wilma Scholte op Reimer ${ }^{1}$, Rotterdam (The Netherlands), Peter Weissberg ${ }^{8}$, London (UK), David Wood ${ }^{1}$, London (UK), John Yarnell ${ }^{1}$, Belfast (UK), Jose Luis Zamorano', Madrid (Spain)

Other experts who contributed to parts of the guidelines: Edmond Walma, Schoonhoven (The Netherlands), Tony Fitzgerald, Dublin (Ireland), Marie Therese Cooney, Dublin (Ireland), Alexandra Dudina, Dublin (Ireland) European Society of Cardiology (ESC) Committee for Practice Guidelines (CPG):, Alec Vahanian (Chairperson) (France), John Camm (UK), Raffaele De Caterina (Italy), Veronica Dean (France), Kenneth Dickstein (Norway), Christian Funck-Brentano (France), Gerasimos Filippatos (Greece), Irene Hellemans (The Netherlands), Steen Dalby Kristensen (Denmark), Keith McGregor (France), Udo Sechtem (Germany), Sigmund Silber (Germany), Michal Tendera (Poland), Petr Widimsky (Czech Republic), José Luis Zamorano (Spain)

Document reviewers: Irene Hellemans (CPG Review Coordinator) (The Netherlands), Attila Altiner (Germany), Enzo Bonora (Italy), Paul N. Durrington (UK), Robert Fagard (Belgium), Simona Giampaoli (Italy), Harry Hemingway (UK), Jan Hakansson (Sweden), Sverre Erik Kjeldsen (Norway), Mogens Lytken Larsen (Denmark), Giuseppe Mancia (Italy), Athanasios J. Manolis (Greece), Kristina Orth-Gomer (Sweden), Terje Pedersen (Norway), Mike Rayner (UK), Lars Ryden (Sweden), Mario Sammut (Malta), Neil Schneiderman (USA), Anton F. Stalenhoef (The Netherlands), Lale Tokgözoglu (Turkey), Olov Wiklund (Sweden), Antonis Zampelas (Greece)

${ }^{1}$ European Society of Cardiology (ESC) including European Association for Cardiovascular Prevention and Rehabilitation (EACPR) and Council on Cardiovascular Nursing, ${ }^{2}$ European Association for the Study of Diabetes (EASD), ${ }^{3}$ International Diabetes Federation Europe (IDF-Europe), ${ }^{4}$ European Stroke Initiative (EUSI), ${ }^{5}$ International Society of Behavioural Medicine (ISBM), ${ }^{6}$ European Society of Hypertension (ESH), ${ }^{7}$ European Society of General Practice/Family Medicine (ESGP/ FM/WONCA), ${ }^{8}$ European Heart Network (EHN), ${ }^{9}$ European Atherosclerosis Society (EAS).

* Corresponding author. Department of Cardiology, The Adelaide and Meath Hospital, Tallaght, Dublin 24, Ireland, Tel: +353 14144105 ; fax: +353 1414 3052; e-mail: ian.graham@amnch.ie

The content of these European Society of Cardiology (ESC) Guidelines has been published for personal and educational use only. No commercial use is authorized. No part of the ESC Guidelines may be translated or reproduced in any form without written permission from the ESC. Permission can be obtained upon submission of a written request to Oxford University Press, the publisher of the European Heart Journal and the party authorized to handle such permissions on behalf of the ESC.

Disclaimer. The ESC Guidelines represent the views of the ESC and were arrived at after careful consideration of the available evidence at the time they were written. Health professionals are encouraged to take them fully into account when exercising their clinical judgement. The guidelines do not, however, over-ride the individual responsibility of health professionals to make appropriate decisions in the circumstances of the individual patients, in consultation with that patient, and, where appropriate and necessary, the patient's guardian or carer. It is also the health professional's responsibility to verify the rules and regulations applicable to drugs and devices at the time of prescription. 


\section{Table of Contents}

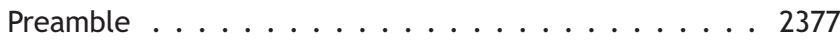

Introduction . . . . . . . . . . . . . . . 2378

The scope of the problem: past and future . . . 2379

Scientific background . . . . . . . . . . . 2379

Practical aspects: coronary artery disease . . . 2379

Heart failure . . . . . . . . . . . . . 2380

Aortic aneurysm and dissection . . . . . . . . 2380

Peripheral arterial disease . . . . . . . . . . 2380

Stroke . . . . . . . . . . . . . . . . . 2380

Practical aspects: prevention and management

of stroke. . . . . . . . . . . . . 2380

Prevention strategies and policy issues . . . . . 2380

Scientific background . . . . . . . . . . . . 2380

Practical aspects: policy issues . . . . . . . . 2381

Prevention in clinical practice . . . . . . . 2381

How to evaluate scientific evidence . . . . . . . 2381

Scientific background . . . . . . . . . . . . . 2381

What is 'evidence'? . . . . . . . . . . . . . 2381

Grading of evidence . . . . . . . . . . . . . 2382

The problems of evidence and guidance . . . . 2382

Practical aspects . . . . . . . . . . . . . 2382

Priorities, total risk estimation, and objectives . . 2383

Introduction . . . . . . . . . . . . . 2383

Priorities. . . . . . . . . . . . . . 2383

Total risk estimation . . . . . . . . . . . . . . 2384

How do I assess risk? . . . . . . . . . . . . . . . . . . . . . 2384

Conclusions . . . . . . . . . . . . . 2386

Principles of behaviour change and management of

behavioural risk factors . . . . . . . . . . . . 2388

Scientific background . . . . . . . . . . 2388

The physician/caregiver-patient interaction as a means towards behavioural change . . . . 2388

Specialized and multimodal interventions . . . 2389

Practical aspects: management of behavioural risk factors . . . . . . . . . . . . . . 2389

Smoking . . . . . . . . . . . . . . . . . . . . . . . . 2390

Scientific background . . . . . . . . . 2390

Practical aspects: prevention and management

of smoking . . . . . . . . . . . . . . 2390

Nutrition . . . . . . . . . . . . . . . . . . . . . . 2391

Scientific background . . . . . . . . . . . . 2391

Practical aspects: management . . . . . . . . . 2391

Overweight and obesity . . . . . . . . . . . . . . . . 2391

Scientific background . . . . . . . . . . . . . . 2391

Body weight and risk . . . . . . . . . . . . 2391

Which index of obesity is the best predictor of cardiovascular risk and cardiovascular risk

factors-body mass index (BMI), waist

circumference (WC), or waist-hip

circumference ratio (WHR)? . . . . . . . . . . . 2392

Imaging and fat distribution . . . . . . . . . 2392

Practical aspects: management of obesity and overweight . . . . . . . . . . . . . 2392

Physical activity and body weight . . . . . . . . 2392

Diet and behavioural interventions . . . . . . . 2393

Drug treatment of overweight ...... 2393

Physical activity . . . . . . . . . . . . . . . . . . . 2393

Scientific background . . . . . . . . . . 2393

Estimating physical activity . . . . . . 2393

Practical aspects: management . . . . . . . . . 2393

Heart rate . . . . . . . . . . . . . . . . . 2394
Scientific background . . . . . . . . . . . . . 2394

Practical aspects: management . . . . . . . . . . 2394

Blood pressure . . . . . . . . . . . . . . . . 2394

Scientific background . . . . . . . . . . . 2394

Risk stratification and target organ damage 2395

Practical aspects: management of

hypertension ............. . . . 2396

Who to treat? . . . . . . . . . . . 2396

How to treat? . . . . . . . . . . . . 2396

Antihypertensive drugs . . . . . . . . . . . . . 2396

Desirable blood pressure . . . . . . . . . . . 2397

Duration of treatment . . . . . . . . 2397

Plasma lipids . . . . . . . . . . . . . . . . . . . . . 2397

Scientific background . . . . . . . . . . . 2397

Practical aspects: management . . . . . . . . 2397

Should statins be given to all persons with

cardiovascular disease? . . . . . . . . . . 2397

Diabetes . . . . . . . . . . . . . . . . . 2399

Scientific background . . . . . . . . . . . 2399

Practical aspects: management . . . . . . . . . 2399

The metabolic syndrome. . . . . . . . . . . . . . . . . 2400

Scientific background . . . . . . . . . . 2400

Practical aspects: management . . . . . . . . . 2400

Psychosocial factors . . . . . . . . . . . . . . 2400

Scientific background . . . . . . . . . . . 2400

Practical aspects: management of psychosocial

risk factors in clinical practice . . . . . . . . . 2401

Inflammation markers and haemostatic factors . . 2401

Scientific background . . . . . . . . . . . . . . 2401

Genetic factors . . . . . . . . . . . . . . . . 2402

Family history: scientific background . . . . . . 2402

Family history: practical aspects . . . . . . . . 2402

Phenotypes: scientific background . . . . . . 2402

Genotypes: scientific background . . . . . . . . . 2402

DNA-based tests for risk prediction . . . . 2402

Practical aspects . . . . . . . . . . . . . 2402

DNA-based tests for risk prediction . . . . 2402

Pharmacogenetics . . . . . . . . . . . 2402

Severe familial dyslipidaemias and coronary

heart disease . . . . . . . . . . . 2403

Familial hypercholesterolaemia (FH) . . . . 2403

Familial combined hyperlipidaemia (FCH) . 2403

Familial high-density lipoprotein

deficiency syndromes . . . . . . . . . . . 2403

New imaging methods to detect asymptomatic

individuals at high risk for cardiovascular events . 2403

Scientific background . . . . . . . . . . . 2403

Gender issues: cardiovascular disease prevention

in women . . . . . . . . . . . . . . . . . 2404

Scientific background . . . . . . . . . . . . . 2404

Practical aspects . . . . . . . . . . . . . 2404

Renal impairment as a risk factor in cardiovascular

disease prevention . . . . . . . . . . . . . . . 2405

Scientific background . . . . . . . . . . . 2405

Practical aspects: management . . . . . . . . . 2405

Cardioprotective drug therapy . . . . . . . . . 2405

Scientific background . . . . . . . . . . . 2405

Antiplatelet therapies . . . . . . . . . . 2405

$\beta$-Blockers ............ . . . . 2405

ACE inhibitors ............. . . . 2405

Anticoagulation ........... . . . 2405

Practical aspects: management . . . . . . . . . 2406

Antiplatelet therapy: aspirin . . . . . . . . 2406 
Antiplatelet therapy: clopidogrel . . . . . 2406

$\beta$-Blockers . . . . . . . . . . 2406

ACE inhibitors . . . . . . . . . 2406

Calcium channel blockers . . . . . . . 2406

Diuretics . . . . . . . . . . . . . . . 2406

Anticoagulation ............... 2406

Implementation strategies . . . . . . . . . . . . 2406

Scientific background . . . . . . . . . . 2406

Barriers to the implementation of

guidelines . . . . . . . . . . . . . . 2407

Doctor-patient relationship . . . . . . . . . 2407

Practical aspects . . . . . . . . . . . 2407

Important arenas for training . . . . . . . . 2407

Implementation strategies . . . . . . . . . . . 2407

References ... . . . . . . . . . 2408

\section{Preamble}

Guidelines and Expert Consensus Documents summarize and evaluate all currently available evidence on a particular issue with the aim to assist physicians in selecting the best management strategies for a typical patient, suffering from a given condition, taking into account the impact on outcome, as well as the risk-benefit ratio of particular diagnostic or therapeutic means. Guidelines are not substitutes for textbooks. The legal implications of medical guidelines have been discussed previously.

A great number of Guidelines and Expert Consensus Documents have been issued in recent years by the European Society of Cardiology (ESC) as well as by other societies and organizations. Because of the impact on clinical practice, quality criteria for development of guidelines have been established in order to make all decisions transparent to the user. The recommendations for formulating and issuing ESC Guidelines and Expert Consensus Documents can be found on the ESC web site (http://www.escardio. org/knowledge/guidelines/rules).

In brief, experts in the field are selected and undertake a comprehensive review of the published evidence for management and/or prevention of a given condition. A critical evaluation of diagnostic and therapeutic procedures is performed, including assessment of the risk-benefit ratio. Estimates of expected health outcomes for larger societies are included, where data exist. The level of evidence and the strength of recommendation of particular treatment options are weighed and graded according to predefined scales, as outlined in the tables below.

The experts of the writing panels have provided disclosure statements of all relationships they may have which might be perceived as real or potential sources of conflicts of interest. These disclosure forms are kept on file at the European Heart House, headquarters of the ESC. Any changes in conflict of interest that arise during the writing period must be notified to the ESC. The Task Force report was entirely supported financially by the ESC and was developed without any involvement of industry.

The ESC Committee for Practice Guidelines (CPG) supervises and coordinates the preparation of new Guidelines and Expert Consensus Documents produced by Task Forces, expert groups, or consensus panels. The Committee is also responsible for the endorsement process of these Guidelines and Expert Consensus Documents or statements. Once the document has been finalized and approved by all the experts involved in the Task Force, it is submitted to outside specialists for review. The document is revised, and finally approved by the CPG and subsequently published.

After publication, dissemination of the message is of paramount importance. Pocket-sized versions and personal digital assistant (PDA)-downloadable versions are useful at the point of care. Some surveys have shown that the intended end-users are sometimes not aware of the existence of guidelines, or simply do not translate them into practice, so this is why implementation programmes for new guidelines form an important component of the dissemination of knowledge. Meetings are organized by the ESC, and directed towards its member National Societies and key opinion leaders in Europe. Implementation meetings can also be undertaken at national levels, once the guidelines have been endorsed by the ESC member societies, and translated into the national language. Implementation programmes are needed because it has been shown that the outcome of disease may be favourably influenced by the thorough application of clinical recommendations.

Thus, the task of writing Guidelines or Expert Consensus documents covers not only the integration of the most recent research, but also the creation of educational tools and implementation programmes for the recommendations. The loop between clinical research, writing of guidelines, and implementing them in clinical practice can then only be completed if surveys and registries are performed to verify that real-life daily practice is in keeping with what is recommended in the guidelines. Such surveys and registries also make it possible to evaluate the impact of implementation of the guidelines on patient outcomes. Guidelines and recommendations should help the physicians to make decisions in their daily practice; however, the ultimate judgement regarding the care of an individual patient must be made by the physician in charge of his/her care.

\section{Classes of recommendations}

Class I

Evidence and/or general agreement that a given treatment or procedure is beneficial, useful, and effective

Class II Conflicting evidence and/or a divergence of opinion about the usefulness/efficacy of the given treatment or procedure

Class Ila Weight of evidence/opinion is in favour of usefulness/efficacy

Class Ilb Usefulness/efficacy is less well established by evidence/opinion

Class III Evidence or general agreement that the given treatment or procedure is not useful/ effective, and in some cases may be harmful

Levels of evidence

Level of evidence A Data derived from multiple randomized clinical trials or meta-analyses

Level of evidence B Data derived from a single randomized clinical trial or large non-randomized studies

Level of evidence C Consensus of opinion of the experts and/ or small studies, retrospective studies, registries 


\section{Introduction}

The rationale for an active approach to the prevention of atherosclerotic cardiovascular disease (CVD) is based on five key points:

\section{Why develop a preventive strategy in clinical} practice?

1. Cardiovascular disease (CVD) is the major cause of premature death in Europe. It is an important cause of disability and contributes substantially to the escalating costs of health care

2. The underlying atherosclerosis develops insidiously over many years and is usually advanced by the time that symptoms occur

3. Death from CVD often occurs suddenly and before medical care is available, so that many therapeutic interventions are either inapplicable or palliative

4. The mass occurrence of CVD relates strongly to lifestyles and to modifiable physiological and biochemical factors

5. Risk factor modifications have been shown to reduce CVD mortality and morbidity, particularly in high risk subjects

By the early 1990s there was a plethora of similar yet confusingly different national and international guidelines for the prevention of CVD. In order to try to define the areas of agreement, the ESC, the European Atherosclerosis Society and the European Society of Hypertension agreed to collaborate, resulting in a set of recommendations for the prevention of coronary heart disease (CHD) that was published in 1994. ${ }^{1}$ These guidelines were revised in 1998 and 2003 by the second and third Joint Task Forces. ${ }^{2,3}$ A strength of the guidelines is that, from the outset, it was stressed that CVD is usually the product of multiple interacting risk factors. This resulted in the production of risk charts that attempt to simplify the estimation of total CVD risk, and a realization that risk management requires attention to all modifiable risk factors.

It was appreciated that the original partners needed assistance from other bodies and experts, in particular in the fields of behavioural medicine and diabetes. In addition, it is acknowledged that much practical preventive advice is delivered by family doctors, nurses, and through voluntary bodies such as Heart Foundations. These considerations are reflected in the expanded partnership represented in the present guidelines, and in the list of experts whose input has been sought.

The Third Joint Task Force Guidelines saw a change from CHD to CVD prevention, to reflect the fact that atherosclerosis may affect any part of the vascular tree. A new risk chart called SCORE (Systematic COronary Risk Evaluation) was developed which was based on 12 European cohort studies and allowed the estimation of 10 -year risk of cardiovascular death. Separate charts were produced for high and low risk regions of Europe. More explicit clinical priorities were developed. Less emphasis was placed on the terms 'primary' and 'secondary' prevention since risk is a continuum-asymptomatic persons may have investigational evidence of atherosclerotic disease. A rigorous external review process was undertaken.

The Fourth Joint Task Force has taken note of feedback in several areas:
(1) More detailed guidance was sought from the World Organization of National Colleges, Academies and academic associations of general practitioners/family physicians (WONCA, or the 'World Organization of Family Doctors' for short) and from the ESC Working Group on Cardiovascular Nursing, since these bodies represent the professionals that are heavily engaged in the practical delivery of preventive advice in many European countries.

(2) The current ESC approach to grading evidence was examined in detail. Concern was expressed that the present system, while logical, tends to give priority to drug treatments since these are more amenable to double-blind randomized controlled trials than lifestyle measures, even if observational studies indicate powerful benefits from, for example, smoking cessation. For this reason, the gradings have not been included in the present documents, and further debate on this topic is strongly recommended.

(3) All risk estimation systems, including SCORE, will overestimate risk in countries that have experienced a decline in CVD mortality, and underestimate risk if mortality has increased. The development of national guidance has always been recommended by the Task Force and, as part of this process, recalibration of the SCORE charts to allow for time trends in both mortality and risk factor distributions in individual countries is recommended. In the Third Joint Guidelines, the need to address the problem of a high relative but low absolute risk in younger persons was dealt with by extrapolating a young person's risk to age 60 to flag persons who will become at high absolute risk. If interpreted too literally, this approach might result in excessive use of drug treatments in young people. In the present guidelines, this approach has been replaced with a simple relative risk chart to be used in conjunction with the SCORE absolute risk chart.

(4) A re-examination of the SCORE data sets indicated that the impact of self-reported diabetes on risk may have been underestimated. The issue of predicting total events as well as just CVD mortality also receives more attention, as do gender issues, central obesity, highdensity lipoprotein (HDL) cholesterol, heart rate, renal impairment, and manifestations of CVD other than CHD.

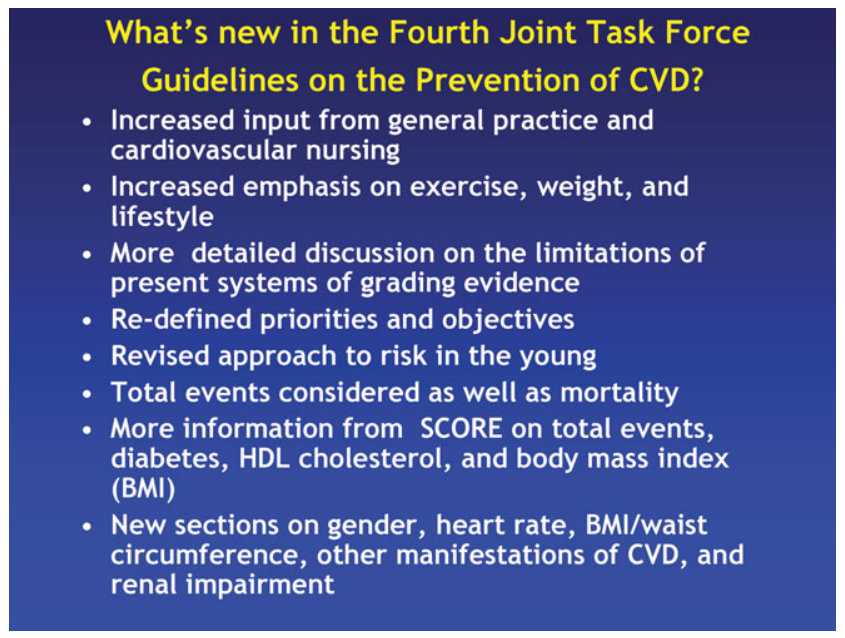

These Guidelines attempt to find areas of broad agreement among different professional bodies and scientific disciplines. With the help of WONCA, a particular effort has been made to 
harmonize the advice that may be given to primary care and second-line care health professionals. The production of more detailed guidelines by the partner societies is encouraged; as examples, reference is made to the ESH/ESC guidelines on the management of arterial hypertension ${ }^{4}$ and to the guidelines on diabetes, pre-diabetes and CVD by the ESC/EASD. ${ }^{5}$ Implicit in this partnership process is that these will be compatible with the generic Joint Guidelines.

The development of national guidance on CVD prevention is also specifically encouraged. The Joint Guidelines should be regarded as a framework from which national guidelines can be developed to suit local political, economic, social, and medical circumstances. The production of guidelines is only one step in the process of prevention, and the development of national multidisciplinary implementation partnerships is recommended; the section on implementation addresses some of the issues involved.

It should be appreciated that the Fourth Joint Task Force Guidelines are for the use of physicians and other health professionals engaged in clinical practice. Therefore, they give the highest priority to those individuals at highest CVD risk because such persons gain most by active risk factor management. However, they should be complemented by national and European public health strategies aimed at whole populations in a co-ordinated and comprehensive effort to reduce the enormous burden of CVD that afflicts European populations. In this way, we hope that the guidelines will promote higher quality of care to help reduce this burden and CVD in Europe. These issues inform a major new initiative, the publication of the European Health Charter, available through www. heartcharter.eu. The Charter was produced by the ESC, European Union (EU), and the European Heart Network, in partnership with the World Health Organization (WHO). The relationship between the Charter and the present Guidelines may be summarized:

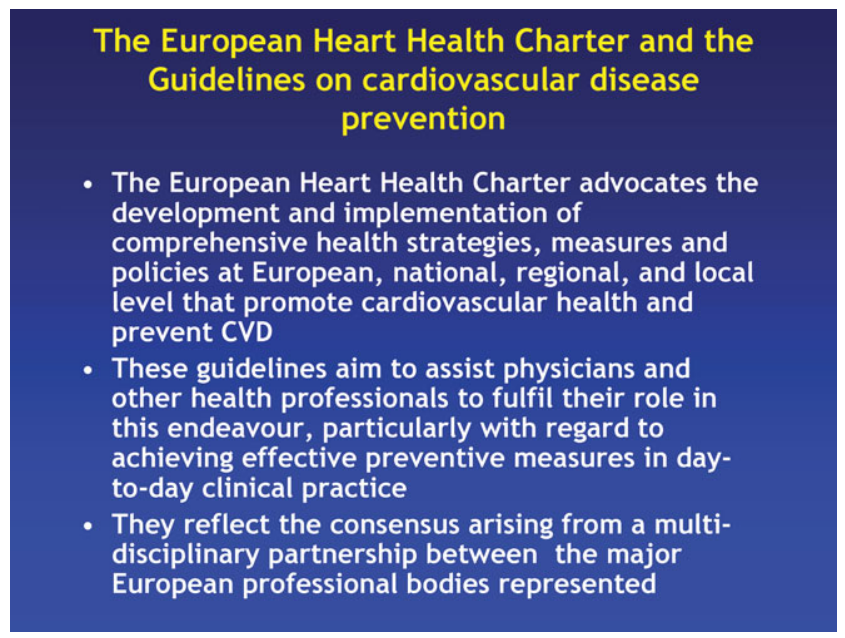

\section{The scope of the problem: past and future}

\section{Scientific background}

CVDs were the direct cause of $>4$ million deaths in Europe around the year 2000 (1.9 million in the EU), accounting for $43 \%$ of all deaths of all ages in men and for $55 \%$ in women (Table 1 from www.ehnheart.org $\left.{ }^{6}\right) .{ }^{7}$ CVDs were also the major cause of hospital discharges, with an average rate of 2557 per 100000 population around the year 2002. Out
Table 1 All deaths from circulatory disease in Europe. All ages. Year 2000 or circa

\begin{tabular}{llr}
\hline All causes & Men & 4519403 \\
All circulatory & Women & 4336346 \\
& Men & 1963644 \\
CHD & Women & 2307945 \\
& Men & 967258 \\
Stroke & Women & 983229 \\
& Men & 504307 \\
Other & Women & 775571 \\
& Men & 492079 \\
& Women & 637405 \\
\hline
\end{tabular}

of these, 695 per 100000 were caused by CHD and 375 per 100000 by stroke, but more than half were due to other forms of chronic heart disease. The estimated total cost of CVDs in the EU countries was $€ 168757$ million in 2003 . $^{8}$

CVD mortality rates vary with age, gender, socio-economic status, ethnicity, and geographical region. Mortality rates increase with age, and are higher in men, in people of low socio-economic status, in Central and Eastern Europe, and in immigrants of South Asian origins. There are marked socioeconomic gradients in CVD morbidity and mortality within European countries, which are partially explained by socioeconomic differences in conventional risk factors, such as smoking, blood pressure (BP), blood cholesterol, and glucose.

Total CVD mortality has been falling consistently, both in middle life and at older ages, since 1970 in Western Europe. ${ }^{9}$ In Central and Eastern Europe, they started to decline only in recent years, and they remain very high in such countries. There is still nearly a 10 -fold gradient in male CHD mortality between Eastern Europe and France at ages 35-74, and up to a 6-fold difference in stroke mortality. Declines in CHD mortality are related to population-wide behavioural changes in nutrition and smoking in both Western and Eastern Europe. The incidences of $\mathrm{CHD}^{10}$ and stroke have also been declining in Western Europe, but increasing in other countries, principally in Eastern Europe and Spain.

\section{Practical aspects: coronary artery disease}

Changes in CHD mortality at the end of the 20th century were mostly explained by changes in incidence rather than changes in short-term case fatality of acute myocardial infarction (AMI). ${ }^{11}$ Major emphasis is needed in the control of risk factors and of the determinants of incident CHD. The reduction in blood pressure noted at population level is only partly attributable to an increase in the proportion of hypertensive subjects receiving treatment, suggesting that despite the importance of medication to individuals, other determinants of BP lowering are more powerful in whole populations. Risk factor control in high risk patients and in patients with established CHD remains poor, especially regarding obesity, smoking, and $\mathrm{BP}$, and mostly so in diabetic patients, in spite of issued guidelines indicating the need for reinforcing dissemination and implementation of costeffective prevention actions in an organized way. ${ }^{12}$

As survival after acute events improves, prevalent CHD increases, especially in older women. It is known that diabetes is a more powerful risk factor for women, and, thus, control of risk factors among diabetic patients becomes a 
special priority. As the prevalence of overweight and obesity increases worldwide, an increase in the prevalence of type 2 diabetes and hence all its complications may be anticipated. Consequently, control of the growing epidemic of obesity should be a priority.

The clinical manifestations of CVD may be very different. Hospital statistics reveal only the tip of the iceberg, since sudden cardiac death occurring outside the hospital still represents a large proportion of all cardiovascular deaths.

\section{Heart failure}

Pump failure of the heart is a common cause of death in the elderly, although this not always reflected in mortality statistics because of the limitations of coding rules. Hospital admission rates for heart failure have been increasing in the USA and in Europe. Hypertension, obesity, and diabetes are major risk factors. Although a small proportion of clinical cases are due to valve disease (often linked with CHD), or to cardiomyopathy, epidemiological studies suggest that, in well developed countries, the majority of cases are due to ischaemia. ${ }^{13}$

\section{Aortic aneurysm and dissection}

Aortic aneurysm is also atherosclerotic in nature, and increasing mortality trends have been shown in some European countries. ${ }^{14}$ It is a potentially preventable cause of death, particularly when confined to the abdominal aorta. The prevalence is $5 \%$ in men aged 60 years or more, and $1-2 \%$ in women. Screening for this condition has been suggested since elective surgical repair carries a 5-8\% 30 -day mortality in comparison with $50 \%$ mortality for ruptured aneurysm; a trial of screening conducted in the UK has shown encouraging results. ${ }^{15}$

\section{Peripheral arterial disease}

It is known that coronary and peripheral vessels are affected by the same disease process, requiring the same treatment modalities. Peripheral arterial disease (PAD) occurs almost as frequently in women as in men. ${ }^{16}$ The correlation of PAD with CHD, myocardial infarction (MI), and stroke reflects the widespread nature of atherosclerosis. However, some minor differences have emerged from epidemiological studies regarding the risk factors for these diseases. Smoking appears to be more important in the aetiology of PAD than in CHD. ${ }^{17} \mathrm{~A}$ positive family history, hypertension, diabetes, dyslipidaemia including increased total and lowdensity lipoprotein (LDL) cholesterol and decreased HDL cholesterol, increased fibrinogen and C-reactive protein (CRP), advanced age, and physical inactivity seem to be common risk factors.

As in CHD, effective risk factor management is essential. Risk reduction can be achieved through lifestyle modification, particularly physical activity and exercise, smoking cessation, and therapies such as use of statins, antiplatelet therapies, antithrombotic strategies, angiotensin-converting enzyme (ACE) inhibitors, and $\beta$-blockers. ${ }^{16,18,19}$ The beneficial effects of statins in these patients have been shown in large trials. ${ }^{20}$ Statins not only lower the risk of PAD and vascular events, but they also improve the symptoms associated with PAD. There is also evidence that statins reduce surgical mortality and improve graft patency and limb salvage in PAD patients. ${ }^{21}$

\section{Stroke}

The incidence of stroke increases exponentially with age, affecting about 25 per 100000 in the age group 35-44 years and 1500 per 100000 in age group 75-84 years annually. Stroke is the third leading cause of death in many countries. Intracerebral haemorrhage and subarachnoid haemorrhage contribute 10 and $5 \%$ of strokes, respectively. Ischaemic stroke may be due to large vessel disease, small vessel disease, emboli from the heart or from the aortic arch, or other rarer identified causes, while a large proportion still remains undetermined. ${ }^{22}$

The most important risk factor is hypertension, followed by smoking and diabetes. Others are sedentary lifestyle, overuse of alcohol, and illicit drugs, elevated cholesterol, use of oral contraceptives or postmenopausal hormones, overweight, low socio-economic status (SES), and atherosclerotic stenosis of extracranial vessels.

\section{Practical aspects: prevention and management of stroke}

Antihypertensive treatment reduces risk of both ischaemic and haemorrhagic stroke, and stroke prevention is the most important effect of antihypertensive treatment. Smoking should be discouraged and physical activity encouraged. Alcohol intake in low amounts may not be harmful. With regard to statin therapy, stroke survivors should be treated in the same way as those with other manifestations of CVD. Carotid endarterectomy in symptomatic patients with stenosis of the internal carotid artery reducing the lumen $>70 \%$ reduces the risk of recurrent stroke.

Prophylactic antithrombotic treatment: Within the therapeutic range of international normalized ratio (INR) 2-3, anticoagulation reduces stroke risk in patients with atrial fibrillation. Antiplatelet therapy is indicated in patients with non-cardioembolic ischaemic stroke. Aspirin is the most widely used drug in doses of 75-150 mg a day. The combination of aspirin and dipyridamole gives an additional risk reduction. Clopidogrel has an effect similar to aspirin in patients with ischaemic cerebrovascular disease. Combination of clopidogrel and aspirin is not recommended for stroke survivors. For a more comprehensive review, readers are referred to the European Stroke Initiative. ${ }^{23}$

\section{Prevention strategies and policy issues}

\section{Scientific background}

Three strategies for the prevention of CVD can be distinguished: population, high-risk and secondary prevention. The three strategies are necessary and complement each other. The population strategy in particular is critical to reducing the overall incidence of CVD since it aims to reduce risk factors at population level through lifestyle and environmental changes that affect the whole population without requiring the medical examination of individuals. This type of strategy is mostly achieved by establishing ad hoc policies and community interventions.

The strategies aimed to diminish the total cardiovascular risk of individuals are the high risk primary prevention and the secondary prevention strategies. The former deals with healthy persons belonging to the upper part of the 
risk distribution, and the second with patients with established cardiovascular organ damage or disease. To prevent one single cardiovascular event, it will be necessary to intervene in many subjects with no apparent benefit to them (prevention paradox). Furthermore, the number of subjects in whom an intervention is needed to prevent one case will vary in different populations or population subgroups (e.g. in women) depending on their underlying prevalences and distribution of risk factors, and the incidence rate of disease.

\section{Practical aspects: policy issues}

The Fourth Task Force aligns and fully endorses the initiatives of major international organizations in taking steps to implement measures at the population level, such as those for tobacco control established by the WHO Framework Convention for Tobacco Control, ${ }^{24}$ the EU initiative on obesity, ${ }^{25}$ the WHO Global Strategy on diet, physical activity, and health, ${ }^{26}$ and the Osaka Declaration on Heart Health which can be summarized as:

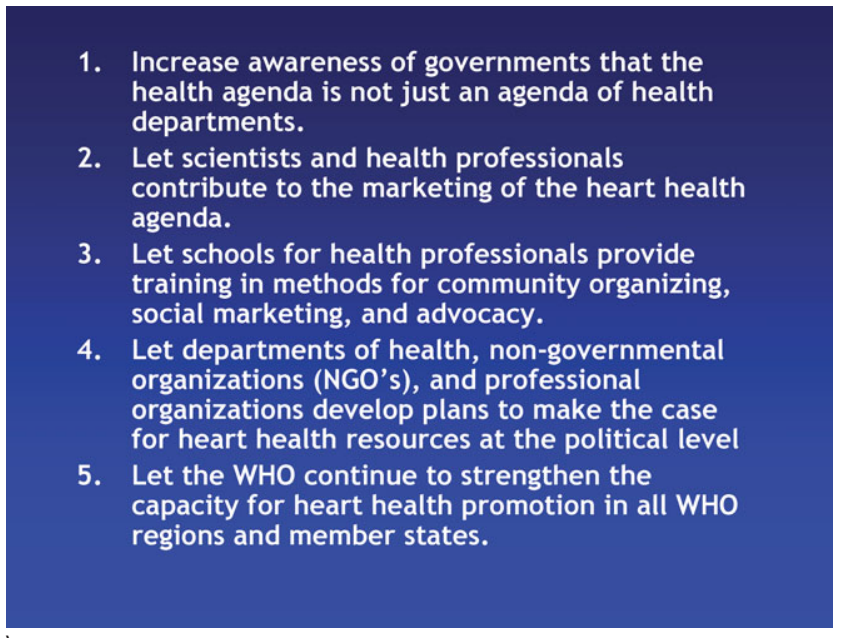

Likewise, the EU Council on Employment, Social Policy, Health, and Consumer Affairs in June 2004 and an EU Heart Health Conference that resulted in the Luxembourg Declaration of 29 June 2005 defined the characteristics that are necessary to achieve cardiovascular health:

- Avoidance of tobacco

- Adequate physical activity (at least 30 min per day)

- Healthy food choices

- Avoiding overweight

- BP below 140/90 mmHg

- Total cholesterol below $5 \mathrm{mmol} / \mathrm{L}$ ( $200 \mathrm{mg} / \mathrm{dL})$.

The Fourth Task Force encourages health professionals of all countries to participate actively in the design and implementation of such national and international policies and community interventions.

\section{Prevention in clinical practice}

There is no evidence that mass screening for detection of early stages of CHD or stroke is a cost-effective way to prevent disease. For opportunistic detection of biological risk factors or of lifestyles to detect persons at high risk, the following are necessary:
- accurate and adequate systems of measurement are routinely available

- real time for advice or treatment as appropriate

- continuity of care

- patient access to treatments, regardless of SES.

Programmes for secondary prevention of CHD have proven to be effective in improving processes of care, readmissions to hospital, functional status, and overall mortality, especially if they incorporate exercise programmes. However, their effect sizes are quite modest and their costeffectiveness on a large scale remains uncertain. ${ }^{27,28}$

\section{How to evaluate scientific evidence}

\section{Scientific background}

Evidence-based medicine (EBM) has been defined as the integration of individual clinical expertise with the best available clinical evidence from systematic research. It involves asking answerable questions, searching for the best evidence, critically appraising the evidence, applying the evidence to individual patient care, and evaluating the process. ${ }^{29}$ Despite over a decade of educational effort, it is rare for clinicians to practise EBM as intended, with many considering that the major issue is finding the evidence. $^{30}$

This report aims to provide guidelines under the auspices of the Fourth Joint Task Force of the ESC and other European Societies on Cardiovascular Disease Prevention. The Task Force wishes these guidelines to be as evidence based as possible. Good guidelines are a major mechanism for improving the delivery of health care and improving patient outcomes. ${ }^{31}$ It has been shown that guidelines based on credible evidence are more likely to be adopted. ${ }^{32}$

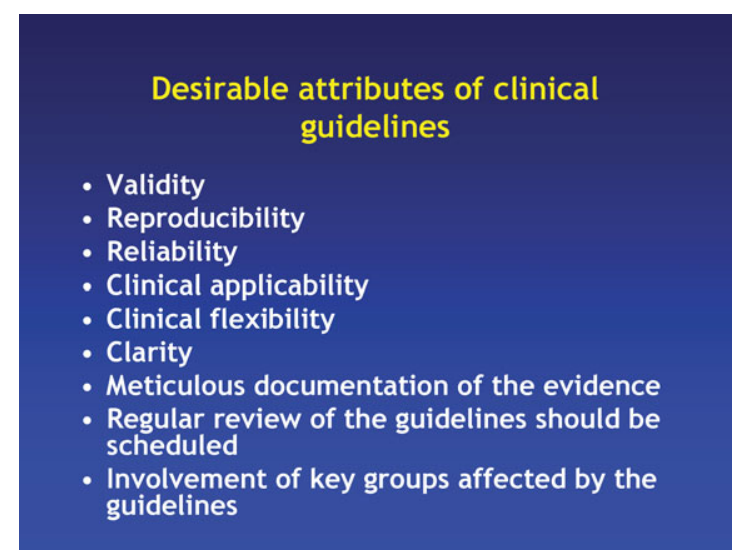

\section{What is 'evidence'?}

The evaluation of interventions and diagnostic methods can make use of a wide range of sources of evidence: experience, retrospective case review, case reports, case series, historic and geographic comparisons, drug (and postmarketing) surveillance studies, pharmacoepidemiological databases, cross-sectional studies, case-control studies, cohort studies, randomized controlled trials, and systematic reviews of trials and of observational studies. Traditionally, hierarchies of evidence have been promoted as a means of prioritizing recommendations. These generally put systematic reviews at the top of the hierarchy and case reports at 
the bottom. However, this approach may be misleading as the quality of evidence ultimately depends on the question to be answered.

It is clear that different questions require different scientific methods, and that reliance on one source of evidence to the exclusion of others is likely to be misleading. This is particularly true in CVD prevention. Lifestyle measures such as smoking cessation, exercise, and healthy eating are less amenable to double blind randomized controlled trials than are drug treatments, and to promote slavish adherence to the primacy of the randomized controlled trial may result in guidelines that promote excessive usage of drugs. Systematic reviews and randomized controlled trials are not the most appropriate method for identifying rare hazards of treatment. Case reports may provide the first hint that a treatment is hazardous, but they require confirmation in large prospective surveillance surveys.

\section{Grading of evidence}

In using evidence to produce guidance or recommendations for clinical or public health practice, it is important to distinguish between the quality of the evidence (is it robust, little likelihood of bias, generalizable, etc.) and the strength of a recommendation underpinned by the evidence. Not all high quality evidence merits a strong recommendation.

Guideline developing bodies have generally used the 'hierarchy of evidence approach'. Application of the hierarchy of evidence method requires explicit judgements to be made about the quality of the evidence (e.g. completeness, potential for bias, adequacy of outcomes assessed, etc.) Critically, both the benefits and the hazards of interventions need to be taken into account in producing clinical guidance. While such an approach provides transparency, there are also disadvantages, as outlined above. There have also been difficulties in the implementation of these graded recommendations. For example, in implementing a guideline, some recommendations that are crucial to the overall improvement of care may be underpinned by little or no strong evidence. If a decision to implement only high grade recommendations was undertaken on the grounds of resource constraints, then important elements of the guideline may be overlooked. Consequently, there is interest in developing a system that retains the desirable ability to maintain transparency but avoids perversity in implementation.

The WHO have established a working group to develop such a system, called GRADE. Evidence is graded based on the outcomes relevant to the question being answered. This is appraised in four domains: study design, study quality, consistency, and directness (generalizability). Based on the scoring of these attributes, the quality of evidence for the specific outcome is defined as high, moderate, low, or very low grade. ${ }^{33}$ This system cannot tackle the implementation problems discussed above but provides a clear judgement of whether the benefits of an intervention outweigh the adverse effects. This provides a transparent method of prioritizing interventions for implementation. As experience in using this system grows, it will probably become a more widely used tool for the generation of clinical guidance.

\section{The problems of evidence and guidance}

We have attempted to ensure that the most appropriate evidence is used to underpin recommendations. For population prevention programmes, observational epidemiological findings are an important first step in considering causality. Behaviours such as smoking cessation and exercise are less amenable to randomized controlled trials than drug treatments. Clearly, systematic reviews of observational studies are preferable to citation of single observational studies. However, it is important to be aware that the increased precision provided by pooling data may be spurious if the control for confounding and other biases is weak in the index studies. ${ }^{34}$

A growing concern in epidemiology is that with some associations causation has been wrongly attributed. This appears to be the case for antioxidant vitamins, where observational studies suggested a reasonable protective effect, but randomized controlled trials have shown that the interventions may even be harmful. ${ }^{35,36} \mathrm{~A}$ further concern for us is the nature of available evidence. Much of the evidence concerns drug treatments rather than lifestyle interventions or health system improvements.

In examining the effects of interventions, we have given prominence to Cochrane systematic reviews where they exist as these are conducted to a rigorous standard and are updated periodically. We have used other systematic reviews where these exist and have only cited individual trials where they make particular points of interest, or are sufficiently large to provide a clear answer to a clinical question. Where we feel the evidence is scant, we have stated this.

When examining effect sizes, we have not used numbers needed to treat as these have quite marked problems, ${ }^{37}$ particularly in preventive cardiology where baseline rates of CVD vary markedly throughout Europe. Consequently a number needed to treat would be needed for countries with low, medium, and high risk. Moreover, numbers needed to treat for different age groups and for men and women would be required. Relative risk reductions on treatment are applicable to all European populations, age groups, and men and women as, in general, most treatments have the same relative benefits at different levels of risk.

\section{Practical aspects}

In this report, we have attempted to follow an evidencebased approach. We have defined the following questions:

- What is the evidence that specific risk factors cause CVD?

- What is the evidence that these risk factors vary in importance among those with and without established CVD?

- What is the evidence that interventions for populations lead to reductions in risk factors and CVD outcomes?

- What is the evidence that interventions for individuals lead to reductions in risk factors and CVD outcomes?

We have systematically and critically reviewed the relevant literature to answer each question posed. Certain difficulties are apparent with regard to the current ESC hierarchical grading system. The present system is likely to favour drug treatments over major lifestyle measures because the latter are less amenable to double-blind 
randomized controlled trials. For this reason, after prolonged debate, the Task Force has not included the table of the grades that it prepared. However, it is anticipated that this issue will require further debate.

Efforts have been made to implement the guidelines through the various participating societies. Previous guidelines have been evaluated by means of EUROASPIRE I and II. ${ }^{38,39}$

\section{Priorities, total risk estimation, and objectives Introduction}

At the outset, it is stressed that these guidelines are just that, and not didactic rules. They should be interpreted in the light of the clinician's own knowledge and judgement, the patient's view, and in the light of local conditions and practicalities and as new knowledge becomes available. Indeed the development of national guidelines is strongly encouraged, with objectives, priorities, and implementation strategies that are adapted to suit local conditions, both medical and economic.

The priorities suggested are to assist the physician in dealing with individual people and patients. As such, they acknowledge that individuals at the highest levels of risk gain most from risk factor management. As noted elsewhere, although such individuals gain most, most deaths in a community come from those at lower levels of risk, simply because they are more numerous compared with high risk individuals who, paradoxically, develop fewer events in absolute terms-the Rose Paradox. ${ }^{40}$ Thus a strategy for individuals at high risk must be complemented by public health measures to reduce, as far as is practicable, population levels of cardiovascular risk factors and to encourage a healthy lifestyle.

The encouragement of total risk estimation as a crucial tool to guide patient management has been a cornerstone of the Guidelines since the first (1994) edition. ${ }^{1}$ This is because clinicians treat whole people (and not individual risk factors), whose cardiovascular risk usually reflects the combined effects of several risk factors that may interact, sometimes multiplicatively.

Although clinicians often ask for thresholds to trigger intervention, this is problematic since risk is a continuum and there is no exact point where, for example, a drug is automatically indicated. This issue is dealt with in more detail, as is the issue of how to advise younger persons at low absolute but high relative risk, and the fact that all elderly people will eventually be at high risk of death and may be overexposed to drug treatments.

The overall objectives of cardiovascular prevention are to reduce mortality and morbidity in those at high absolute risk and to assist those at low absolute risk to maintain this state, through a healthy lifestyle. Here, the risk charts are helpful-if BP is hard to control fully, for example, total risk can still be reduced by stopping smoking or perhaps reducing cholesterol levels further. Although thresholds for total cardiovascular risk included in this guideline are arbitrary, targets for individual risk factors are even more problematic in that they will always be open to debate, are not always achievable, and, notably, because they seem to promote a uni-risk factor approach to prevention. Yet clinicians ask for guidance, so an attempt to define desirable levels of individual risk factors has been made in the context of more specific objectives.

\section{Priorities}

Individuals at highest risk gain most from preventive efforts, and this guides the following priorities:

What are the priorities for CVD prevention in clinical practice?

1. Patients with established atherosclerotic CVD

2. Asymptomatic individuals who are at increased risk of CVD because of

2.1 Multiple risk factors resulting in raised total CVD risk ( $25 \%$ 10-year risk of CVD death)

2.2 Diabetes type 2 and type 1 with microalbuminuria

2.3 Markedly increased single risk factors especially if associated with end-organ damage

3. Close relatives of subjects with premature atherosclerotic CVD or of those at particularly high risk

What are the objectives of cardiovascular disease prevention?

What are the objectives of CVD prevention?

1. To assist those at low risk of CVD to maintain this state lifelong, and to help those at increased total CVD risk to reduce it

2. To achieve the characteristics of people who tend to stay healthy:

2.1 No smoking

2.2 Healthy food choices

2.3 Physical activity: $\mathbf{3 0}$ min of moderate activity a day

$2.4 \mathrm{BMI}<25 \mathrm{~kg} / \mathrm{m}^{2}$ and avoidance of central obesity

$2.5 \mathrm{BP}<140 / 90 \mathrm{mmHg}$

2.6 Total cholesterol $<5 \mathrm{mmol} / \mathrm{L}(\sim 190 \mathrm{mg} / \mathrm{dL})$

2.7 LDL cholesterol $<3 \mathrm{mmol} / \mathrm{L}(\sim 115 \mathrm{mg} / \mathrm{dL})$

2.8 Blood glucose $<6 \mathrm{mmo} / \mathrm{L}(\sim 110 \mathrm{mg} / \mathrm{dL})$

3. To achieve more rigorous risk factor control in high risk subjects, especially those with established CVD or diabetes:

3.1 Blood pressure under $130 / 80 \mathrm{mmHg}$ if feasible

3.2 Total cholesterol $<4.5 \mathrm{mmol} / \mathrm{L}(\sim 175 \mathrm{mg} / \mathrm{dL})$ with an option of $<4 \mathrm{mmol} / \mathrm{L}(-155 \mathrm{mg} / \mathrm{dL})$ if feasible

$3.3 \mathrm{LDL}$ cholesterol $<2.5 \mathrm{mmol} / \mathrm{L}(\sim 100 \mathrm{mg} / \mathrm{dL})$ with an option of $<2 \mathrm{mmol} / \mathrm{L}(\sim 80 \mathrm{mg} / \mathrm{dL})$ if feasible

3.4 Fasting blood glucose $<6 \mathrm{mmol} / \mathrm{L}(\sim 110 \mathrm{mg} / \mathrm{dL})$ and HbA1c $<6.5 \%$ if feasible

4. To consider cardioprotective drug therapy in these high risk subjects especially those with established atherosclerotic CVD 
In general, a middle aged person with a 10-year risk of CVD death of $5 \%$ or more is regarded as at high risk. Examination of the FINRISK MONICA data (which contribute substantially to the SCORE high risk population charts) suggests that the equivalent total (fatal + non-fatal) CVD risk is about $10 \%$-more in younger men and less in women and the eldery. The likelihood of requiring medication in addition increases with increasing risk.

\section{Total risk estimation}

Total cardiovascular risk in the context of these guidelines means the likelihood of a person developing an atherosclerotic cardiovascular event over a defined period of time.

The importance of total risk estimation before management decisions are made is illustrated in Table 2 and Figure 1. The figure illustrates that the effect of lipid levels on risk is modest in women who are at otherwise low risk, and that the risk advantage of being female is lost by the combination of smoking and mild hypertension. Table 2 shows that a person with a total cholesterol of $8 \mathrm{mmol} / \mathrm{L}$ can be at 10 times lower risk than someone with

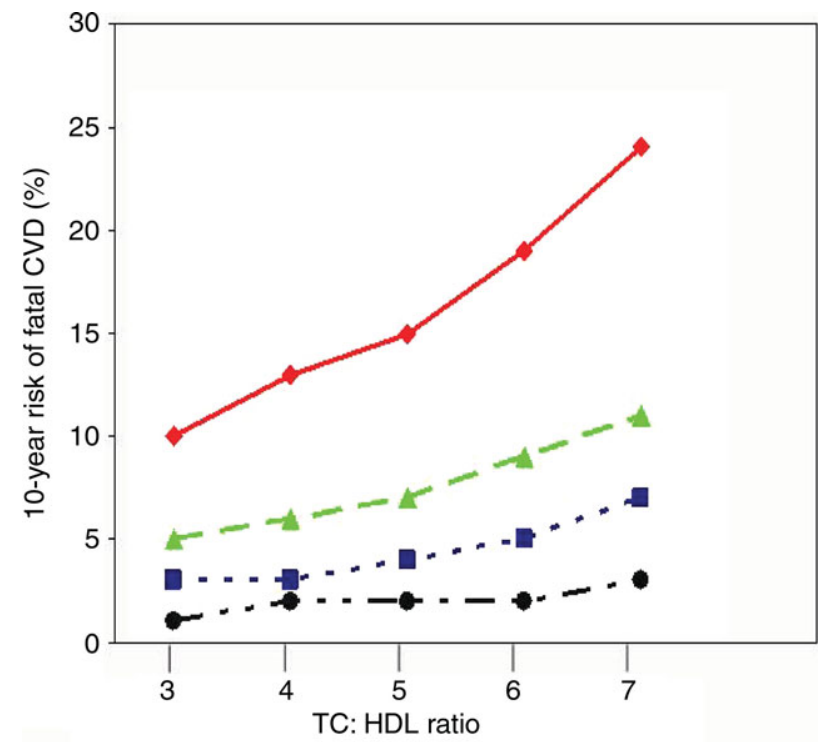

$$
\begin{aligned}
& - \text { Men, smoking, SBP=160 mm } \mathrm{mg} \\
& -\mathbf{-} \text { - Men, non-smoking, SBP=120 mm Hg } \\
& - \text { - Women, smoking, SBP }=160 \mathrm{mmHg} \\
& - \text { - Women, non-smoking, SBP }=160 \mathrm{mmHg}
\end{aligned}
$$

Figure 1 The relationship of total cholesterol (TC):HDL cholesterol ratio to 10 -year fatal CVD events in men and women aged 60 years with and without risk factors, based on a risk function derived from the SCORE project. SBP = systolic blood pressure.

Table 2 Impact of combinations of risk factors on risk

\begin{tabular}{llllll}
\hline Sex & $\begin{array}{l}\text { Age } \\
\text { (years) }\end{array}$ & $\begin{array}{l}\text { Cholesterol } \\
(\mathrm{mmol} / \mathrm{L})\end{array}$ & $\begin{array}{l}\text { BP } \\
(\mathrm{mmHg})\end{array}$ & Smoker & $\begin{array}{l}\text { Risk } \\
(\%)\end{array}$ \\
\hline $\mathrm{F}$ & 60 & 8 & 120 & No & 2 \\
$\mathrm{~F}$ & 60 & 7 & 140 & Yes & 5 \\
$\mathrm{M}$ & 60 & 6 & 160 & No & 8 \\
M & 60 & 5 & 180 & Yes & 21 \\
\hline
\end{tabular}

a total cholesterol of $5 \mathrm{mmol} / \mathrm{L}$ if the latter is a male hypertensive smoker. Randomized controlled drug trials of single risk factors do not give sufficient data to address these issues fully. While audits such as EuroAspire ${ }^{38,39}$ suggest inadequate risk factor management in very high risk subjects, it is also likely that, in the context of low risk subjects who have not had a vascular event, there is the potential for substantial overuse of drugs by inappropriate extrapolation of the results of trials conducted mostly on high risk men to low risk individuals. In general, women and old and young subjects have been under-represented in the classic drug trials that have informed guidelines to date.

For these considerations to impact on clinical practice, it is essential for the clinician to be able to assess risk rapidly and with sufficient accuracy to allow logical management decisions.

\section{How do I assess risk?}

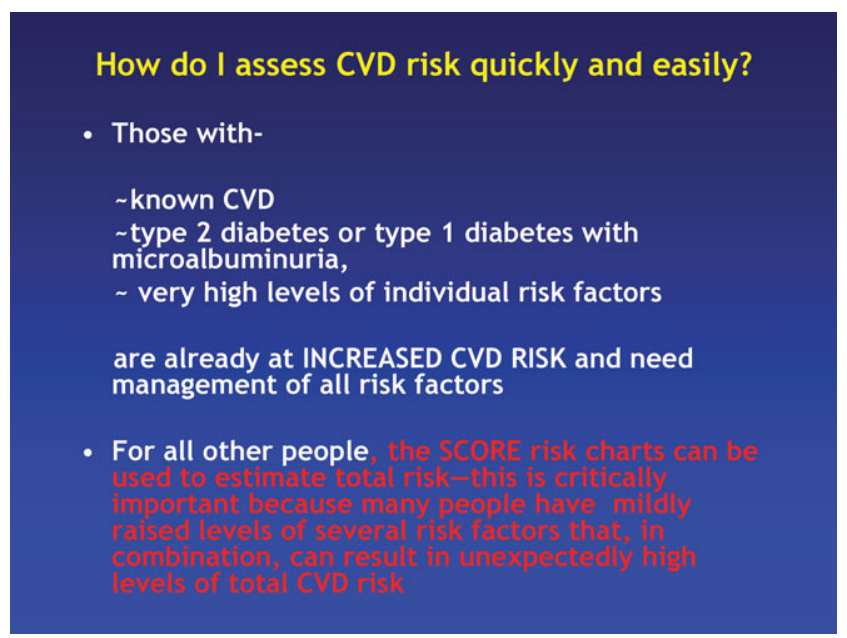

The need to assess total risk easily and quickly led to the development of the risk chart used in the 1994 and 1998 Guidelines. $^{1,2,41}$ There were several problems with this chart. First, it was derived from American data from the Framingham study and the applicability of the chart to all European populations was uncertain. Secondly, the data set used was fairly small. Thirdly, the definitions of non-fatal CHD events differed from those used in many other studies, making it difficult to validate the chart. Finally, estimation of the risk of other manifestations of atherosclerosis such as stroke or aneurysm of the abdominal aorta was not possible.

The 2003 Guidelines $^{3}$ used a new system for risk estimation called SCORE, ${ }^{42}$ based on data from 12 European cohort studies, and includes 205178 subjects examined at baseline between 1970 and 1988 with 2.7 million years of follow-up and 7934 cardiovascular deaths.

Risk charts such as SCORE are intended to facilitate risk estimation in ostensibly healthy persons. Patients who have had a clinical event such as an acute coronary syndrome or stroke, who have type 2 diabetes or type 1 diabetes with microalbuminuria, or who have a markedly increased level of a single risk factor have already declared themselves to be at markedly increased risk and automatically qualify for intensive risk factor evaluation and management. 
SCORE differs from earlier risk estimation systems in several important ways, and has been modified somewhat for the present guidelines:

- The SCORE system estimates the 10-year risk of a first fatal atherosclerotic event, whether heart attack, stroke, aneurysm of the aorta, or other. All ICD (International Classification of Diseases) codes that could reasonably be assumed to be atherosclerotic are included. Most other systems estimate CHD risk only.

- The choice of CVD mortality rather than total (fatal + nonfatal) events was deliberate although not universally popular. Non-fatal event rates are critically dependent upon definitions and the methods used in their ascertainment. Striking changes in both diagnostic tests and therapies have occurred since the SCORE cohorts were assembled. Critically, the use of mortality allows re-calibration to take into account time trends in CVD mortality. Any risk estimation system will overpredict in countries in which mortality has fallen and underpredict in those in which it has risen. Recalibration to allow for secular changes can be undertaken if good quality, up-to-date mortality and risk factor prevalence data are available. Data quality does not permit this for non-fatal events. For these reasons, the CVD mortality charts were produced and have, indeed, been re-calibrated for a number of European countries. Country-specific versions of HeartScore are available for Belgium, Germany, Greece, The Netherlands, Poland, Spain, and Sweden. Nevertheless it is essential to address the issue of total risk.

In the 2003 Guidelines, ${ }^{3}$ a 10 -year risk of CVD death of 5\% or more was arbitrarily considered high risk. Yet this implies a 95\% chance of not dying from CVD within 10 years, less than impressive when counselling patients. The new nomenclature in this 2007 Guideline is that everyone with a 10-year risk of CVD death of $5 \%$ or more has an increased risk. Naturally the risk of total fatal and non-fatal events is higher, and clinicians naturally wish for this to be quantified. The biggest contributor to the high risk SCORE charts is FINRISK, which has data on non-fatal events defined according to the MONICA project. ${ }^{43}$ Calculating total event rates from FINRISK suggests that, at the level (5\%) at which risk management advice is likely to be intensified, total event risk is about $10 \%$, more $(15 \%)$ in younger men and somewhat less in women. The 'multiplier' to convert CVD mortality to total events is also smaller in older people, presumably because a first event is more likely to be fatal.

As noted in the Introduction, clinicians often ask for thresholds to trigger certain interventions, but this is problematic since risk is a continuum and there is no threshold at which, for example, a drug is automatically indicated. A particular problem relates to young people with high levels of risk factors-a low absolute risk may conceal a very high relative risk. In the 2003 Guidelines, ${ }^{3}$ it was suggested to extrapolate risk to age 60 to stress that a high absolute risk would occur if preventive action were not taken. It was not intended that such a young person should be necessarily treated as if they were 60 , but a literal interpretation of this suggestion could lead to excessive drug treatment in younger persons. This part of the text has been rephrased, and a relative risk chart added to the absolute risk charts to illustrate that, particularly in younger persons, lifestyle changes can reduce risk substantially, as well as reducing the increase in risk that will occur with ageing.

- Another problem relates to old people. In some age categories, the vast majority, especially of men, will have estimated CVD death risks exceeding the 5-10\% threshold, based on age (and gender) only, even when other CVD risk factor levels are relatively low. This could lead to excessive usage of drugs in the elderly. Preventive treatments in the elderly should be evidence based unless clearly indicated.

- As before, charts are presented for both total cholesterol and the cholesterol:HDL cholesterol ratio. They look remarkably similar. However, subsequent work on the SCORE database, as yet unpublished, has shown that HDL cholesterol can contribute substantially to risk prediction if entered as an independent variable.

- Dealing with the impact of additional risk factors such as HDL cholesterol, body weight, family history, and newer risk markers is difficult within the constraint of a paper chart. The electronic, interactive version of SCORE, HeartScore (available through escardio.org), is not so constrained. It presently replicates SCORE in electronic format, but will be used to accommodate the results of new SCORE analyses, such as those relating to HDL cholesterol, as these are checked and validated. It should be stressed, however, that although many risk factors other than the few included in the available risk functions have been identified (such as CRP and homocysteine levels), their contribution to absolute CVD risk estimations of individual patients (in addition to the older risk factors) is generally modest.

- The impact of self-reported diabetes has been re-examined. While there is heterogeneity between cohorts, overall the impact of diabetes on risk appears greater than in risk estimation systems based on the Framingham cohort, with relative risks of approximately five in women and three in men.

Some of the advantages of using the risk charts may be summarized:

\section{Advantages in using the SCORE risk chart}

- Intuitive, easy to use tool

- Takes account of the multifactorial nature of CVD

- Estimates risk of all atherosclerotic CVD, not just CHD

- Allows flexibility in management-if an ideal risk factor level cannot be achieved, total risk can still be reduced by reducing other risk factors

- Allows a more objective assessment of risk over time

- Establishes a common language of risk for clinicians

- Shows how risk increases with age

- The new relative risk chart helps to illustrate how a young person with a low absolute risk may be at a substantially higher and reducible relative risk. 
How do I use the SCORE charts to assess total CVD risk in asymptomatic persons?

1. Use the low risk chart in Belgium*, France, Greece*, Italy, Luxembourg, Spain*, Switzerland, and Portugal; use the high risk chart in other countries of Europe

* Updated, re-calibrated charts are now available for Updated, re-calibrated charts are now available for
Belgium, Germany, Greece, The Netherlands, Poland, Belgium, Germany,
Spain, and Sweden

2. Find the cell nearest to the person's age, cholesterol, and $B P$ values, bearing in mind that risk will be higher as the person approaches the next age, cholesterol or BP category

3. Check the qualifiers

4. Establish the absolute 10-year risk for fatal CVD

Note that a low absolute risk in a young person may conceal a high relative risk; this may be explained to the person by using the relative risk chart. As the person ages, a high relative risk will translate into a high absolute risk. More intensive lifestyle advice will be needed in such persons.

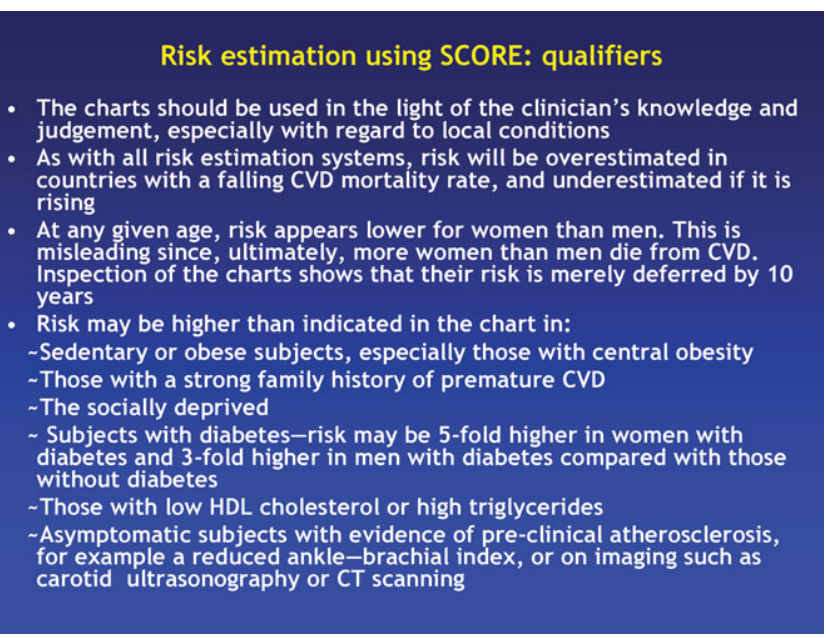

The SCORE risk charts are shown in Figures 2-6, including a chart of relative risks.

The relative risk chart in Figure 6 is useful in explaining to a younger person that, even if their absolute risk is low, it may still be 10-12 times higher than that of a person of a similar age with low risk factors.

\section{Conclusions}

The priorities defined in this section are for clinical use and reflect the fact that those at highest risk of a CVD event gain most from preventive measures. This approach should complement public actions to reduce community risk factor levels and promote a healthy lifestyle.

Estimation of total risk remains a crucial part of the present guidelines. The SCORE system has been updated with an estimate of total CVD risk as well as risk of CVD death. New information on diabetes is included. Information on relative as well as absolute risk is added to facilitate the counselling of younger persons whose low absolute risk may conceal a substantial and modifiable age-related risk.

The difficulty in imposing arbitrary thresholds or targets upon a continuous variable such as risk is acknowledged. Nevertheless, specific objectives are defined in terms of desirable levels of individual risk factors. This must be seen as an aid to clinicians in planning risk management strategies with their patients. The primacy of managing total risk rather than focusing on individual risk factors is stressed.

Priorites, risk estimation, and the definition of objectives reflect an attempt to make complex issues simple and

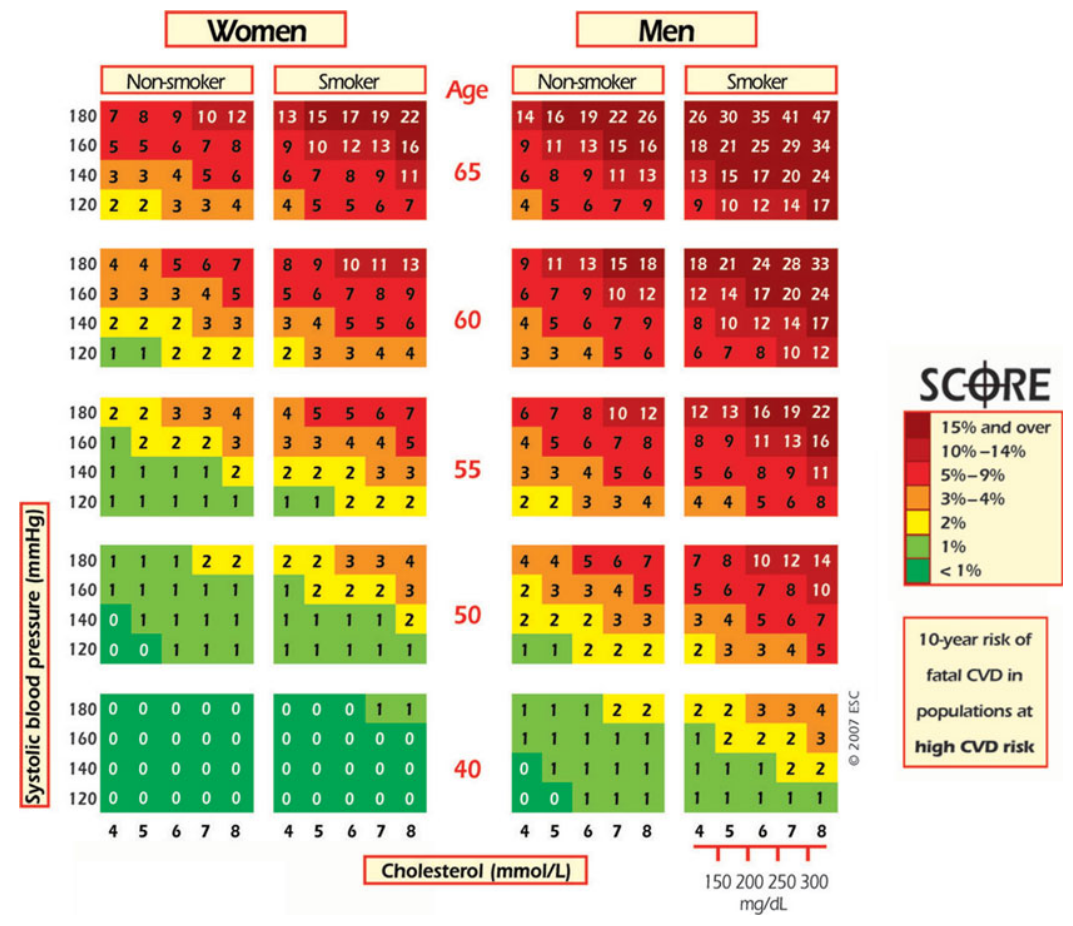

Figure 2 SCORE chart: 10-year risk of fatal CVD in populations at high CVD risk based on the following risk factors: age, gender, smoking, systolic blood pressure, and total cholesterol. (c) The European Society of Cardiology. 


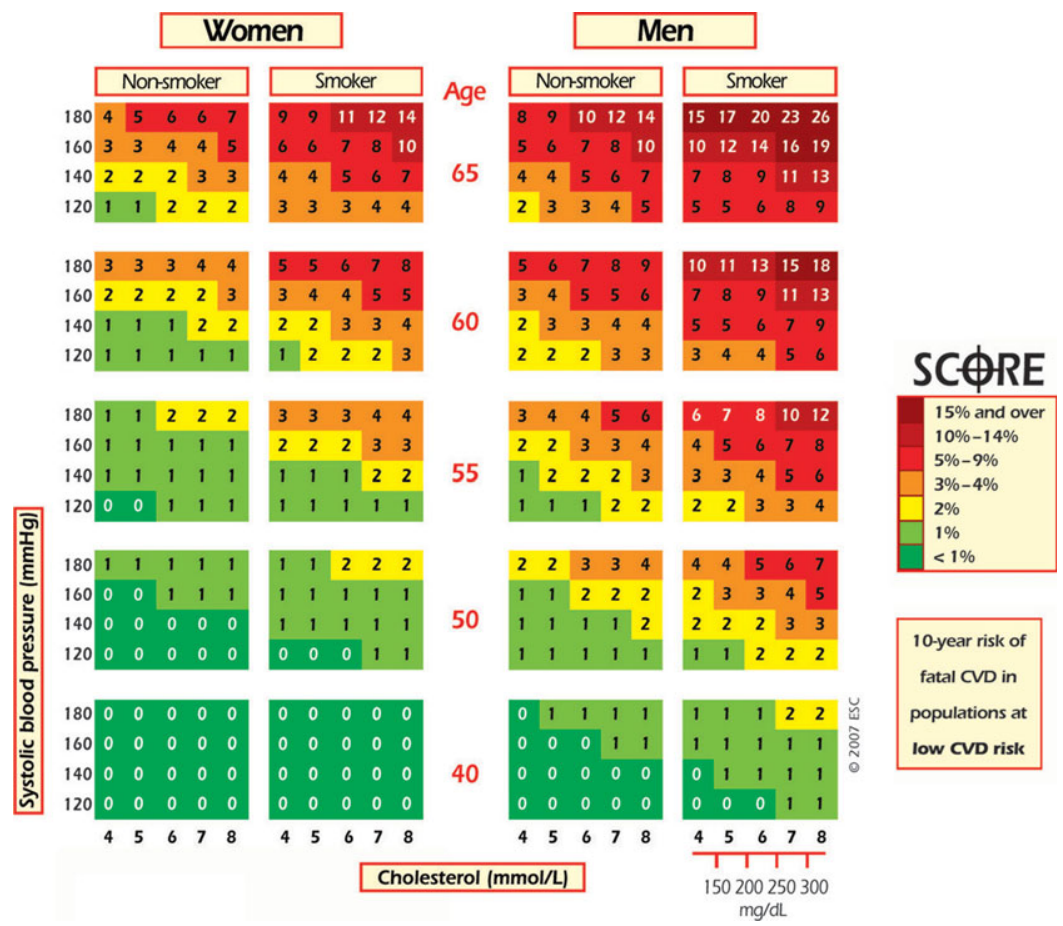

Figure 3 SCORE chart: 10-year risk of fatal CVD in populations at low CVD risk based on the following risk factors: age, gender, smoking, systolic blood pressure, and total cholesterol. (c) The European Society of Cardiology.

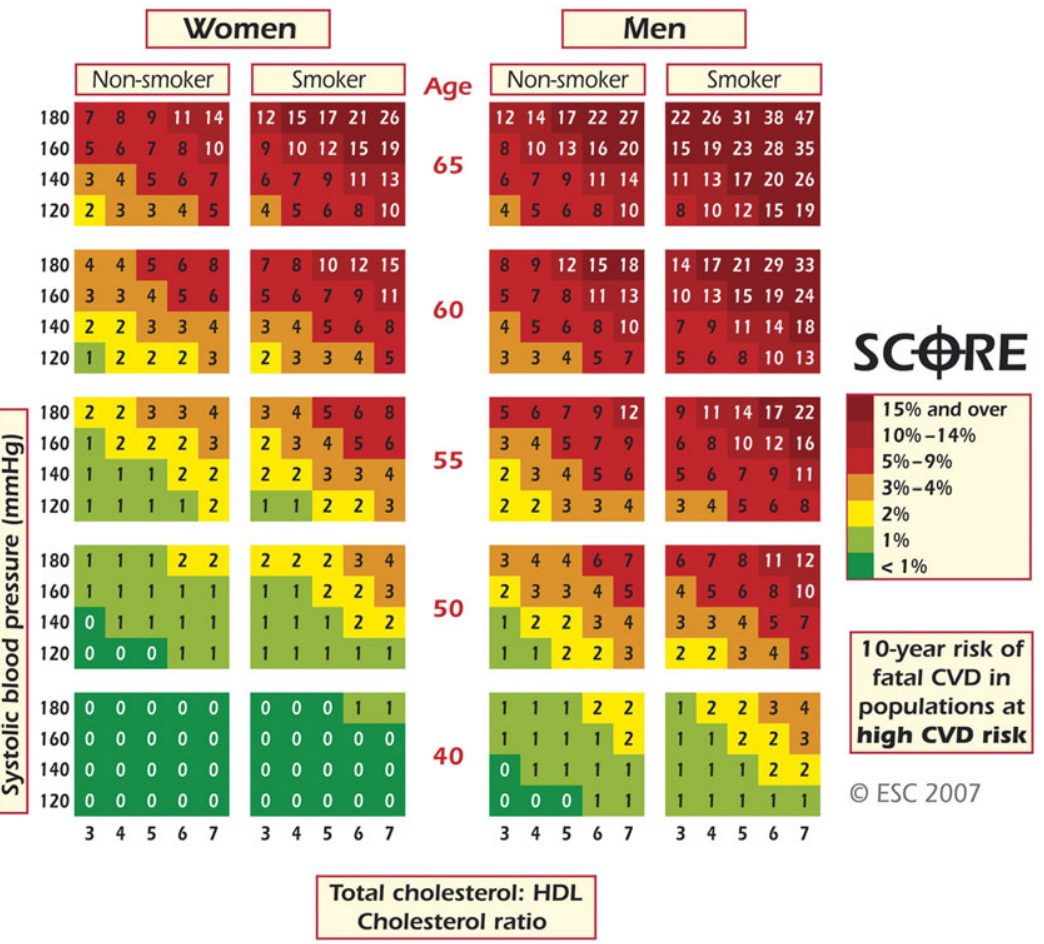

Figure 4 SCORE chart: 10-year risk of fatal CVD in populations at high CVD risk based on the following risk factors: age, gender, smoking, systolic blood pressure, and total cholesterol:HDL cholesterol ratio. (C) The European Society of Cardiology. 


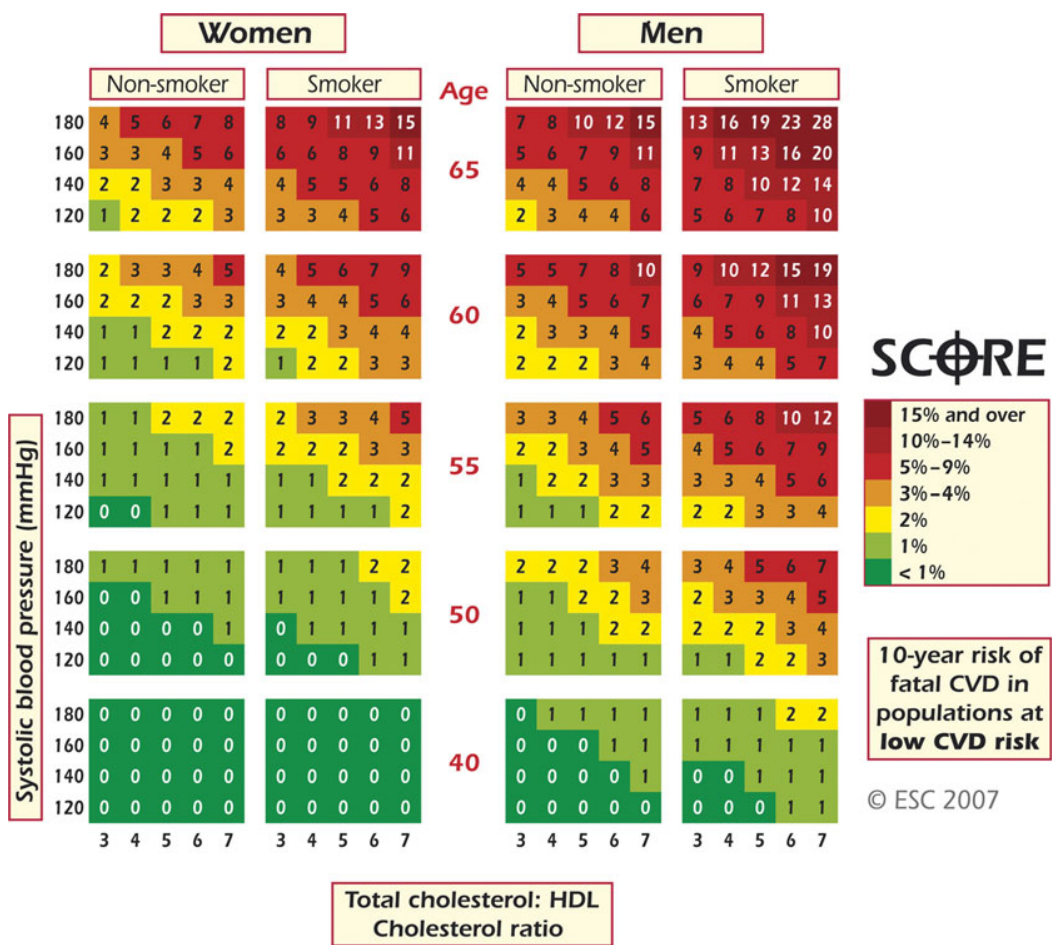

Figure 5 SCORE chart: 10-year risk of fatal CVD in populations at low CVD risk based on the following risk factors: age, gender, smoking, systolic blood pressure, and total cholesterol:HDL cholesterol ratio. (c) The European Society of Cardiology.
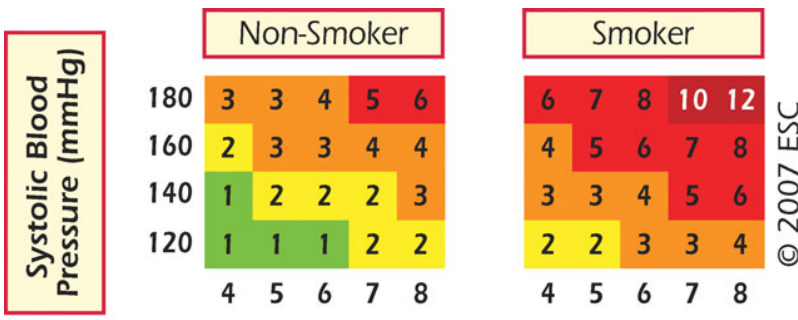

\section{Cholesterol (mmol/L)}

Figure 6 Relative risk chart. (c) The European Society of Cardiology.

accessible. Their very simplicity makes them vulnerable to criticism. Above all they must be interpreted in the light of the physician's detailed knowledge of their patient and in the light of local guidance and conditions.

The flow chart on p. 2389 gives a short summary of the recommendations.

\section{Principles of behaviour change and management of behavioural risk factors}

\section{Scientific background}

Physicians and other health professionals in the primary and out-patient care setting are in a unique position to contribute significantly to the improved prevention and management of CVD. Physicians are generally perceived by the general public as the most reliable and credible source of information on health and advice. Patients usually want to receive as much information as possible from physicians, and often prefer to receive assistance from them in order to change behaviours such as smoking, nutrition and diet, and physical activity, rather than attend special programmes elsewhere.

\section{The physician/caregiver-patient interaction as a means towards behavioural change}

A friendly and positive physician-patient interaction is a powerful tool to enhance patients' coping with stress and illness and adherence to recommended lifestyle change and medication.

Social support provided by caregivers, including physicians, and shared decision making can help patients maintain healthy habits and adhere to medical advice.

Previous negative, unsuccessful attempts to change behaviour, however, often result in a lower self-efficacy for future change in that behaviour, and often lead to another failure. A crucial step in changing negative experiences to positive is to set realistic goals, and goal setting combined with self-monitoring of the chosen behaviour are the main tools to achieve a positive outcome. This in turn will increase self-efficacy for the chosen behaviour, and thereafter new goals could be set. Moving forward in small 


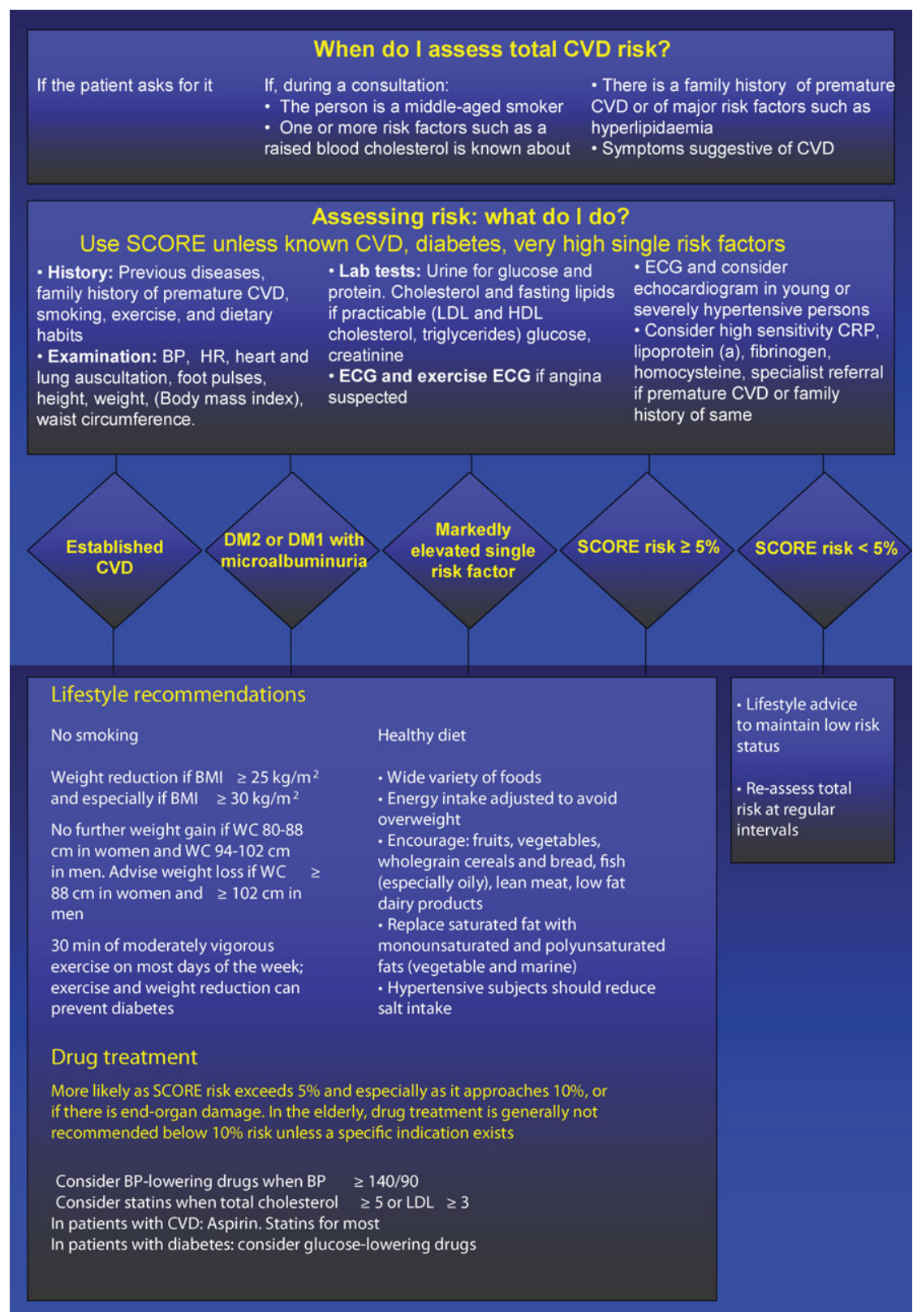

consecutive steps is one of the key points in long-term behaviour change.

\section{Specialized and multimodal interventions}

A number of specialized psychosocial intervention strategies have been demonstrated to have positive effects on risk factors, but the specific content and approaches taken by these interventions vary. Even if they intend to target only one behavioural risk factor, group-based behavioural interventions often contain elements which affect multiple risk factors. Interventions adding psychosocial and psychoeducational components to standard cardiological care can significantly improve quality of life and diminish cardiovascular risk factors. ${ }^{44-46}$
Practical aspects: management of behavioural risk factors

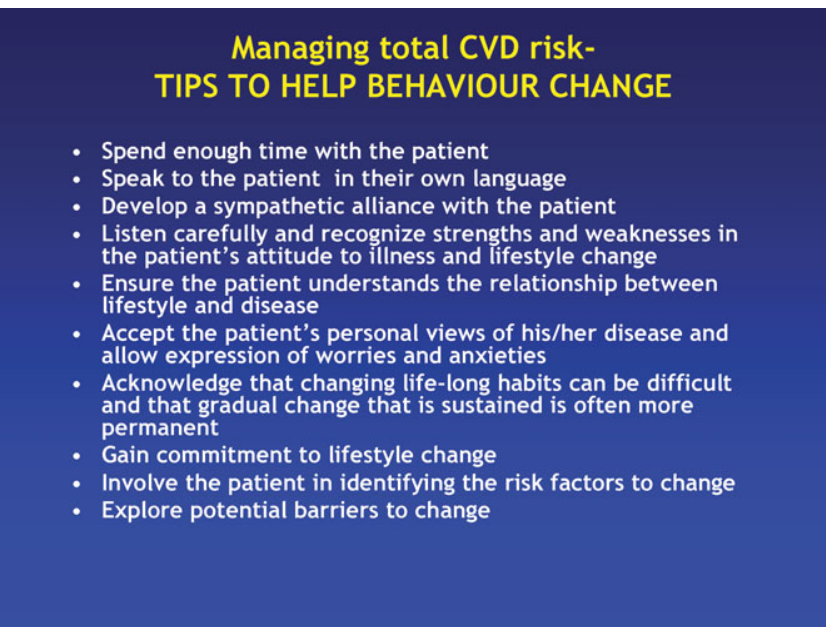




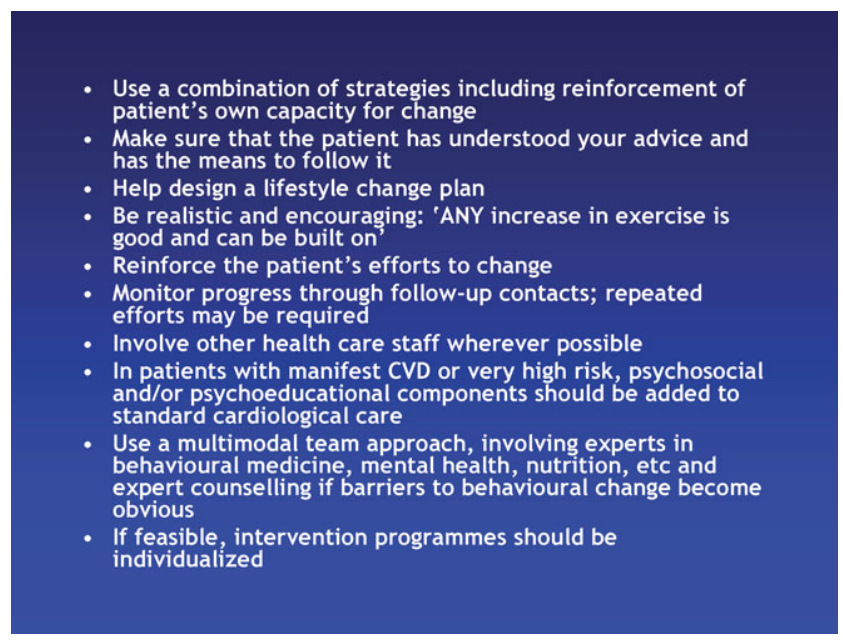

Managing total CVD risk:

Why do people find it hard to change their lifestyle?

- Socio-economic status: Low SES, including low educational level and low income, impedes the ability to adopt lifestyle change

- Social isolation: People living alone are more likely to have unhealthy lifestyles

- Stress: Stress at work and at home makes it more difficult for people to adopt and sustain a healthy lifestyle

- Negative emotions: Depression, anxiety and hostility impede lifestyle change

- Complex or confusing advice

Increased physician awareness of these factors facilitates empathy, counselling, and the provision of sympathetic, simple, and explicit advice

\section{Smoking}

\section{Scientific background}

There is overwhelming evidence for an adverse effect of smoking on health. ${ }^{47}$ This adverse effect of smoking is related to the amount of tobacco smoked daily and to the duration of smoking. The effects of smoking on CVD interact synergistically in the presence of other CVD risk factors such as age, gender, arterial hypertension, and diabetes.

Passive smoking has been shown to increase the risk of CHD and other smoking-related diseases. ${ }^{48}$

The benefits of smoking cessation have been extensively reported. ${ }^{49,50}$ Some of the advantages are almost immediate; others take more time. Stopping smoking after an Ml is potentially the most effective of all preventive measures. Sufficient efforts should be devoted to this end.

\section{Practical aspects: prevention and management of smoking}

The assessment of smoking status should be done at every opportunity.

Stopping smoking should be encouraged in all smokers. There is no age limit to the benefits of smoking cessation.

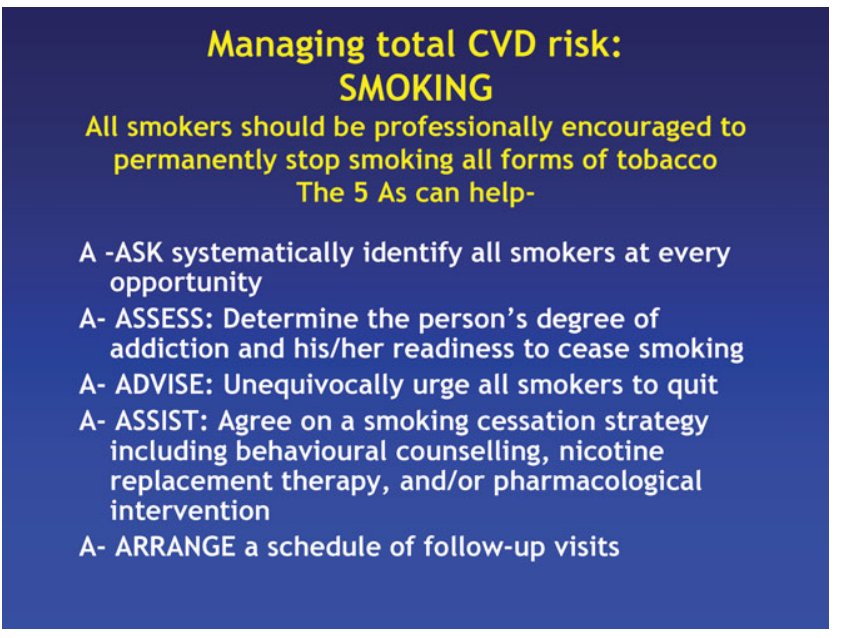

Quitting smoking is a complex and difficult process, because the habit is strongly addictive both pharmacologically and psychologically. Quitting can be facilitated with professional assistance. The physician's firm and explicit advice that a person should stop smoking completely is the most important factor in getting the smoking cessation process started. The momentum for smoking cessation is particularly strong at the time of diagnosing atherothrombotic CVD and in connection with an invasive treatment, such as coronary artery bypass grafting, percutaneous transluminal coronary angioplasty, or vascular surgery. The physician's advice is equally important in helping healthy high risk individuals to attempt to quit smoking. Assessing whether the person is willing to try to quit, brief reiteration of the cardiovascular and other health hazards of smoking, and agreeing on a specific plan with a follow-up arrangement are the decisive first steps and essential features of the brief initial advice of smoking cessation in clinical practice.

Both individual and group behavioural interventions are effective in helping smokers to quit. ${ }^{51}$ However, the quality of physician-patient communication seems to be more relevant than the quantity of counselling sessions or the intervention format (group vs. individual). Support by the partner and family is very important in smoking cessation. Involvement of the family in the smoking cessation process and getting other smoking family members to quit smoking together with the patient is of great help.

Nicotine chewing gum and transdermal nicotine patches have been widely used in helping quitters to go through the difficult initial weeks or months of smoking cessation.

Antidepressant medication in aiding long-term smoking cessation has been shown to be effective. Bupropion and nortriptyline can aid smoking cessation.

Another new pharmacological agent that may be of help in smoking cessation is varenicline, a nicotine acetylcholine receptor agonist. Among long-term smokers, treatment with varenicline was associated with a smoking cessation rate of $23 \%$ at 1 year as compared with 15 and $10.3 \%$ in the groups treated with buproprion and placebo, respectively. Reports that it may be more effective than buproprion or placebo need confirmation. 


\section{Nutrition}

\section{Scientific background}

Fatty acids regulate cholesterol homeostasis and concentrations of blood lipoproteins, and affect the levels of other cardiovascular risk factors, such as BP, haemostasis, and body weight, through various mechanisms. There are strong, consistent, and graded relationships between saturated fat intake, blood cholesterol levels, and the mass occurrence of CVD. The relationships are accepted as causal. n-3 fatty acids, in contrast, showed protective effects on fatal events in patients who had suffered a previous MI. Sodium intake, especially in the form of sodium chloride, influences arterial BP and therefore the risk of arterial hypertension, stroke, CHD, and heart failure. Intervention trials with vitamin supplements have failed to demonstrate any protection against CHD. Besides micro- and macronutrients, dietary patterns, including fruit and vegetables, monounsaturated fatty acid-rich oil (such as olive oil), and low fat dairy products, have been associated with decreased incidence of cardiovascular events.

\section{Practical aspects: management}

Dietetics is an integral part of cardiovascular patient risk management. All patients having a CVD and those individuals at high risk should be given professional advise on the food and dietary options which reduce the cardiovascular risk. A varied and energy-balanced regimen together with regular exercise is critical to the preservation of a good cardiovascular health.

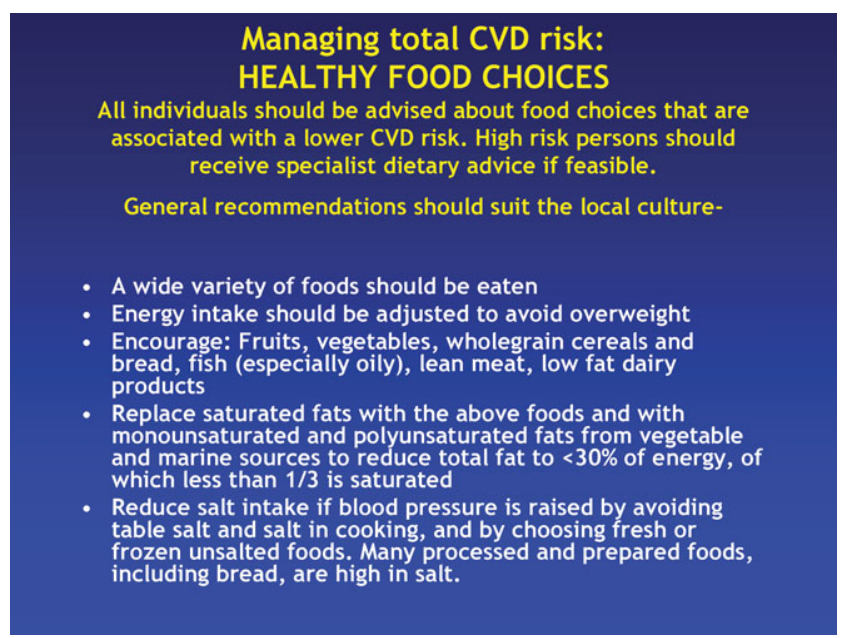

Dietetic recommendations should be defined individually, taking into account the subject's risk factors-dyslipidaemia, hypertension, diabetes, and obesity.

\section{Overweight and obesity}

\section{Scientific background}

As societies develop a higher standard of living, cardiovascular mortality initially increases. This is followed by a reduction in both major risk factors such as blood cholesterol and high BP which, together with improvements in therapy, translate into reduced cardiovascular mortality. The exceptions to these trends are body weight and diabetes which tend to increase as other risk factors decline. Obesity is becoming a worldwide epidemic in both children and adults. ${ }^{52}$ Currently it is estimated that, worldwide, over 1 billion people are overweight, and over 300 million are obese. Over one-third of children are overweight or obese.

\section{Body weight and risk}

It is now clear that fat, and in particular intra-abdominal visceral fat, is a metabolically active endocrine organ that is capable of synthesizing and releasing into the bloodstream an important variety of peptides and non-peptide compounds that may play a role in cardiovascular homeostasis. Fat is associated with increased secretion of free fatty acids, hyperinsulinaemia, insulin resistance, hypertension, and dyslipidaemia. ${ }^{53,54}$ This impacts on CVD risk factors and hence on risk. The mechanical effects of overweight impact on non-cardiovascular causes of morbidity and mortality. The health effects of increasing body weight are summarized in Table 3.

Interestingly, the effects of multivariate adjustment on the association between lipid levels and risk and between body weight and risk are different. Raised blood cholesterol or a reduced HDL cholesterol level remain independently associated with risk after adjustment for other major risk factors, whereas the association between weight and risk tends to lose significance. This should not be interpreted as indicating that body weight is not important; rather, it may be critically important because it exerts its effect on risk by its adverse effects on many risk factors.

Table 3 Impact of increasing body weight on risk factors, morbidity, and mortality

\begin{tabular}{|c|c|c|}
\hline Risk factors & Morbidity & Mortality \\
\hline $\begin{array}{l}\text { Raised BP } \\
\text { Raised total and LDL } \\
\text { cholesterol } \\
\text { Reduced HDL } \\
\text { cholesterol } \\
\text { Increased waist } \\
\text { circumference } \\
\text { Sleep apnoea } \\
\text { Obesity hypoventilation } \\
\text { syndrome } \\
\text { Physical inactivity }\end{array}$ & $\begin{array}{l}\text { Type } 2 \text { diabetes } \\
\text { Insulin resistance } \\
\text { Coronary heart disease } \\
\text { Stroke } \\
\text { Osteoarthritis (knee) } \\
\text { Cancer } \\
\text { Low back pain due to } \\
\text { obesity } \\
\text { Breathlessness } \\
\text { Polycystic ovary } \\
\text { syndrome } \\
\text { Infertility } \\
\text { Cholelithiasis } \\
\text { Asthma (exacerbation) } \\
\text { Venous } \\
\text { thromboembolic } \\
\text { pulmonary } \\
\text { embolism } \\
\text { Inflammation } \\
\text { Autonomic nervous } \\
\text { system dysfunction }\end{array}$ & $\begin{array}{l}\text { Increased total } \\
\text { and cardiovascula } \\
\text { mortality }\end{array}$ \\
\hline
\end{tabular}


Which index of obesity is the best predictor of cardiovascular risk and cardiovascular risk factors-body mass index (BMI), waist circumference (WC), or waist-hip circumference ratio (WHR)?

Recent studies have demonstrated that regional distribution of adipose tissue may be more important in determining cardiovascular risk than total body weight. Excess central (visceral abdominal) fat in particular has been shown to be strongly associated with metabolic and cardiovascular risk. ${ }^{55}$ This has led to increased interest in anthropometric measures of risk. Most data are available for BMI, waist-hip circumference ratio (WHR), and, more recently, simple waist circumference (WC). Such measures of risk are cheap and universally available. WC, while simple, may be more prone to measurement error than BMI. The optimal level for measurement of WC is midway from the lower rib margin to the anterior superior iliac crest. The evidence supporting each measure in estimating risk is now considered.

BMI has been extensively used to define the groups of body weight $\left[\mathrm{kg} /\right.$ height $\left.(\mathrm{m})^{2}\right]$ using classifications suggested by the National Institutes of Health and the WHO. In adults, overweight is defined by an increased $\mathrm{BMI}$ ranging from 25 to $29.9 \mathrm{~kg} / \mathrm{m}^{2}$ and obesity by $B M I \geq 30 \mathrm{~kg} / \mathrm{m}^{2}$. Increasing $\mathrm{BMI}$ is highly associated with CVD.

The association between both increasing WC and WHR and greater risk of development of CVD has been demonstrated in cohort and case-control studies. ${ }^{56}$ In general, these have shown that the measurement of WC in addition to $\mathrm{BMI}$ gives additional information for CVD risk estimation. The association between increasing WC or WHR and the presence of other cardiovascular risk factors or the metabolic syndrome has been shown in many cross-sectional studies. ${ }^{57}$ There is no consistent information on which of these anthropometric measures is superior.

Both the WHO report on obesity ${ }^{58}$ and the American National Heart, Lung, and Blood Institute (NHLBI) expert panel on obesity ${ }^{59}$ recommend the use of WC as an additional indicator of metabolic risk factors, within each category of BMI. Of various definitions, ${ }^{58,59}$ the WHO cut-off points are the most widely accepted in Europe; two action levels are recommended. Action level $1-W C \geq 94 \mathrm{~cm}$ in men and $\geq 80 \mathrm{~cm}$ in women-represents the threshold at which no further weight should be gained. Action level $2-W C \geq 102 \mathrm{~cm}$ in men and $\geq 88 \mathrm{~cm}$ in women represents the threshold at which weight reduction should be advised. The cut-off points have been calculated based on white people, and it is apparent that different cut-off points for anthropometric measurements are required in different races and ethnicities. ${ }^{60}$

In conclusion, there is no solid evidence for superiority of either variable in the prediction of risk factors. WC has the advantage of simplicity, may be a slightly better estimator of risk than BMI, but is probably more prone to measurement error.

\section{Imaging and fat distribution}

Several measurements have been described for assessing the anatomical distribution of fat, such as computed tomography (CT), ultrasound (US), and magnetic resonance imaging (MRI). They allow changes in intra-abdominal fat to be monitored. However, they are expensive and time consuming, and are to be regarded as specialist research tools rather than everyday risk assessment tools at this time.

Anthropometric measurements such as WC and WHR provide a useful estimation of the proportion of abdominal or upper-body fat, but they do not distinguish between accumulations of deep abdominal (visceral) fat and subcutaneous abdominal fat. CT can be considered the gold standard not only for adipose tissue evaluation but also for multicompartment body measurement; ${ }^{61}$ the subcompartments of adipose tissue volume, visceral and subcutaneous adipose tissue, can be accurately measured with errors of 1.2 and $0.5 \%$, respectively.

MRI provides results similar to $\mathrm{CT}$ without exposure to ionizing radiation, the main problem with $\mathrm{CT}$ multislice measurements. It demonstrates good reproducibility for total and visceral adipose tissue volumes. ${ }^{62}$

Several studies demonstrated a highly significant correlation between the intra-abdominal adipose tissue determined by CT and by US. ${ }^{63,64}$

Sagittal abdominal diameter is derived either from a CT abdominal $\operatorname{scan}^{65}$ or by using a sagittometer placed over the abdomen perpendicular to the length axis of the trunk at the iliac crest level (L4-5) with the subject in the supine position on a firm bench with the knees bent. ${ }^{66}$ Sagittal abdominal diameter correlates strongly with visceral fat volume as measured by $\mathrm{CT}^{67} \mathrm{CT}$ scanning is expensive and involves exposure to radiation. It is not as yet recommended for routine clinical risk assessment.

\section{Practical aspects: management of obesity and overweight}

Intentional weight loss in obese patients can improve or prevent many of the obesity-related risk factors for CHD. Reduction in BP occurs before attainment of desirable body weight.

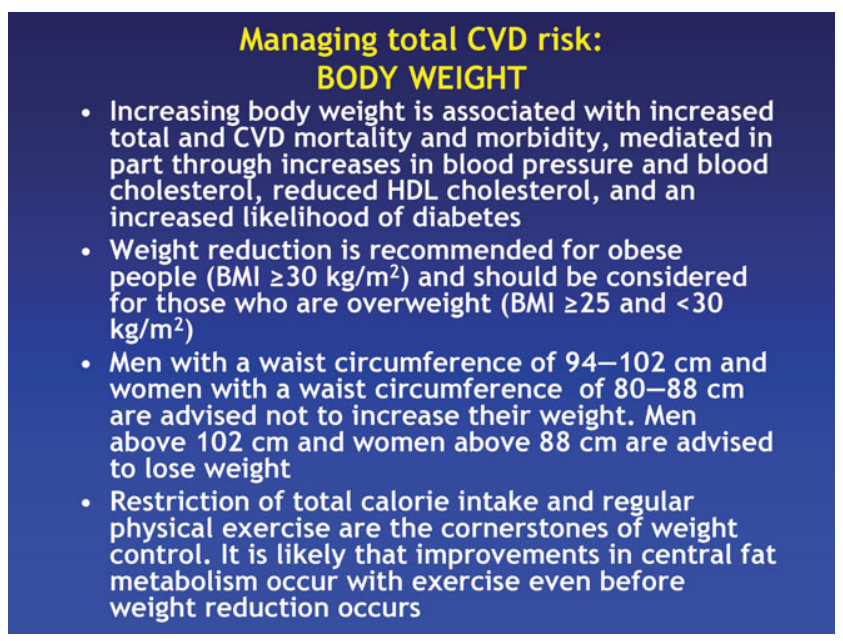

\section{Physical activity and body weight}

There is sufficient evidence available from intervention studies supporting the role of physical activity and moderate to vigorous exercise in promoting weight loss. ${ }^{68}$ Recent research has indicated that exercise may have beneficial effects before a training effect is apparent ${ }^{69,70}$ and may impact on abdominal fat metabolism before weight loss occurs. ${ }^{69,70}$ This information may be valuable in motivating high risk persons to initiate exercise. 


\section{Diet and behavioural interventions}

Many different diets and behavioural interventions have been proposed for the treatment of obesity. The control of overweight is dependent upon achieving the appropriate balance between energy intake and expenditure. The dietary approaches vary in their total energy content, macronutrient composition (protein, carbohydrates, and lipids), energy density, and glycaemic index. ${ }^{71}$ The low fat diet is considered the standard approach to weight reduction and has a more favourable effect on LDL cholesterol. Total fat intake should be kept between 25 and 35\% of energy. The reduction in saturated fats is the preferred target due to its effects on the lipoprotein profile. Intake of saturated and trans fatty acids should be $<7 \%{ }^{72}$

The low carbohydrate diet has become popular and in the short term decreases body weight greatly and also has a good effect on plasma triglycerides and HDL cholesterol. ${ }^{73}$ However, its long-term safety is still under investigation. Alcohol is a major source of calories and reduction may be an important part of weight control.

Behaviour modification inducing long-term lifestyle change leading to a gradual weight loss is the basis of all obesity treatment. According to a recent Cochrane review, behavioural and cognitive-behavioural therapy helps to lose additional weight when added to diet and exercise programmes. ${ }^{74}$ Behavioural interventions have also been shown to help maintain weight loss. ${ }^{75}$

\section{Drug treatment of overweight}

In general, the contribution of drug treatments is modest and, in the past, some products have had serious side effects.

Orlistat inhibits intestinal lipases to prevent the hydrolysis and uptake of fat. Weight loss is usually modest, and gastrointestinal disturbance may occur. It should be used with a full and balanced diet.

Sibutramine enhances a feeling of satiety after food by an effect of its metabolites which inhibit noradrenaline and serotonin uptake. Both contraindications and side effects are appreciable.

Rimonabant is an endocannabinoid receptor inhibitor that appears capable of inducing a modest but sustained weight loss in combination with a calorie-controlled diet. It may improve glucose tolerance, beneficially affect lipid metabolism, and is associated with a modest reduction in BP. Possible adverse effects on depression are being monitored. It remains to be seen if its promising effects on weight and other risk factors will translate into hard evidence of reduced cardiovascular events.

\section{Physical activity}

\section{Scientific background}

- A lack of regular physical activity may contribute to the early onset and progression of CVD.

- Almost any increase in physical activity will result in health benefits.

- Assessment of physical activity is a key element of risk evaluation.

Physical inactivity is a significant public health problem in Europe: children have become less physically active and only in a few countries do children have access to the recommended daily dose of physical activity. More than half of adolescents become physically inactive after leaving school.

Adults face a significant decrease in physical demands at their place of work and, during leisure time, fewer people are physically active. A sedentary lifestyle is associated with a doubling of the risk of premature death and with an increased risk of CVD. ${ }^{76,77}$ Avoiding a sedentary lifestyle during adulthood may extend total life expectancy and CVD-free life expectancy (by $1.3-3.5$ years). ${ }^{78}$

Physical training has a wide variety of beneficial effects on the course of atherosclerosis, resulting in a 20-25\% reduction in overall mortality. ${ }^{79}$ Yet, in Europe, a minority of CVD patients participate in exercise training programmes. Even fewer patients with chronic heart failure (CHF) are enrolled, although they may well benefit from adapted exercise training.

In the elderly population, approximately a quarter of the population suffer from CVD. Physiological and mental changes that come with increasing age may contribute to physical inactivity, but regular physical activity may effectively slow down the age-related changes, thereby improving physical functioning and extending disease-free survival.

\section{Estimating physical activity}

For an assessment of physical activity, different methods are available: doubly labelled water, indirect calorimetry, direct observation, activity monitors (pedometers, accelerometers), heart rate monitors and questionnaires, or activity diaries. For physical fitness and exercise capacity, maximal incremental exercise testing is used. ${ }^{80}$

In clinical practice, the assessment should be combined with a total CVD risk estimation using the SCORE/HeartScore method. In individuals at low risk, a brief interview concerning the person's physical activity may suffice, but in high risk persons this may be completed with an exercise test. Assessment in adults with known CVD should be combined with exercise testing in order to detect myocardial ischaemia, stratify for risk, and give guidance on the clinical management.

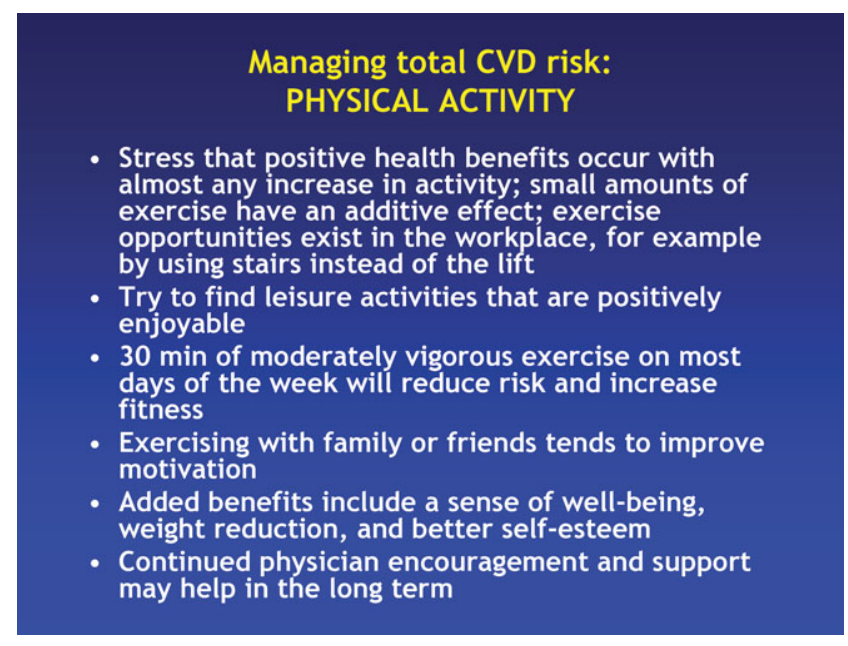

\section{Practical aspects: management}

In the young population, the promotion of physical fitness is the shared responsibility of parents, school staff, health 
care providers, politicians, and society as a whole: each child in Europe should have access to periods of physical activity each day. Here, more research is needed to find instruments for measuring physical fitness and activity, and to create programmes to improve and maintain physical activity.

The choice of lifestyle, including maintained physical fitness, remains the sole responsibility of the individual person. This may be supported by family and friends, work environment, access to attractive and affordable leisure time activities, and by health-promoting campaigns. Regular physical exercise within the resources of the work place is recommended. The ultimate goal is at least half an hour of physical activity on most days of the week as almost any increase in activity is associated with measurable health benefits.

The intensity may be defined in terms of target heart rate or perceived exertion. A heart rate during peak exercise of $60-75 \%$ of the average maximum heart rate is preferred. The Borg scale of perceived exertion may be applied, using the level of 'moderate exertion'. This may be easily achieved by a wide variety of activities such as brisk walking or jogging, cycling, swimming, gardening, aerobic dancing, tennis, golf, or even cross-country skiing. ${ }^{81}$

Recommendations for patients with known CVD have to be based on a comprehensive clinical judgement including exercise testing. A majority will benefit from a cardiac rehabilitation programme: in addition to supervised physical exercise in patient groups, this includes lifestyle advice and support as well as measures aimed at risk reduction. If patients prefer to perform the programme at home, they will need clear prescriptions, encouragement, and regular follow-up by their physician. For patients with mild to moderate heart failure, both dynamic interval training with moderate intensity and resistance training may be advantageous.

When counselling elderly persons, it is recommended to maintain daily physical activity on a moderate to submaximum level. Principles of behavioural change including social support, self-efficacy, and positive reinforcement should be applied, and programmes should start off at low intensity but gradually increase to moderate levels. Key elements of activity programmes for the elderly are a combination of endurance, strength, balance, and flexibility.

Even the elderly CVD patient may benefit from rehabilitation programmes: exercise training is safe, improves strength, aerobic fitness, endurance, and physical function, and there are no gender differences in the outcome.

Thus, the assessment, counselling, and support in the maintenance of physical activity are core tasks for physicians and other health workers engaged in the prevention of cardiovascular disease.

\section{Heart rate}

\section{Scientific background}

Elevated heart rate has been shown to be associated with increased risk of all-cause mortality, CVD mortality, and development of CVD in the general population, hypertensives, diabetics, and those with pre-existing coronary artery disease. ${ }^{82,83}$ The relationship is also seen in animal models. Levine demonstrated the semi-logarithmic inverse relationship between heart rate and life expectancy in mammalian species. ${ }^{84} \mathrm{~A}$ reduction in the development of atherosclerosis has been demonstrated in cholesterol-fed monkeys after pharmacological or surgical reduction of heart rate. ${ }^{85}$

Most epidemiological studies have shown the relationship to be strong, graded, and independent of other factors including BP and physical activity. While virtually all of the studies demonstrated a significant effect in men, the relationship between CVD mortality and elevated heart rate in women and the elderly was non-significant after multivariate adjustment in some of the studies. Risk of sudden death in men is particularly associated with elevated resting heart rate. ${ }^{86}$

A low heart rate may be exerting its effect on CVD through anti-arrhythmic or anti-ischaemic effects. Other possible mechanisms are the direct effect on haemostatis of an elevated heart rate causing progression of atherosclerosis.

No trial has investigated the effect of lowering heart rate on prognosis in asymptomatic people. Meta-analyses of $\beta$-blocker and calcium channel blocker therapy in post-MI patients and in CHF have demonstrated their benefits in these patients. ${ }^{87,88}$ Studies have shown that the benefit achieved is related to the level of heart rate reduction; however, it is uncertain if this is the only mechanism in the benefit of $\beta$-blockade. ${ }^{89}$

\section{Practical aspects: management}

In the general population, avoidance of elevated heart rate through lifestyle measures can be recommended. These include regular physical activity, avoidance of psychological stress, and excessive use of stimulants such as caffeine. Pharmacological reduction of heart rate cannot be recommended in the asymptomatic population.

Both $\beta$-blockers and selective $I_{f}$ channel blockers are effective in the treatment of angina. ${ }^{90} \beta$-Blockers are recommended in patients post-MI and in CHF patients in carefully titrated doses.

\section{Blood pressure}

\section{Scientific background}

Elevated $\mathrm{BP}$ is a risk factor for $\mathrm{CHD}^{91}$, heart failure, CVD, peripheral vascular disease, and renal failure in both men and women. ${ }^{91-94} \mathrm{BP}$ levels correlate inversely with cognitive function, and hypertension is associated with an increased incidence of dementia. ${ }^{95} \mathrm{CHD}$ and stroke mortality increase progressively and linearly from BP levels as low as $115 \mathrm{mmHg}$ systolic and $75 \mathrm{mmHg}$ diastolic upward. ${ }^{96}$

In addition, longitudinal data obtained from the Framingham Heart Study indicated that BP values in the 130-139/ 85-89 $\mathrm{mmHg}$ range are associated with a $>2$-fold increase in relative risk from CVD compared with those with $\mathrm{BP}$ levels below $120 / 80 \mathrm{mmHg} .{ }^{97}$

The classification of hypertension used in the 2003 and 2007 ESH/ESC guidelines has been retained (Table 4). Isolated systolic hypertension should be graded as the same as the systolic BP values indicated for systolic-diastolic hypertension. However, the association with a low diastolic 
Table 4 Definition and classification of blood pressure levels

\begin{tabular}{llll}
\hline Category & Systolic & & Diastolic \\
\hline Optimal & $<120$ & and & $<80$ \\
Normal & $120-129$ & and/or & $80-84$ \\
High normal & $130-139$ & and/or & $85-89$ \\
Grade 1 hypertension & $140-159$ & and/or & $90-99$ \\
Grade 2 hypertension & $160-179$ & and/or & $100-109$ \\
Grade 3 hypertension & $\geq 180$ & and/or & $\geq 110$ \\
Isolated systolic hypertension & $\geq 140$ & and & $<90$ \\
\hline
\end{tabular}

Isolated systolic hypertension should be graded $(1,2,3)$ according to systolic blood pressure values in the ranges indicated, provided that diastolic values are $<90 \mathrm{mmHg}$. Grades 1,2 , and 3 correspond to classification of mild, moderate, and severe hypertension, respectively. These terms have now been omitted to avoid confusion with quantification of total cardiovascular risk.
BP (e.g. $60-70 \mathrm{mmHg}$ ), indicating a wide pulse pressure, should be regarded as higher risk.

\section{Risk stratification and target organ damage}

The decision to start pharmacological treatment depends not only on the BP level but also on total cardiovascular risk, which calls for a careful history, physical examination, and laboratory tests to identify (i) the presence of clinically established CVD; (ii) the co-existence of other cardiovascular risk factors; and (iii) the presence of subclinical CVD or end-organ damage-an intermediate stage in the continuum of cardiovascular risk. The presence of clinically established cardiovascular or renal disease markedly increases the risk of subsequent cardiovascular events at all levels of BP (Table 5).

The co-existence of other cardiovascular risk factors (smoking, increased plasma cholesterol, family history of

Table 5 Factors influencing prognosis in hypertension

\begin{tabular}{|c|c|c|c|}
\hline Risk factors & Target organ damage & Diabetes mellitus & Established CVD or real disease \\
\hline - Systolic and diastolic BP levels & $\begin{array}{l}\text { Electrocardiographic LVH } \\
\text { (Sokolow-Lyons > } 38 \mathrm{~mm} ; \\
\text { Cornell }>2440 \mathrm{~mm} \times \mathrm{ms} \text { ) }\end{array}$ & $\begin{array}{l}\text { - Fasting plasma } \\
\text { glucose } \geq 7.0 \mathrm{mmol} / \mathrm{L} \\
(126 \mathrm{mg} / \mathrm{dL})\end{array}$ & $\begin{array}{l}\text { - Cerebrovascular disease: } \\
\text { ischaemic stroke; cerebral } \\
\text { haemorrhage; transient } \\
\text { ischaemic attack }\end{array}$ \\
\hline
\end{tabular}

- Levels of pulse pressure (in the elderly)

- Age $(M>55$ years; $W>65$ years)

or:

- Smoking

- Dyslipidaemia

TC $>5.0 \mathrm{mmol} / \mathrm{L}(190 \mathrm{mg} / \mathrm{dL})$

or:

- $\quad$ LDL-C > $3.0 \mathrm{mmol} / \mathrm{L}(115 \mathrm{mg} / \mathrm{dL})$

or:

- HDL-C: $M<1.0 \mathrm{mmol} / \mathrm{L}(40 \mathrm{mg} / \mathrm{dL})$, $\mathrm{W}<1.2 \mathrm{mmol} / \mathrm{L}(46 \mathrm{mg} / \mathrm{dL})$

or:

- $\quad \mathrm{TG}>1.7 \mathrm{mmol} / \mathrm{L}(150 \mathrm{mg} / \mathrm{dL})$

- Fasting plasma glucose 5.6-6.9 mmol/L (100-125 mg/dL)

- Abnormal glucose tolerance test

- Abdominal obesity [waist circumference $>102 \mathrm{~cm}(\mathrm{M}),>88 \mathrm{~cm}$ (W)]

- Family history of premature CV disease $(M$ at age $<55$ years; $W$ at age $<65$ years)
- Echocardiographic LVH ${ }^{a}$ (LVMI $M \geq 125 \mathrm{~g} / \mathrm{m}^{2}$, $\left.W \geq 110 \mathrm{~g} / \mathrm{m}^{2}\right)$

- Carotid-wall thickening (IMT $\geq 0.9 \mathrm{~mm}$ ) or plaque

- Carotid-femoral pulse wave velocity $>12 \mathrm{~m} / \mathrm{s}$

- Ankle/brachial BP index $<0.9$

- Slight increase in plasma creatinine:

M: $115-133 \mu \mathrm{mol} / \mathrm{L}$

$(1.3-1.5 \mathrm{mg} / \mathrm{dL})$

W: $107-124 \mu \mathrm{mol} / \mathrm{L}$

$(1.2-1.4 \mathrm{mg} / \mathrm{dL})$

- Low estimated glomerular filtration rate ${ }^{\mathrm{b}}$

$\left(<60 \mathrm{~mL} \min / 1.73 \mathrm{~m}^{2}\right)$ or

creatinine clearance ${ }^{c}$

$(<60 \mathrm{~mL} / \mathrm{min})$

- Microalbuminuria 30 $300 \mathrm{mg} / 24 \mathrm{~h}$ or albumin creatinine ratio: $\geq 22(M)$; or $\geq 31 \mathrm{~W}$ ) $\mathrm{mg} / \mathrm{g}$ creatinine
- Postload plasma glucose $>110 \mathrm{mmol} / \mathrm{L}$ $(198 \mathrm{mg} / \mathrm{dL}$

- Heart disease: myocardial infarction; angina;coronary revascularization; heart failure nephropathy; renal impairment (serum creatinine $M>133$, $\mathrm{W}>124 \mu \mathrm{mol} / \mathrm{L}$ ) proteinuria (>300 mg/24 h)

- Peripheral artery disease

- Advanced retinopathy: haemorrhages or exudates, papilloedema

The cluster of three out of five factors among abdominal obesity, fasting blood glucose, $\mathrm{BP} \geq 140 / 85 \mathrm{mmHg}$, low $\mathrm{HDL}$ cholesterol ( $\mathrm{M},<40 \mathrm{mg} / \mathrm{dL}$ or $1.03 \mathrm{mmol} / \mathrm{L} ; \mathrm{W},<50 \mathrm{mg} / \mathrm{dL}$ or $1.29 \mathrm{mmol} / \mathrm{L}$, and high triglycerides $(\geq 150 \mathrm{mg} / \mathrm{dL}$ or $1.7 \mathrm{mmol} / \mathrm{L})$ indicates the presence of a metabolic syndrome.

$\mathrm{M}=$ men; $\mathrm{W}=$ women; $\mathrm{CVD}=$ cardiovascular disease; $\mathrm{IMT}=$ intima-media thickness.

${ }^{a}$ Risk maximal for concentric LVH (left ventricular hypertrophy):increased LVMI (left ventricular mass index) with a wall thickness/radius ratio $\geq 0.42$. bMDRD formula.

${ }^{\mathrm{c}}$ Cockroft-Gault formula. 
premature CVD) also greatly adds to the risk associated with a mild BP elevation (see SCORE risk charts). ${ }^{42}$

\section{Practical aspects: management of hypertension}

Who to treat?

The term 'treatment' should be taken to mean total management. This means detailed lifestyle advice for all those with raised $\mathrm{BP}$, with the judicious use of medication in some. The decision to start antihypertensive drug treatment depends on the presence or absence of established CVD, diabetes, renal disease, target organ damage, and, of critical importance in all other persons, on the SCORE estimate of total CVD risk (Table 6), Persons in whom repeated BP measurements show grade 2 or 3 hypertension (i.e. systolic values $\geq 160 \mathrm{mmHg}$ or diastolic values $\geq 100 \mathrm{mmHg}$ ) are generally regarded as candidates for antihypertensive treatment because a large number of placebo-controlled trials have conclusively demonstrated that, in patients with these BP values, BP reduction lowers cardiovascular morbidity and mortality ${ }^{98-101}$. However, the benefit may be modest in those at low total CVD risk. In particular, randomized controlled trial data are lacking to provide guidance with regard to drug treatment in, for example, younger women without other risk factors. The likely benefits of drug treatment should be weighed against side effects, cost, the use of medical resources, and turning healthy people into 'patients'.

In all grade 1-3 hypertensives, comprehensive risk factor assessment and appropriate lifestyle counselling should be provided after hypertension is diagnosed, while promptness in the initiation of pharmacological therapy depends on the level of total cardiovascular risk. Drug treatment should be initiated promptly in grade 3 hypertension, as well as in grade 1 and grade 2 hypertensives with increased or markedly increased total cardiovascular risk (i.e. in hypertensive patients with established CVD or renal disease, TOD, diabetes, or a SCORE risk of $\geq 5 \%$ ). In grade 1 or 2 hypertensives with moderate total cardiovascular risk, drug treatment may be delayed for some time to allow evaluation of the effects of lifestyle advice on total risk.. However, even in these patients, lack of BP control after a suitable period of non-pharmacological measures should lead to instituting drug treatment in addition to lifestyle measures.

When initial BP is within the high normal range (130-139/ $85-89 \mathrm{mmHg}$ ), the decision on drug intervention depends heavily on total cardiovascular risk. In the case of diabetes or a history of cerebrovascular or coronary disease, evidence ${ }^{102-110}$ justifies the recommendation to start antihypertensive drug administration (together with intense lifestyle changes) even in patients with BP in the high normal range, with associated CVD or diabetes.

\section{How to treat?}

Lifestyle interventions include: weight reduction in overweight/obese individuals; reduction in the use of sodium chloride to $<3.8 \mathrm{~g} /$ day (sodium intake $<1.5 \mathrm{~g} /$ day, i.e. $65 \mathrm{mmol} /$ day); ${ }^{111}$ restriction of alcohol consumption to no more than $10-30 \mathrm{~g}$ of ethanol per day in men (1-3 standard measures of spirits, 1-3 glasses of wine, or 1-3 bottles of beer), and to no more than $10-20 \mathrm{~g}$ of ethanol per day in women (1-2 of these drinks/day); and regular physical activity in sedentary individuals. Hypertensives should be generally advised to eat more fruit and vegetables (4-5 servings per day, i.e. $300 \mathrm{~g})^{112}$ and to reduce intake of saturated fat and cholesterol.

\section{Antihypertensive drugs}

The large number of randomized trials of antihypertensive therapy, both those comparing active treatment vs.

Table 6 Management of total CVD risk-blood pressure

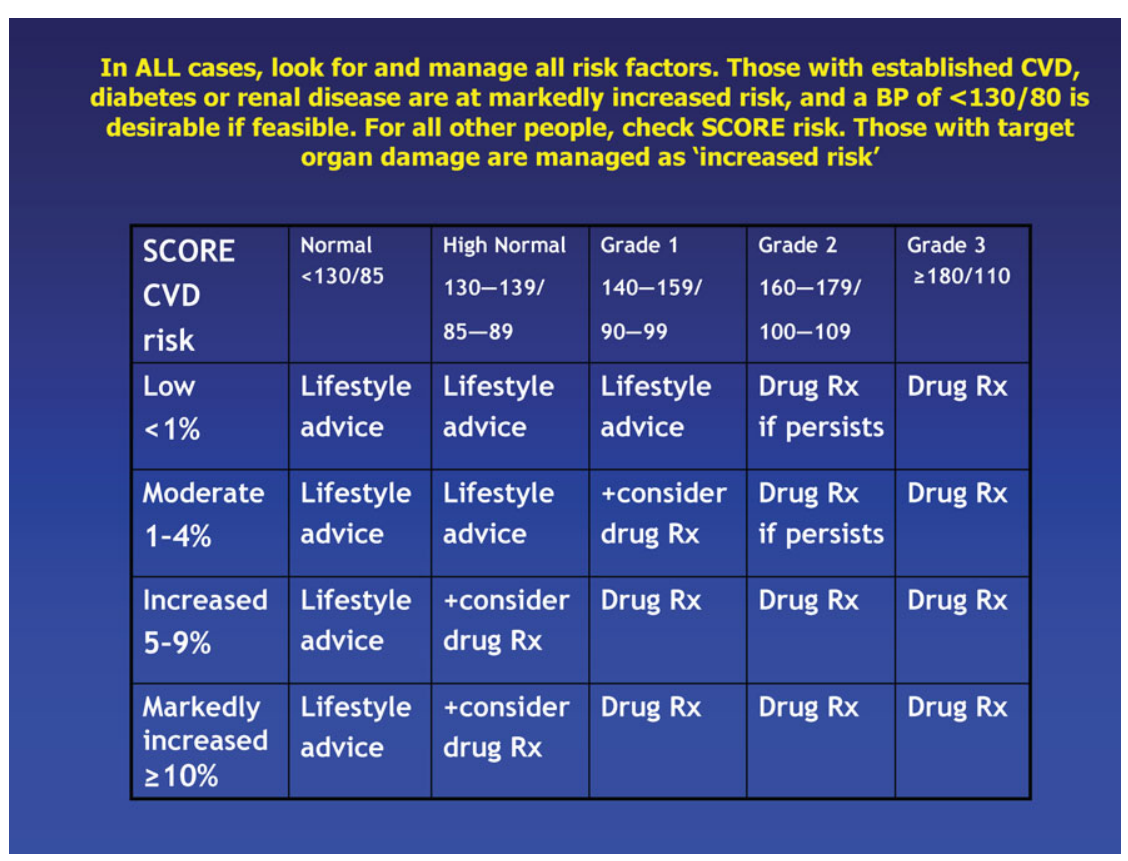


placebo, and those comparing treatment regimens based on different compounds, confirm that (i) the main benefits of antihypertensive treatment are due to lowering of BP per se, and are largely independent of the drugs employed; and (ii) thiazide diuretics (chlorthalidone and indapamide), $\beta$-blockers, calcium antagonists, ACE inhibitors, and angiotensin receptor antagonists can adequately lower BP, and significantly reduce cardiovascular morbidity and mortality. These drugs are thus all suitable for initiation and maintenance of antihypertensive treatment, either as monotherapy or in combination.

Two recent large-scale trials ${ }^{113-115}$ and a meta-analysis ${ }^{116}$ have concluded that $\beta$-blockers may have a reduced ability to protect against stroke, though being equally effective in reducing coronary events and mortality. Moreover, administration of $\beta$-blockers has been proven beneficial in patients with angina, heart failure, and a recent MI. ${ }^{87,117,118}$ Thus, $\beta$-blockers should still be considered a valid option for initial and subsequent antihypertensive treatment strategies. However, they may induce weight gain, ${ }^{119}$ have adverse effects on lipid metabolism, ${ }^{115}$ and increase (compared with other drugs) the incidence of new-onset diabetes. ${ }^{120}$ While these effects are modest, they may indicate caution in hypertensives with multiple metabolic risk factors including the metabolic syndrome and its major components. ${ }^{121,122}$ This applies also to thiazide diuretics, which have dyslipidaemic and diabetogenic effects, particularly when used at high doses. ${ }^{120}$ Thiazides have often been administered together with $\beta$-blockers in trials showing a relative excess of new-onset diabetes, thus making a distinction between the contributions of the two agents difficult to dissociate. These metabolic effects may be less with vasodilating $\beta$-blockers. ${ }^{123,124}$

Trials assessing intermediate end-points suggest other differences between various antihypertensive agents or compounds: ACE inhibitors and angiotensin receptor antagonists have been reported to be particularly effective in reducing left ventricular hypertrophy, ${ }^{125}$ including the fibrotic component, ${ }^{126,127}$ and microalbuminuria and proteinuria, ${ }^{106,128-130}$ and in preserving renal function and delaying end-stage renal disease. ${ }^{130-133}$ Calcium antagonists, beside being effective on left ventricular hypertrophy, appear particularly beneficial in slowing down progression of carotid hypertrophy and atherosclerosis. ${ }^{134-136}$ Evidence concerning the benefits of other classes of antihypertensive agents is much more limited.

Combination treatment is frequently needed to control BP. ${ }^{137}$ Drugs that have a long-lasting effect and a documented ability to lower BP effectively over $24 \mathrm{~h}$ with once-a-day administration are preferred. Simplification of treatment improves adherence to therapy, ${ }^{138}$ while effective $24 \mathrm{~h}$ BP control is prognostically important in addition to office blood pressure control. ${ }^{139}$ Long-acting drugs also minimize $\mathrm{BP}$ variability and this may offer protection against progression of target organ damage and risk of cardiovascular events. ${ }^{140-142}$

\section{Desirable blood pressure}

The primary goal of treatment of the hypertensive patient is to achieve the maximum reduction in the long-term total risk of cardiovascular morbidity and mortality. This requires treatment of all the reversible risk factors identified, including smoking, dyslipidaemia, or diabetes, and the appropriate management of associated clinical conditions, as well as treatment of the elevated BP per se.

If possible, BP should be reduced to below $140 / 90 \mathrm{mmHg}$ in all hypertensive patients who qualify for drug treatment and lower if lack of side effects permits. In diabetic patients, antihypertensive treatment should be more intense, and a goal of $<130 / 80 \mathrm{mmHg}$ has been proposed. The same target is appropriate for subjects with established cardiovascular disease if feasible.

\section{Duration of treatment}

Generally, antihypertensive therapy should be maintained indefinitely. In general clinical practice, hypertension is not well treated and only a minority of subjects achieve a BP of $<140 / 90 \mathrm{mmHg} .{ }^{143}$ Increasing compliance with antihypertensive treatment and achieving a wide BP control in the population thus represents a major challenge for clinical practice in the future.

\section{Plasma lipids \\ Scientific background}

The relationship between a raised plasma cholesterol and atherosclerotic vascular disease fulfils all of the criteria for causality. The evidence that reducing plasma cholesterol reduces risk is equally unequivocal. The higher the risk, the greater the benefit. A $10 \%$ reduction in plasma total cholesterol is followed by a $25 \%$ reduction in incidence of coronary artery disease after 5 years, and a reduction of LDL cholesterol of $1 \mathrm{mmol} / \mathrm{L}(\sim 40 \mathrm{mg} / \mathrm{dL})$ is accompanied by a $20 \%$ reduction in $\mathrm{CHD}$ events. ${ }^{144}$ While the relationship between a reduced HDL cholesterol level and risk is strong, trial data do not yet permit the definition of a target level for HDL cholesterol. Raised plasma triglycerides signal the need to look for those other factors that may be associated with the so-called metabolic syndrome.

\section{Practical aspects: management}

As with raised $B P$, the first principle of management is to assess and control all components of total CVD risk by means of appropriate advice with regard to smoking, exercise, nutrition, and BP control.

In general, total plasma cholesterol should be below $5 \mathrm{mmol} / \mathrm{L}(190 \mathrm{mg} / \mathrm{dL})$, and LDL cholesterol should be below $3 \mathrm{mmol} / \mathrm{L}(115 \mathrm{mg} / \mathrm{dL})$. In the highest risk subjects, especially those with clinically established atherosclerotic CVD and patients with diabetes, the treatment goals should be lower: total cholesterol $<4.5 \mathrm{mmol} / \mathrm{L}$ ( $\sim 175 \mathrm{mg} / \mathrm{dL})$ with an option of $<4 \mathrm{mmol} / \mathrm{L}(\sim 155 \mathrm{mg} / \mathrm{dL})$ if feasible, and LDL cholesterol $<2.5 \mathrm{mmol} / \mathrm{L}(\sim 100 \mathrm{mg} /$ $\mathrm{dL})$ with an option of $<2 \mathrm{mmol} / \mathrm{L}(\sim 80 \mathrm{mg} / \mathrm{dL})$ if feasible. If these targets are not feasible, total risk can still be reduced by means of increased efforts to control other risk factors.

\section{Should statins be given to all persons with cardiovascular disease?}

Relative risk reductions seem to be constant at all lipid levels, but absolute risk reductions are small in those with 
low lipid levels, with little evidence of a reduction in total mortality. The universal use of statins may be unrealistic in some economies.

No specific treatment goals are defined for HDL cholesterol and triglycerides, but concentrations of HDL cholesterol $<1.0 \mathrm{mmol} / \mathrm{L}(\sim 40 \mathrm{mg} / \mathrm{dL})$ in men and $<1.2 \mathrm{mmol} / \mathrm{L}$ ( $\sim 45 \mathrm{mg} / \mathrm{dL})$ in women, and, similarly, fasting triglycerides $>1.7 \mathrm{mmol} / \mathrm{L}(\sim 150 \mathrm{mg} / \mathrm{dL})$, serve as markers of increased cardiovascular risk. Values of HDL cholesterol and triglycerides should also be used to guide the choice of drug therapy.

Asymptomatic people at high multifactorial risk of developing CVD, whose untreated values of total and LDL cholesterol are already close to 5 and $3 \mathrm{mmol} / \mathrm{L}$, respectively, seem to benefit from further reduction of total cholesterol to $<4.5 \mathrm{mmol} / \mathrm{L}(175 \mathrm{mg} / \mathrm{dL})$ and, if feasible, lower, and from further reduction of $\mathrm{LDL}$ cholesterol to $<2.5 \mathrm{mmol} / \mathrm{L}$ (100 mg/dL) and, if feasible, lower, with lipid-lowering drugs.

Table 7 summarizes the management of plasma lipids in clinical practice. The first step is to assess total cardiovascular risk and to identify these components of risk that are to be modified. If the 10-year risk of cardiovascular death is $<5 \%$ and will not exceed $5 \%$ if the individual's risk factor combination is projected to age 60 , professional advice on diet, regular physical activity, and stopping smoking should be given to keep the cardiovascular risk low. Risk assessment should be repeated at 5-year intervals.

Note that assessment of total risk does not pertain to patients with familial hypercholesterolaemia, since total cholesterol $>8 \mathrm{mmol} / \mathrm{L}(\sim 320 \mathrm{mg} / \mathrm{dL})$ and LDL cholesterol $>6 \mathrm{mmol} / \mathrm{L}(\sim 240 \mathrm{mg} / \mathrm{dL})$ by definition places a patient at high total risk of CVD, especialy as the raised cholesterol level will have been present since childhood. This high risk justifies lipid-lowering therapy even in young asymptomatic subjects.

If the 10 -year risk of cardiovascular death is $\geq 5 \%$, or will become $\geq 5 \%$ if the individual's risk factor combination is projected to age 60 , a full analysis of plasma lipoproteins (total cholesterol, LDL cholesterol, HDL cholesterol, and triglycerides) should be performed, and intensive lifestyle advice, particularly dietary and physical activity advice, should be given. If values of total and LDL cholesterol fall below $5 \mathrm{mmol} / \mathrm{L}(\sim 190 \mathrm{mg} / \mathrm{dL})$ and $3 \mathrm{mmol} / \mathrm{L}$ ( $\sim 115 \mathrm{mg}$ / $\mathrm{dL})$, respectively, and the total CVD risk estimate has become $<5 \%$, then these persons should be followed at yearly intervals to ensure that cardiovascular risk remains low without drugs. In contrast, if total CVD risk remains $\geq 5 \%$, lipid-lowering drug therapy should be considered to lower total and LDL cholesterol even further. The goals in such persistently high risk individuals are to lower total cholesterol to $<4.5 \mathrm{mmol} / \mathrm{L}(\sim 175 \mathrm{mg} / \mathrm{dL})$ with an option of $<4 \mathrm{mmol} / \mathrm{L}(\sim 155 \mathrm{mg} / \mathrm{dL})$ if feasible, and to lower LDL cholesterol to $<2.5 \mathrm{mmol} / \mathrm{L}(\sim 100 \mathrm{mg} / \mathrm{dL})$ with an option of $<2 \mathrm{mmol} / \mathrm{L}(\sim 80 \mathrm{mg} / \mathrm{dL})$ if feasible. As stated earlier, these lower values are not goals of therapy for patients with higher untreated values. It has to be stressed that the benefits of cholesterol-lowering therapy depend on initial levels of risk: the higher the risk, the greater the benefit.

Since the lifelong CVD risk in diabetic patients may be as high as in non-diabetic individuals with prior CVD, particularly if they have some other risk factors or have microalbuminuria, earlier and intensive prevention using lipid-lowering drugs, even in type 2 diabetic patients with moderate risk, is needed. ${ }^{145,146}$

Table 7 Management of total CVD risk-lipids

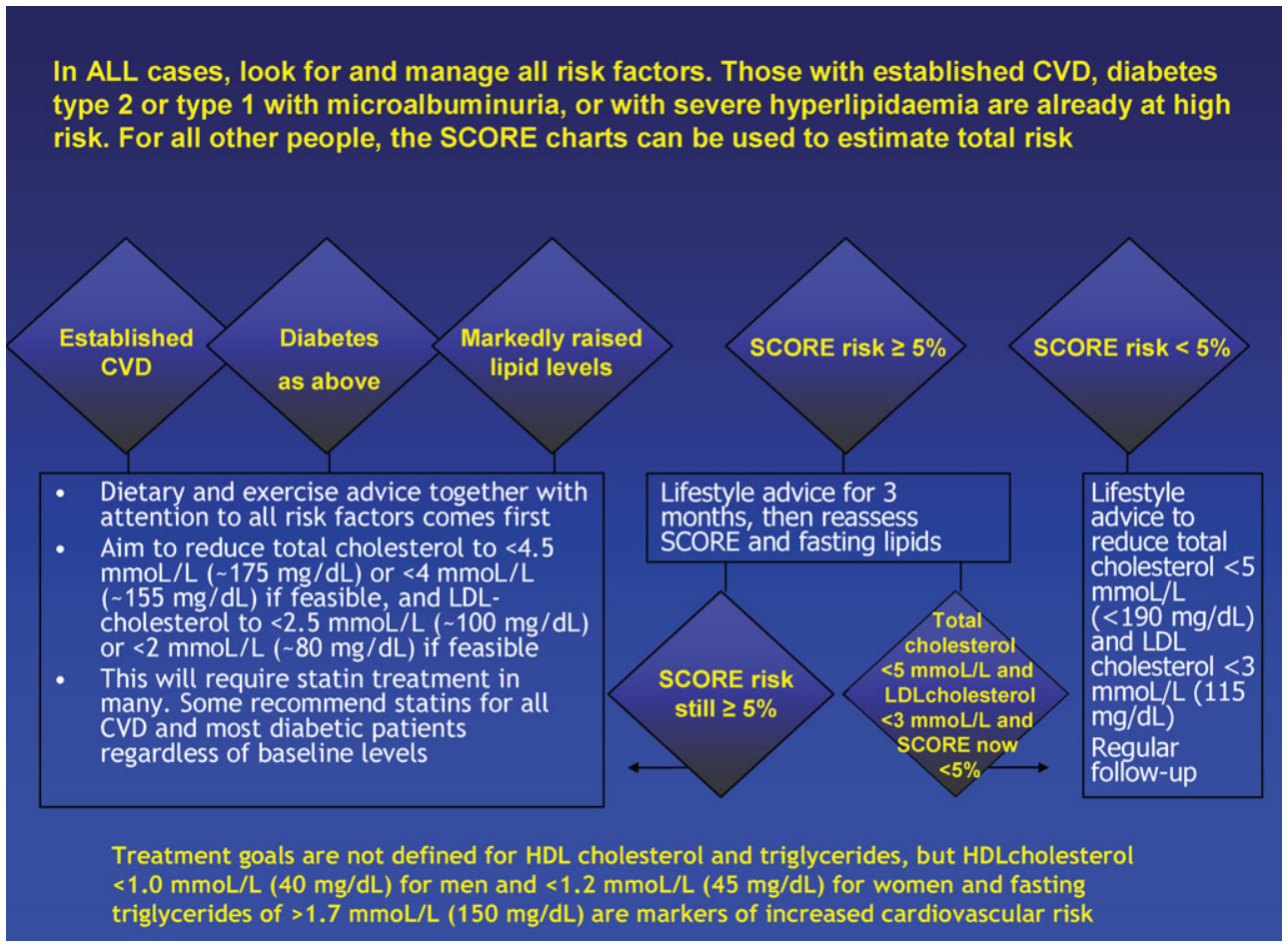


Despite early observational studies indicating that plasma cholesterol is not associated with overall rates of stroke, and that lowering cholesterol does not lower the risk of stroke, most of the large statin trials reported significant reductions in stroke rates in patients with or at high risk of getting coronary artery disease ${ }^{147-149}$ due to a reduction in the rates of ischaemic stroke. ${ }^{150}$ Therefore, the patients with cerebrovascular disease as well as the patients with PAD merit the same degree of attention to treatment of plasma lipids as patients with coronary artery disease.

In all patients with an acute coronary syndrome, statin treatment should be initiated while the patients are in the hospital. ${ }^{151-153}$ Such early drug treatment should nevertheless be combined with effective lifestyle changes and particularly dietary intervention after hospital discharge.

The benefits of statins appear to apply to both genders and most ages, ${ }^{145}$ although the benefits in healthy, asymptomatic women are not proven.

The current armamentarium of lipid-lowering drugs includes inhibitors of hydroxy-3-methyl-glutaryl-CoA reductase (statins), fibrates, bile acid sequestrants (anion exchange resins), niacin (nicotinic acid), and selective cholesterol absorption inhibitors (e.g. ezetimibe). Statins have been shown not only to reduce hyperlipidaemia but also to reduce cardiovascular events and mortality as well as the need for coronary artery by-pass grafting and various forms of coronary angioplasty. Statins in the highest doses seem also to halt progression or induce regression of coronary atherosclerosis. ${ }^{105,154}$ Therefore, they should be used as the drugs of first choice. These drugs are easy to use and all have proved safe in large trials. ${ }^{144}$. Liver dysfunction is occasional and reversible. Rhabdomyolysis is rare; severe muscle pain requires immediate cessation of therapy. Because statins are prescribed on a long-term basis, possible interactions with other drugs (ciclosporin, macrolides, azole antifungals, calcium antagonists, protease inhibitors, sildenafil, warfarin, digoxin, nicotinic acid, fibrates, etc.) deserve particular attention, as many patients will receive pharmacological therapy for concomitant conditions during the course of statin treatment. ${ }^{155}$

Selective cholesterol absorption inhibitors can be used in combination with statins in patients not reaching treatment goals with statins. Bile acid sequestrants also decrease total and LDL cholesterol, but tend to increase triglycerides. Fibrates and nicotinic acid are used primarily for triglyceride lowering and increasing HDL cholesterol, while fish oils (omega-3 fatty acids) are used for triglyceride lowering.

In some patients, combination therapy with different lipid-lowering drugs is necessary to achieve the treatment goals. The combination of statins with fibrates has been associated with a moderately higher likelihod of myopathy and occasional rhabdomyolysis. Therefore, patients must be carefully selected and carefully instructed about warning symptoms. However, these adverse effects are very rare and should not be the reason to deny the combined treatment to patients who really need it.

In some patients, goals cannot be reached even on maximal lipid-lowering therapy, but they will still benefit from treatment to the extent to which cholesterol has been lowered. Increased attention to other risk factors offers an additional way to reduce total risk.

\section{Diabetes}

\section{Scientific background}

The extensive literature on diabetes and its precursor stages and CVD has been thoroughly reviewed in the recent guidelines on diabetes, pre-diabetes and cardiovascular disease created by the Joint Task Force of the ESC and the European Association for the Study of Diabetes. In addition to the full text of the present guideines, the readers are referred to that document. ${ }^{5}$

\section{Practical aspects: management}

In subjects with impaired glucose tolerance, it has been demonstrated that progression to diabetes can be prevented or delayed by lifestyle intervention. Even temporary interventions seem to have a long-lasting impact years after the intervention period.

In patients with type 1 diabetes as well as with type 2 diabetes, randomized trials consistently show that good metabolic control prevents microvascular complications. In relation to macrovascular disease the picture is less clear. In type 1 diabetes, long-lasting effects of optimized metabolic control on the risk of developing CVD have been demonstrated, but this could be an effect mediated through the effect on microvascular complications. In type 2 diabetes, the combined evidence from epidemiological studies and intervention trials strongly indicates an effect of glucose control on risk of CVD. Consequently, there is reason to aim for good glucose control in both types of diabetes. In type 1 diabetes, glucose control requires appropriate insulin therapy and concomitant professional dietary therapy. In type 2 diabetes, professional dietary advice, reduction of overweight, and increased physical activity should be the first treatment, followed by pharmacological treatment (oral hypoglycaemic treatment and insulin when needed) aiming at good glucose control. Recommended treatment targets for type 2 diabetes are given in Table 8. As to $\mathrm{HbA}_{1 \mathrm{c}}$ and glucose targets, in patients who receive treatment with insulin or drugs stimulating insulin secretion (sulphonylureas, nateglinide, and repaglinide), special attention should be paid to avoidance of hypoglycaemic episodes, with guidance obtained from glucose self-monitoring. Targets for

Table 8 Treatment targets in patients with type 2 diabetes

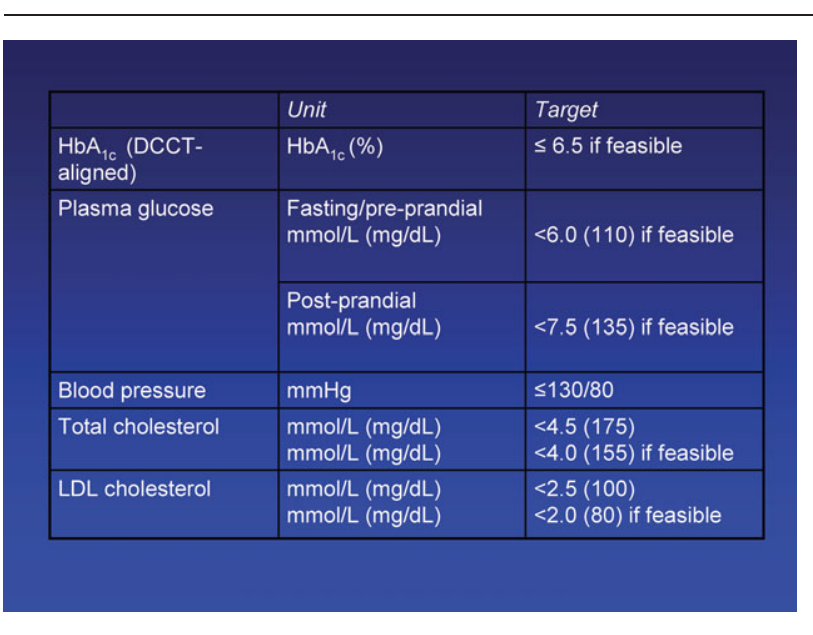


blood pressure and lipids are generally more ambitious in patients with diabetes than in non-diabetic subjects.

\section{The metabolic syndrome}

\section{Scientific background}

The metabolic syndrome describes the clustering of cardiovascular risk factors in individuals with obesity or insulin resistance. It identifies individuals with increased risk of developing CVD in accordance with the clustering of risk factors, but does not indicate risk of CVD over and above the effect of the risk factors involved.

\section{Practical aspects: management}

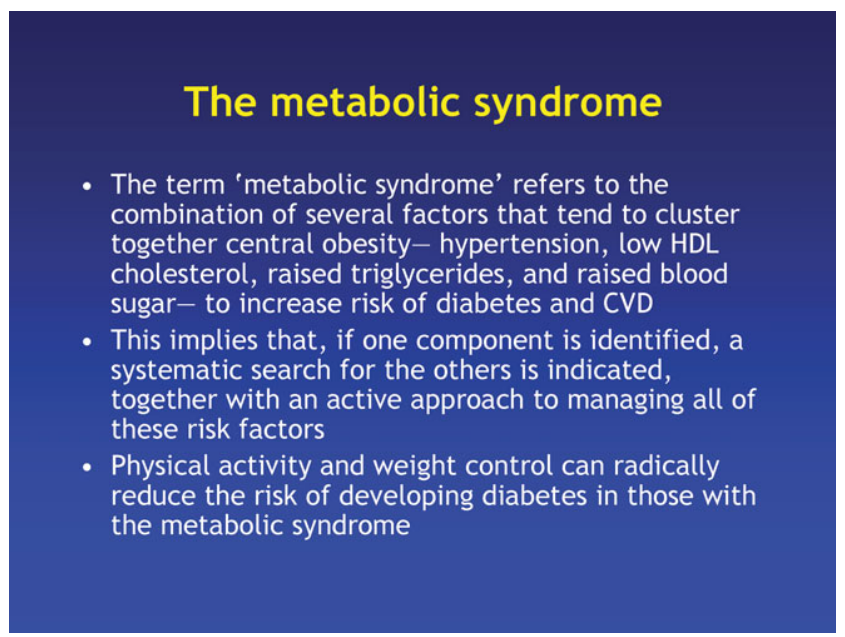

The diagnosis of the metabolic syndrome is of greatest importance in non-diabetic subjects as an indicator of an increased risk of developing type 2 diabetes and CVD. The interest in the metabolic syndrome should, however, not displace the use of other similar risk scoring tools from their primary place in the identification of individuals at high risk of CVD. Among different definitions for the metabolic syndrome formulated by international and national expert groups, the original NCEP-ATP III definition and its revision recommended by the American Heart Association (AHA) and $\mathrm{NHLBI}^{156,157}$ (see Table 9) and the definition created by the Consensus Panel of the International Diabetes Federation (IDF) ${ }^{158}$ (see Table 10) have been developed for clinical use, but it is important to realize that the prevalence obtained with these definitions is far from similar, and individuals labelled as having the metabolic syndrome will to a substantial extent be different. The prevalence of the metabolic syndrome is clearly higher with the AHA/NHLBI revision of the NCEP-ATP III definition than with the original NCEP-ATP III definition and the IDF definition. This is mainly caused by the lowered cut-off for impaired fasting glycaemia in the two new definitions, but with the IDF definition the emphasis on central obesity defined by strict cut-offs also contributes. The original NCEP-ATP III definition is more robust in the prediction of CVD risk, with a higher positive predictive value than the revised NCEP-ATP III definition and the IDF definition.

Lifestyle has a strong influence on all the components of the metabolic syndrome and, therefore, the main emphasis
Table 9 Original and revised NCEP-ATP III definitions of the metabolic syndrome

At least three of the following five components

Central obesity: waist circumference $>102 \mathrm{~cm}$ in men, $>88 \mathrm{~cm}$ in women

Elevated triglycerides: $\geq 1.7 \mathrm{mmol} / \mathrm{L}(\geq 150 \mathrm{mg} / \mathrm{dL})$

Low HDL cholesterol: $<1.03 \mathrm{mmol} / \mathrm{L}(<40 \mathrm{mg} / \mathrm{dL})$ in men, $<1.29 \mathrm{mmol} / \mathrm{L}(<50 \mathrm{mg} / \mathrm{dL})$ in women

Raised blood pressure: systolic BP $\geq 130 \mathrm{mmHg}$ and/or diastolic $\mathrm{BP} \geq 85 \mathrm{mmHg}$, or treatment of previously diagnosed hypertension

Impaired fasting glycaemia: fasting plasma glucose $\geq 6.1 \mathrm{mmol} / \mathrm{L}$ $(110 \mathrm{mg} / \mathrm{dL})[\geq 5.6 \mathrm{mmol} / \mathrm{L}(\geq 100 \mathrm{mg} / \mathrm{dL})]^{\mathrm{a}}$ or previously diagnosed type 2 diabetes

aThe revised version recommended by the AHA/NHLBI uses the lower cut-off for impaired fasting glycaemia.

Table 10 The IDF definition of the metabolic syndrome

Central obesity defined by ethnic-specific waist circumference criteria $\geq 94 \mathrm{~cm}$ in Europid men, $\geq 80 \mathrm{~cm}$ for Europid women and any two of the following four components:

Elevated triglycerides: $\geq 1.7 \mathrm{mmol} / \mathrm{L}$ ( $\geq 150 \mathrm{mg} / \mathrm{dL}$ ) or specific treatment for this lipid abnormality

Low HDL cholesterol: $<1.03 \mathrm{mmol} / \mathrm{L}(<40 \mathrm{mg} / \mathrm{dL})$ in men, $<1.29 \mathrm{mmol} / \mathrm{L}(<50 \mathrm{mg} / \mathrm{dL})$ in women or specific treatment for this lipid abnormality

Raised blood pressure: systolic BP $>130 \mathrm{mmHg}$ and/or diastolic BP $>85 \mathrm{mmHg}$, or treatment of previously diagnosed hypertension

Impaired fasting glycaemia: fasting plasma glucose $\geq 5.6 \mathrm{mmol} / \mathrm{L}$ (100 mg/dL) or previously diagnosed type 2 diabetes

in the management of the metabolic syndrome should be in professionally supervised lifestyle changes, particularly efforts to reduce body weight and increase physical activity. Elevated BP, dyslipidaemia, and hyperglycaemia (in the diabetic range) may, however, need additional drug treatment as recommended in the present guidelines.

\section{Psychosocial factors}

\section{Scientific background}

There is increasing scientific evidence that psychosocial factors contribute independently to the risk of CHD even after statistical control for the effects of standard risk factors. ${ }^{159}$ In addition to increasing the risk of a first event and worsening the prognosis in CHD, these factors may act as barriers to treatment adherence and efforts to improve lifestyle, as well as to promote health and well-being in patients and populations.

The following psychosocial risk factors have been shown to influence both the risk of contracting CHD and the worsening of clinical course and prognosis in patients with CHD:

- Low socio-economic status

- Social isolation and lack of social support

- Stress at work and in family life

- Negative emotions including depression and hostility. 
It is now evident that psychosocial risk factors do not occur in isolation from one another, but tend to cluster in the same individuals and groups, for example, those with low SES. In addition to risky health behaviours such as smoking and unhealthy nutrition, persons with psychosocial risk factors such as depression are also more likely to express physiological characteristics such as autonomic, endocrine, and inflammatory changes that are involved in promoting CVD.

Evidence is also accumulating of therapeutic and preventive intervention methods that counteract psychosocial risk factors and promote healthy behaviours and lifestyle. ${ }^{44,45,160}$ Several psychosocial interventions have been shown to have beneficial effects on distress and physiological risk factors, ${ }^{44,46}$ and some studies also showed improved CVD outcomes, especially in white men and in patients who achieved the proximal goals of the intervention. Specific behavioural group treatments for women with CHD may be useful for reducing distress and exhaustion. In patients with CHD and severe co-morbid depression, selective serotonin re-uptake inhibitors can be given to treat depression and improve quality of life. Results from non-randomized trials indicate that these substances may also improve prognosis in depressed patients.

\section{Practical aspects: management of psychosocial risk factors in clinical practice}

- Assess all patients for psychosocial risk factors, e.g. depression and hostility, low SES, social isolation, and chronic life stress by clinical interview or standardized questionnaires. A selection of screening instruments is given in Albus et al. ${ }^{161}$

- Core questions for the assessment of psychosocial risk factors include the following. It should be noted that these rather blunt questions will need to be phrased with sensitivity if a constructive rapport with the patient is to be established:

- Low SES. Do you have no more than mandatory education? Are you a manual worker?

- Social isolation. Are you living alone? Do you lack a close confidant? Do you lack any person to help you in case of illness?

- Work and family stress. Do you have enough control over how to meet the demands at work? Is your reward appropriate for your effort? Do you have serious problems with your spouse?

- Depression. Do you feel down, depressed, and hopeless? Have you lost interest and pleasure in life?

- Hostility. Do you frequently feel angry over little things? If someone annoys you, do you regularly let your partner know? Do you often feel annoyed about habits other people have?

- Discuss relevance with patient in respect to quality of life and medical outcome.

- Use principles of enhanced communication and behavioural counselling as described above.

- Patients with low SES need special preventive effort.

- In patients at high risk or those with established CVD and psychosocial risk factors, prescribe multimodal, behavioural intervention, integrating individual or group counselling for psychosocial risk factors and coping with stress and illness.

- Refer to a specialist in the case of clinically significant emotional distress. Patients with clinical depression should receive treatment with psychotherapy or antidepressant medication, preferably selective serotonin re-uptake inhibitors, according to established guidelines. Those not accepting treatment should be closely followed and treatment offered again if depression persists for more than 4-6 weeks.

\section{Inflammation markers and haemostatic factors}

\section{Scientific background}

Risk factors may be classed into several hierarchical categories as follows: classical, established, emerging, and putative, and also as risk markers. The highest level of classification achieved thus far by the heterogeneous group of factors discussed in these guidelines is 'emerging', but many are under active investigation in clinical and epidemiological studies. These factors are associated with many different biological systems such as those regulating platelets, coagulation, fibrinolysis, endothelial function, and the inflammatory response. These interact in ways which remain incompletely understood, but in which scientific interest and achievement is considerable. In addition to their potential utility in long-term risk prediction of CVDs, close associations between inflammatory markers and obesity and diabetes have been demonstrated, which strengthens the case for their scientific investigation.

There is strong evidence from pathological ${ }^{162,163}$ and epidemiological studies ${ }^{164-167}$ that the circulating markers of activated inflammation and haemostasis are closely associated with the development of fatal and non-fatal MI. A large case series, based in a national primary care database, showed that first $\mathrm{Ml}$ and stroke were each more common following recent respiratory or urinary tract infections, the risk being greatest within the first 3 days after diagnosis (relative risks 5.0 and 3.2, respectively), and falling during the following weeks. ${ }^{168} \mathrm{~A}$ recent report from Europe, as part of the WHO's MONICA study, showed that population levels of certain haemostatic factors differed between participating centres and countries, and showed significant associations with the incidence of CHD in the centres.

Prospective epidemiological studies have also linked inflammatory markers with the development of type 2 diabetes mellitus, and interleukin-6 (IL-6), a pro-inflammatory cytokine, with CHF. Some studies have demonstrated that risk prediction for $\mathrm{CHD}$, and for both $\mathrm{CHD}$ and stroke can be improved by the addition of these newer risk factors to risk models which include all established risk factors. A recent report in the USA proposed that CRP should be used as an 'option' in current guidelines, ${ }^{169}$ but this proposal has been questioned both in the USA and in Europe. ${ }^{170,171}$

Incorporation of CRP and other emerging risk factors into routine practice for prediction of cardiovascular risk may be premature, therefore, and criteria for the rigorous evaluation of such factors have been proposed. These criteria include: applicability to all relevant clinical cardiovascular events; ability to predict in short, intermediate, and longterm follow-up; standardized measurements; examination of variability; the degree of correlation with established risk factors; and improvement in overall prediction, among other criteria. A number of meta-analyses of observational epidemiological studies have been conducted, e.g. for $\mathrm{CRP}^{172}$ and for fibrinogen. ${ }^{173}$ Such meta-analyses will 
provide evidence of the possible utility of emerging risk factors in future clinical practice; but current investigations of determinants of inflammatory markers, which include physical activity, dietary factors, alcohol, and weight loss as protective factors, and infections such as periodontitis as a potentially treatable risk factor, encourage the detailed examination of this group of markers in future research.

Another important point regarding these meta-analyses is that CRP (as well as fibrinogen and possibly other biomarkers) is often seriously confounded by other unmeasured variables and subject to reverse causality (i.e. pre-clinical disease causes rises in CRP). Consequently, large-scale meta-analyses, like those cited above, fall into the trap of promoting the idea that the evidence of a causal link is strong. An alternative approach, examining genotypes directly, has been carried out by several groups, demonstrating that predicted associations between CRP genotypes that code for higher levels of circulating CRP are not associated with CVD or risk factors. However, a large meta-analysis of seven haemostatic genes showed that variants of factor $V$ gene and of the prothrombin gene may be moderately associated with risk of coronary disease. ${ }^{174}$

\section{Genetic factors}

Genetic information is divided into three categories: family history, phenotypes, and genotypes.

\section{Family history: scientific background}

Some studies have established the importance of family history as a coronary risk factor for CHD, and have shown that the risk associated with family history of early CHD (in first-degree relatives, male $<55$ years and female $<65$ years) ranges between 1.5 and 1.7 and is independent of classical CHD risk factors. ${ }^{175,176}$

The risk of CHD increases with a positive history

- in a first degree relative (parents, son, daughter, brother or sister), in a second degree relative (grandparents, aunt or uncle), or in a third degree relative (cousin);

- as the number of family members with CHD increases; and

- the younger the age at which family members develop CHD.

\section{Family history: practical aspects}

Risk factor assessment, and a family history of premature CHD, including a detailed history and a drawing of a pedigree, should therefore be carried out in the first degree relatives of any patient developing coronary disease before 55 years in men and 65 years in women. Lifestyle advice and, where appropriate, therapeutic management of risk factors should be offered to members of families where coronary disease is highly prevalent.

\section{Phenotypes: scientific background}

The study of the genetic determinants of 'phenotypes' which are involved in the pathophysiology of CHD (dyslipidaemia, hypertension, endothelial dysfunction, diabetes, cardiac and vascular hypertrophy, and atherosclerosis) is likely to be clinically relevant, and each has its own genetic and environmental determinants.
For many of these phenotypes (measurable traits) there is a good evidence for a relatively strong genetic determination, which is usually estimated by 'heritability'. For example, for apoproteins and lipid traits, heritability varies between 40 and $60 \% ;{ }^{177}$ for plasma Lp(a), heritability is $>90 \% .{ }^{178}$ Since meta-analyses show that levels of $L p(a)$ are associated with a 1.6 -fold greater risk of $\mathrm{CHD},{ }^{179}$ an effect which is of similar magnitude to smoking, the Lp(a) gene would appear to be a major genetic factor for CHD.

The data suggest a moderate to high heritability for emerging risk factors such as intercellular adhesion molecule (ICAM), IL-6, phospholipase A2 (PLA2), etc. ${ }^{180,181}$

\section{Genotypes: scientific background}

The levels of CHD risk traits are influenced by both environmental and genetic factors. The concept of geneenvironment interaction is necessary to understand how genetic information can be used for accurate risk assessment, ${ }^{182}$ and this is likely to be of major research importance in the future. Genetic polymorphisms are defined as sequence variants that occur at a frequency $>1 \%$. These include single nucleotide polymorphisms (SNPs) as well as insertion/deletion and copy number variants which have recently been reported to be very common. ${ }^{183}$

A large number of 'candidate' genes have already been investigated in relation to $\mathrm{CHD}$ traits and to risk of $\mathrm{CHD}$ itself.

Several variants in genes involved in lipid metabolism [e.g. apolipoprotein E (APOE), apolipoprotein B (APOB), lipoprotein lipase (LPL), cholesterol ester transfer protein (CETP)], coagulation [plasminogen activator inhibitor 1 (PAl1), glycoprotein IIb/IIla (Gllb/llla), factor V (FV)], and different aspects of endothelial function [endothelial nitric oxide synthase (eNOS), methylenetetrahydrofolate reductase (MTHFR) and ACE] ${ }^{184}$ appear to be associated with statistically significant, although rather modest effects on risk.

\section{DNA-based tests for risk prediction}

Currently available $\mathrm{CHD}$ risk prediction algorithms based on classical risk factors ${ }^{185,186}$ have a very low prediction rate, for example $11 \%$ in a 10 -year follow-up of UK healthy men, and adding risk genotypes may improve this. ${ }^{187}$

Modelling has suggested ${ }^{188}$ that only around 20 genes are needed to explain $50 \%$ of the burden of a disease in the population if the predisposing genotypes are common $(>25 \%)$, even if the individual risk ratios are relatively small (i.e. increasing risk by only $20-50 \%$ ).

\section{Practical aspects}

\section{DNA-based tests for risk prediction}

At the moment, DNA-based tests do not add significantly to diagnostic utility or patient management. In the long term, understanding disease aetiology in terms of genetic determinants may be useful in identifying high risk individuals and adapting therapeutic management to the individual's genetic make-up.

\section{Pharmacogenetics}

Currently, there are few data either for the most effective choice of available drugs based on an individual's genetic make-up, or for the avoidance of dangerous side effects in the field of CVD. 
The full potential of this field will only be realized with much further work.

\section{Severe familial dyslipidaemias and coronary heart disease}

There are many extremely rare inherited conditions where plasma lipids are abnormal and CHD risk is altered. Here we focus on only the three most common of these.

\section{Familial hypercholesterolaemia $(\mathrm{FH})$}

Scientific background: $\mathrm{FH}$ has an estimated prevalence of $1 / 500 .{ }^{189}$ It is characterized by hypercholesterolaemia due to increased LDL levels, xanthomas, premature CHD, and a family history of one or more of these. Angina, heart attacks, or death typically occur in men between 30 and 50 years, and in women between 50 and 70 years, ${ }^{190}$ and those who smoke, are hypertensive, or have other risk factors are at particularly high risk. Several methods with different sensitivity and specificity have been developed for the clinical diagnosis of FH, ${ }^{191-193}$ but the 'gold standard' is a combination of clinical and biochemical factors and the presence of a detectable disease-causing DNA change, which gives the highest clinical utility.

$\mathrm{FH}$ is an autosomal dominant inherited disorder and is usually caused by a mutation in the LDL receptor gene (LDLR). To date, $>700$ different mutations have been identified worldwide (see http://www.ucl.ac.uk/fh), although the spectrum within a single country is much smaller. ${ }^{194,195}$ Screening for deletions and rearrangements of the $L D L R$ gene using a technique called multiplex ligation-dependent probe amplification (MLPA $)^{196}$ has become available, and it is known that up to $5 \%$ of $\mathrm{FH}$ patients may have such a deletion. ${ }^{197}$

A specific mutation occurs in the apolipoprotein B 100 gene $(A P O B)$, the ligand for the LDL receptor, in approximately $3 \%$ of FH patients in the UK, North Europe, and the USA. The disorder has been designated familial defective apolipoprotein B 100 (FDB). ${ }^{198}$ FDB is milder than LDLR-FH but hypercholesterolaemia occurs in childhood and early CHD occurs in some subjects.

Recently, defects in a third gene called protein convertase subtilisin/kexin type 9 (PCSK9), causing monogenic hypercholesterolaemia, have been identified. ${ }^{199}$ These mutations could cause increased degradation of LDL receptors, reduced numbers of receptors on the surface of the cell, and monogenic hypercholesterolaemia.

Using currently available routine clinical genetic diagnostic techniques, ${ }^{192-194}$ it is possible to demonstrate a mutation in the LDLR, PCSK9, or APOB gene in up to 80 $90 \%$ of clinically diagnosed patients, but this is usually only available in a research setting. Such specialist services are available in several European countries, ${ }^{194,195,200-202}$ but each country should have its own programme for genetic testing for $\mathrm{FH}$ because the spectrum of mutations varies between countries.

Current data strongly suggest that DNA testing for $\mathrm{FH}$ complements cholesterol measurement in cascade screening to identify affected subjects unambiguously. ${ }^{203,204}$

Practical aspects: Because of their high CHD risk, patients with FH should be aggressively treated with statins at a young age. Lifestyle advice should be offered and supported. Cascade testing to identify affected relatives should be undertaken. It is likely that, for optimal diagnostic and management results, both phenotypic and genotypic diagnosis should be used.

Familial combined hyperlipidaemia ( $\mathrm{FCH})$

Scientific background: This is the most common of the severe hyperlipidaemias, with a prevalence of perhaps $1 /$ $100{ }^{205} \mathrm{FCH}$ is likely to be more polygenic/multifactorial than $\mathrm{FH}$. A major gene determining the $\mathrm{FCH}$ phenotype has been found in Finnish families, identified as the gene for upstream regulatory factor 1 (USF1)-a major controller of lipid and glucose homeostasis. ${ }^{206}$

Despite no specific mutation within the USF1 gene being identified in $\mathrm{FCH}$ patients, a common haplotype composed of several SNPs is associated with risk of developing $\mathrm{FCH}^{207}$

Practical aspects: Because of their high CHD risk, patients with $\mathrm{FCH}$ should be treated with lipid-lowering therapy and lifestyle advice. There is currently little experience to support the clinical utility of cascade testing to identify affected relatives, but this is likely to be beneficial.

Familial high-density lipoprotein deficiency syndromes Scientific background: The inverse and independent association between HDL cholesterol and the risk of fatal and non-fatal CHD events has been established by clinical and epidemiological studies. A low HDL cholesterol level $<35 \mathrm{mg} / \mathrm{dL}$ ( $0.9 \mathrm{mmol} / \mathrm{L}$ ) has become part of the multiparametric algorithms used for CVD risk estimation. ${ }^{185,186}$

Patients with HDL cholesterol levels below the 5th percentile within a given population can be assumed to have monogenic HDL deficiency. ${ }^{208}$

Practical aspects: Rule out secondary causes and perform a careful physical examination in patients with the virtual absence of HDL. Family studies should be initiated, to demonstrate the vertical transmission of the low $\mathrm{HDL}$ cholesterol phenotype. Since currently there is no routinely used drug available to increase HDL cholesterol levels in patients with familial low HDL cholesterol, these patients should be treated for additional risk factors.

\section{New imaging methods to detect asymptomatic individuals at high risk for cardiovascular events}

\section{Scientific background}

One of the major objectives of a CVD detection programme should be to identify those apparently healthy individuals who have asymptomatic arterial disease in order to slow the progression of atherosclerotic disease, to induce regression, and in particular to reduce the risk of clinical manifestations. The revolution in technology has clearly influenced the decision making of cardiovascular patients, and this can be clearly applied to the early detection of the disease even in asymptomatic patients.

For coronary artery disease, the consequences of coronary atherosclerosis can be objectively assessed non-invasively, using a variety of techniques such as bicycle or treadmill exercise ECG testing, stress echocardiography, or radionuclide scintigraphy. These techniques are routinely used in diagnostic work-up programmes in the clinic; they have rarely been used in the population as screening tools. More recently, new techniques have become available to detect coronary lesions. 
MRI has been evaluated as a means of assessing the presence or absence of coronary artery stenosis. The value of this technique in detecting coronary artery stenosis is still in question. Sensitivity, specificity, and robustness of this technique are not high enough to perform screening for coronary stenoses in asymptomatic people.

A potentially more useful approach for risk stratification is to perform in vivo imaging of the arterial wall using MRI. In vitro, MRI is able to differentiate between the plaque components of carotid, aortic, and coronary artery specimens obtained at autopsy. For the present moment, MRI is a promising research tool, but its use is limited to only a small number of research laboratories at this time. Thus, MRI is not yet appropriate for use in identifying patients at high risk for coronary artery disease.

Coronary calcifications represent atherosclerosis of coronary arteries. Normally, they occur exclusively as atherosclerotic lesions within the intima layer and are not found in healthy coronary vessel walls. On the other hand, atherosclerotic diseased coronary arteries do not necessarily always show calcifications. The extent of coronary calcifications correlates with the extent of the total coronary plaque burden. It should be noted that coronary calcification is an indicator neither for stability nor instability of an atherosclerotic plaque.

Recent developments in technology of the classic CT resulted in multislice CT devices. ${ }^{215}$ With the use of MS-CT it is possible to obtain a clear definition of the coronary vessels in most patients. However, the highest value of this technique seems to be its negative predictive value, reaching close to $98 \%$ in some studies. This very high negative predictive value of the technique leads to the consideration of using MS-CT for screening in certain subsets of the high risk population. Still, we need prospective studies to determine clearly which population may benefit most from this technology.

Although calcium scanning is widely applied today, it should not be uncritically used as a screening method. There is a need for prospective studies that will show the clear benefit on each individual subgroups in which an MS-CT scan is useful.

Population-based studies have shown a correlation between the severity of atherosclerosis in one arterial territory and involvement of other arteries. Atherosclerotic lesions of carotid arteries in the legs are more accessible for non-invasive examinations than those in coronary or intra-cerebral arteries. Therefore, early detection of arterial disease in apparently healthy individuals has also focused on the peripheral arterial territory and on the carotid arteries. Recently, plaque characteristics as assessed by carotid ultrasound were found to be predictive of subsequent cerebral ischaemic events. Patients with echolucent stenotic plaques had a much higher risk of stroke and cerebrovascular events than subjects with other plaque types.

An ankle-brachial index $(\mathrm{ABI})<0.9$ reflects $\geq 50 \%$ stenosis between the aorta and the distal leg arteries. Because of its high sensitivity and specificity (both $>90 \%$ ), an $A B I>0.90$ is considered a reliable sign of peripheral vascular disease. In asymptomatic individuals over 55 years of age, an $A B I$ $<0.9$ may be found in $12-27 \%$. Even in an elderly population (71-93 years), a low ABI further identifies a higher risk CHD subgroup.
Recently it has been shown that the extent of atherosclerosis of retinal arteries correlates with the extent of the total coronary plaque burden. Atherosclerosis of retinal arteries also strongly correlates with plasma total cholesterol, LDL cholesterol, triglycerides, and apoprotein B levels. Since ophthalmoscopy is a non-invasive technique, is easy to perform, and has no adverse effects, it might be used to detect asymptomatic individuals at high risk for cardiovascular events. ${ }^{216,217}$

\section{Gender issues: cardiovascular disease prevention in women}

\section{Scientific background}

More women than men die from CVD, although they do so at an older age. CHD is slightly more common as a cause of death in women, and stroke markedly more common. In contrast, breast cancer accounts for only $3 \%$ of all deaths in women. CVD risk in women is deferred by 10 years compared with that of men. A 55-year-old woman is identical in terms of risk to a 45-year-old man. The decline in CVD mortality in recent years has been greater in men than in women, and CVD incidence has actually increased in women, especially in the oldest groups. ${ }^{209,210}$

- Systolic hypertension becomes more frequent in older women.

- The use of oral contraceptives increases the CVD risk associated with smoking.

- Total cholesterol levels peak at around 60 years of age in women, about 10 years later than in men. ${ }^{211}$

- Diabetes carries a considerably greater risk of fatal CVD in women.

- Obesity is more prevalent in middle-aged and elderly women.

In general, women are disadvantaged at all stages of the clinical evolution of CVD. ${ }^{212}$ Risk management advice, particularly with regard to drug therapy, is hampered by defective evidence, as women are frequently under-represented in therapeutic trials, and there may be gender differences in therapeutic response. ${ }^{213}$ Aspirin reduces the risk of stroke in women but not the risk of an AMI. ${ }^{214}$ For women without CVD, lipid lowering may not affect total or CHD mortality. For women with known CVD, treatment of hyperlipidemia is effective in reducing CHD events, CHD mortality, non-fatal $\mathrm{Ml}$, and revascularization, but does not affect total mortality.

\section{Practical aspects}

(1) European and national public health policy needs to address the problem of inadequate recognition of the size of the problem of CVD in women and to reflect this through publicity and education of both the public and the medical profession.

(2) Clinicians should make a specific point of assessing risk in female patients.

(3) The principles of total risk estimation and management are the same for both sexes, with particular emphasis on the evaluation of smoking, overweight, the use of oral contraceptives, and glucose tolerance in women. 
(4) A low absolute risk in a young woman may conceal a large relative risk that will result in high absolute risk as she ages. Therefore, effective management of lifestyle change is in general more important than drug treatment in order to avoid a high absolute risk in older life.

(5) Extrapolating the results of lipid-lowering trials to young or middle-aged women without other risk factors may lead to substantial overuse of cholesterol-lowering drugs.

(6) Hormone replacement therapy has not been associated with a reduction in cardiovascular risk, although it might be indicated for menopausal symptomatic relief.

\section{Renal impairment as a risk factor in cardiovascular disease prevention}

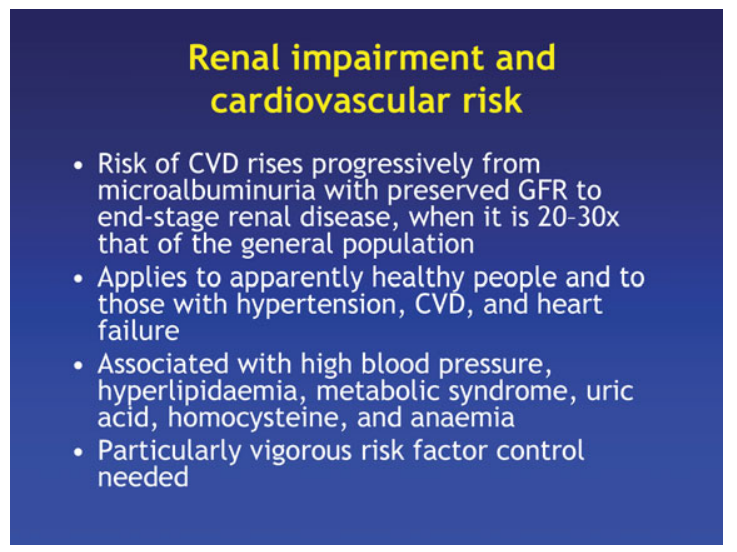

\section{Scientific background}

Renal impairment is associated with the development of CVD and death. The increased risk is already present by the time microalbuminuria develops. The risk progressively increases as renal function deteriorates, and end-stage renal disease (ESRD) is associated with a CVD risk up to 20-30 times that of the general population. ${ }^{218}$ The association between impaired renal function and increased CVD risk is seen in the general population, hypertensives, and patients with pre-existing CVD. The development of renal impairment is associated with risk factors including age, hypertension, dyslipidaemia, and the metabolic syndrome, which are also CVD risk factors. ${ }^{219,220}$ Therefore, the two diseases can develop in parallel. Once ESRD has developed, other factors such as alterations in calcium phosphate homeostasis and anaemia also contribute to CVD risk. ${ }^{221,222}$ In heart failure patients, renal function is independently associated with risk of death, CVD death, and hospitalization.

\section{Practical aspects: management}

The estimated glomerular filtration rate (eGFR) and presence of either microalbuminuria $(30-300 \mathrm{mg} / 24 \mathrm{~h})$ or macroalbuminuria $(>300 \mathrm{mg} / 24 \mathrm{~h})$ are used to assess the stage of renal impairment. An eGFR $<60 \mathrm{~mL} / \mathrm{min}$ is associated with significant CVD risk. Microalbuminuria often accompanies reduced eGFR, and the combination of the two is associated with an additive effect on CVD risk.

An early attempt to control CVD risk factors in patients with renal impairment is needed. Patients with renal impairment and CHD or heart failure may not be treated with all appropriate medications. ${ }^{223}$ Particular attention to ensuring these patients are prescribed all necessary therapeutic interventions will improve survival. ${ }^{224}$

\section{Cardioprotective drug therapy}

\section{Scientific background}

The use of prophylactic drugs which have been shown to reduce morbidity and mortality in clinical trials should be considered, in addition to drugs used for treatment of elevated blood pressure, lipids, and glucose.

\section{Antiplatelet therapies}

In patients with atherosclerotic disease, platelet-modifying drugs result in a significant reduction in all causes of mortality, vascular mortality, and non-fatal MI and stroke. ${ }^{225}$ Addition of clopidogrel has been proven to be beneficial in acute coronary syndromes. ${ }^{226}$ In chronic stable atherosclerotic disease, combination of aspirin and clopidgrel is not associated with a significant benefit in terms of MI, stroke, or CVD death, but is associated with an increased bleeding risk. In asymptomatic individuals, aspirin reduced $\mathrm{Ml}$ and death from CHD, but increased haemorrhagic strokes and gastrointestinal $(\mathrm{Gl})$ bleeding.

\section{$\boldsymbol{\beta}$-Blockers}

Meta-analyses have demonstrated the benefit of $\beta$-blockers in those post-MI, in terms of all-cause mortality, reinfarction, and CHD death. ${ }^{87}$ (DAVIT trials show that verapamil can be considered as an alternative in those post-MI with contraindications to $\beta$-blockers.) In CHF patients, $\beta$-blocker therapy has been shown to reduce all-cause mortality.

\section{ACE inhibitors}

In heart failure patients or those with left ventricular dysfunction, ACE inhibitors have been shown to reduce risk of death, recurrent $\mathrm{MI}$, and progression to persistent heart failure. ${ }^{227}$ ACE inhibitor treatment also reduced risk of death after AMI. Studies assessing the benefit of ACE inhibitors in those with stable coronary disease without left ventricular dysfunction have yielded varying results. In PROGRESS, patients with previous CVD, BP lowering using ACE inhibitor/diuretic combination showed significant reductions in stroke and coronary disease events. In HOPE, in diabetics aged over 55 with one additional risk factor and without left ventricular dysfunction or uncontrolled hypertension, ACE inhibitors reduced risk of death and MI. ${ }^{106}$

\section{Anticoagulation}

Systemic anticoagulation is indicated, particularly in combination with aspirin, in patients post-MI whose risk of thromboembolism is increased. ${ }^{228}$ 


\section{Practical aspects: management}

When to prescribe cardioprotective drugs in addition to those used to treat blood pressure, lipids, and diabetes

- Aspirin for virtually all with established CVD, and in persons at $>10 \%$ SCORE risk once blood pressure has been controlled

- $\beta$-blockers after myocardial infarction and, in carefully titrated doses, in those with heart failure

- ACE inhibitors in those with left ventricular dysfunction and in diabetic subjects with hypertension or nephropathy

- Anticoagulants in those at increased risk of thromboembolic events, particularly atrial fibrillation

Antiplatelet therapy: aspirin Indicated in:

(1) All with established CVD (including diabetics) unless contra-indicated; lifelong treatment with low dose (75-150 mg daily) is recommended.

(2) Asymptomatic individuals, aspirin should only be considered when the 10-year risk of CVD mortality is markedly increased and the BP is controlled.

Antiplatelet therapy: clopidogrel

Indicated in:

(1) Cases of aspirin allergy.

(2) In addition to aspirin, in acute coronary syndromes for 9-12 months.

(3) Combination of aspirin and clopidogrel is not routinely recommended in chronic stable atherosclerotic disease.

\section{$\boldsymbol{\beta}$-Blockers}

Indicated in:

(1) Patients post-MI (including diabetics).

(2) CHF patients.

(3) Angina to relieve the symptoms of myocardial ischaemia.

(4) As an antihypertensive (other antihypertensives preferred in diabetics).

\section{ACE inhibitors}

Indicated in:

(1) Treatment of heart failure or left ventricular dysfunction.

(2) Diabetics to reduce BP to target or if type 1 (and possibly type 2) nephropathy.

(3) To reduce BP to target. Angiotensin receptor blockers can be used in patients with an indication for ACE inhibitors but who cannot tolerate ACE inhibitors.

\section{Calcium channel blockers}

Indicated for:

(1) Reducing BP to target.

(2) Post-Ml if $\beta$-blockers are contra-indicated.
Table 11 Indications for antithrombotic therapy in patients with atrial fibrillation

\begin{tabular}{|c|c|c|}
\hline Risk category & Recommended therapy & \\
\hline No risk factors & $\begin{array}{l}\text { Aspirin, } 81 \text { to } 325 \mathrm{mg} \\
\text { daily }\end{array}$ & \\
\hline $\begin{array}{l}\text { One moderate risk } \\
\text { factor }\end{array}$ & $\begin{array}{l}\text { Aspirin, } 81 \text { to } 325 \mathrm{mg} \\
\text { daily, or warfarin (INR } \\
2.0 \text { to } 3.0 \text {, target } 2.5 \text { ) }\end{array}$ & \\
\hline $\begin{array}{l}\text { Any high risk factor } \\
\text { or more than } 1 \\
\text { moderate risk } \\
\text { factor }\end{array}$ & $\begin{array}{l}\text { Warfarin (INR } 2.0 \text { to } 3.0, \\
\text { target } 2.5)^{\mathrm{a}}\end{array}$ & \\
\hline $\begin{array}{l}\text { Less validated } \\
\text { or weaker risk factors }\end{array}$ & $\begin{array}{l}\text { Moderate risk } \\
\text { factors }\end{array}$ & $\begin{array}{l}\text { High risk } \\
\text { factors }\end{array}$ \\
\hline Female gender & Age $\geq 75$ years & $\begin{array}{l}\text { Previous } \\
\text { stroke, TIA } \\
\text { or embolism }\end{array}$ \\
\hline Age 65 to $74 y$ & Hypertension & Mitral stenosis \\
\hline $\begin{array}{l}\text { Coronary artery } \\
\text { disease }\end{array}$ & Heart failure & $\begin{array}{l}\text { Prosthetic } \\
\quad \text { heart valve }\end{array}$ \\
\hline Thyrotoxicosis & $\begin{array}{l}\text { LV ejection fraction 35\% } \\
\text { or less } \\
\text { Diabetes mellitus }\end{array}$ & \\
\hline
\end{tabular}

aIf mechanical valve, target international normalized ratio (INR) greater than 2.5.

${ }^{\mathrm{b}} \mathrm{LV}=$ left ventricular; TIA $=$ transient ischaemic attack.

\section{Diuretics}

Indicated for:

(1) Reducing BP to target. (Alternative antihypertensives are preferred in type 2 diabetes or those at high risk of developing type 2 diabetes.)

\section{Anticoagulation}

Indicated in:

(1) History of thromboembolic events

(2) Left ventricular thrombus

(3) Persistent or paroxsymal atrial fibrillation - see ESC guidelines on atrial fibrillation ${ }^{229}$ (Table 11)

(4) Consider in:

(i) large anterior $\mathrm{Ml}$

(ii) left ventricular aneurysm

(iii) paroxysmal tachyarrythmias

(iv) post-MI CHF

\section{Implementation strategies}

\section{Scientific background}

Several studies have been carried out to evaluate the effect of different implementation strategies of guidelines on clinical practice.

EUROASPIRE I $(1995 / 96)^{39}$ and II $(2000 / 01)^{38}$ surveys both showed a high prevalence of unhealthy lifestyles, modifiable risk factors, and inadequate use of drug therapies to achieve 
BP and lipid goals in patients with established CHD, with wide variations in medical practice between countries.

Many surveys have shown similar results, some also showing great variance between countries.

There is considerable potential throughout Europe in coronary patients and their families to raise the standard of preventive cardiology through more lifestyle intervention, control of other risk factors and optimal use of prophylactic drug therapies in order to reduce the risk of recurrent disease and death. Similar results have been shown for stroke.

Although the availability of systematic reviews and guidelines reduces the need for doctors to read original studies, they still find it difficult to keep up with such syntheses. Even if doctors are aware of the evidence and are willing to change, to alter well established patterns of care is difficult, especially if the clinical environment is not conducive to change.

\section{Barriers to the implementation of guidelines}

It is essential that clinical guidelines are in concordance with priorities in the health system and with ethical values most clinicians can agree upon. If not, this may be an important reason why many clinicians do not follow guidelines. ${ }^{230}$

The implementation of these guidelines should be based on national surveys to adjust them to the stratification of risk factors and premature CVD death in the individual country and bring them in accordance with priorities set by the health authorities and the professional bodies. The workload put on the health system should be affordable and should not imply that resources should be allocated to prevention strategies when the outcome for the population is better by alternative use.

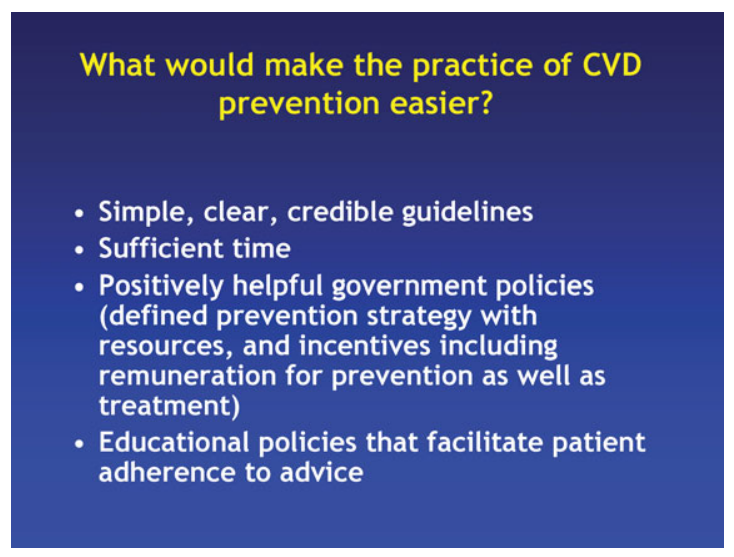

Analyses of the barriers to changing practice, have shown that obstacles to change in practice can arise at different stages in the health care organization, or the wider environment. Most theories on implementation of evidence in health care emphasize the importance of developing a good understanding of such obstacles to develop an effective intervention.

\section{Doctor-patient relationship}

The preventive interventions must be based on a patientcentred approach, where the doctor pays full attention to appraise and meet the patient's concerns, beliefs, and values, and respects the patient's choice even if it is not in concordance with the doctor's first proposal. The changing of lifestyle or taking medication often means for the rest of the patient's life, so the decision must be owned by the patient. Therefore, treatment goals should be set in collaboration with the patient, taking into account the values and priorities of the patient. If the treatment goals are unaffordable, it may lead to frustration and clinical neglect, both by the doctor and by the patient. The doctor should explore the patient's important values, beliefs, and expectations regarding the prevention measures to be taken.

\section{Practical aspects}

\section{Important arenas for training}

There is a need for training of doctors in patient-centred preventive care, with emphasis on

- patient-centred methods in the consultation process

- the motivation to change-how to support and strengthen the patient's decision to adopt healthy habits

- how to evaluate multifactorial risk and use risk charts

- how to communicate risk and the effects of interventions

- how to discuss treatment goals and follow-up.

\section{Implementation strategies}

(1) On the European (international) level:

(a) Publication of the guidelines in relevant journals.

(b) Presentation at international conferences arranged by the participating societies.

(c) Involvement in policy at European Union level through, for example, the Luxembourg Declaration and the development of the European Heart Health Charter.

(2) On the national level:

(a) If not already existing, implementation demands a leading expert group of national organizations representing similar groups to the European Task Force. The group should have acceptance and support from national health authorities.

(b) Adjustment and application of national standards, in accordance with the European Guidelines.

(c) Further implementation should be organized by the National Colleges in accordance with the local needs, see below.

Implementation strategies should consist of a package of different measures, working in combination:

(1) A public health approach, with emphasis on smoking cessation, healthier food and better access to physical activity in all ages should be implemented-to support and complement the individual-oriented high risk strategy of doctor-initiated prevention.

(2) A public information campaign of the Fourth Joint CVD Prevention Guidelines and the corresponding national Guidelines with two main topics:

(a) Information on the concept of multiple risk assessment and treatment, and the intervention thresholds.

(b) What people can do to reduce risk. 
The message should encourage people at high risk to realize their risk and go to see a doctor, but should reassure people with low risk that they can stay healthy without the doctor's help.

(3) An information and education programme aimed at practising doctors (GPs, internists, and others). It should consist of a selection of the effective strategies mentioned above: (a) Lectures and CME activities with interactive participation.

(b) Audit and feedback, preferably combined with outreach visits by trained colleagues.

(c) Dissemination of electronic versions, applicable to hand-held equipment.

(d) Dissemination of simple, one-sheet versions of risk algorithms and treatment recommendations.

The CME Text 'European guidelines on cardiovascular disease prevention in clinical practice: executive summary' is accredited by the European Board for Accreditation in Cardiology (EBAC) for '4' hours of External CME credits. Each participant should claim only those hours of credit that have actually been spent in the educational activity. EBAC works according to the quality standards of the European Accreditation Council for Continuing Medical Education (EACCME), which is an institution of the European Union of Medical Specialists (UEMS). In compliance with EBAC/EACCME guidelines, all authors participating in this programme have disclosed potential conflicts of interest that might cause a bias in the article. The Organizing Committee is responsible for ensuring that all potential conflicts of interest relevant to the programme are declared to the participants prior to the CME activities. CME questions for this article are available at: European Heart Journal http://cme.oxfordjournals.org/cgi/hierarchy/oupcme_node;ehj and European Society of Cardiology http://www.escardio.org/knowledge/guidelines.

\section{References}

1. Pyorala K, De Backer G, Graham I, Poole-Wilson P, Wood D. Prevention of coronary heart disease in clinical practice: recommendations of the Task Force of the European Society of Cardiology, European Atherosclerosis Society and the European Society of Hypertension. Atherosclerosis 1994;110:121-161.

2. Wood D, De Backer G, Faergeman O, Graham I, Mancia G, Pyorala K. Prevention of coronary heart disease in clinical practice. Recommendations of the Second Joint Task Force of European and Other Societies on coronary prevention. Eur Heart J 1998; 19:1434-1503.

3. De Backer G, Ambrosioni E, Borch-Johnsen K, Brotons C, Cifkova R, Dallongeville J, Ebrahim S, Faergeman O, Graham I, Mancia G, Manger Cats V, Orth-Gomér K, Perk J, Pyörälä K, Rodicio JL, Sans S, Sansoy V, Sechtem U, Silber S, Thomsen T, Wood D; Third Joint Task Force of European and Other Societies on Cardiovascular Disease Prevention in Clinical Practice. European guidelines on cardiovascular disease prevention in clinical practice. Third Joint Task Force of European and other Societies on Cardiovascular Disease Prevention in Clinical Practice (constituted by representatives of eight societies and by invited experts). Eur J Cardiovasc Prev Rehab 2003;10(Suppl 1):S1-S78.

4. Mancia G, de Backer G, Dominiczak A, Cifkova R, Fagard R, Germano G, Grassi G, Heagerty AM, Kjeldsen SE, Laurent S, Narkiewicz K, Ruilope L, Rynkiewicz A, Schmieder R, Struiijker, Boudier HAJ, Zanchetti A. European Society of Hypertension (ESH) and European Society of Cardiology (ESC) guidelines for the management of arterial hypertension. J Hypertens 2007;25:1105-1187.

5. Rydén L, Standl E, Bartnik M, Van den Berghe G, Betteridge J, de Boer MJ, Cosentino $F$, Jönsson B, Laakso $M$, Malmberg $K$, Priori S, Ostergren J, Tuomilehto J, Thrainsdottir I, Vanhorebeek I, Stramba-Badiale M, Lindgren P, Qiao Q, Priori SG, Blanc JJ, Budaj A, Camm J, Dean V, Deckers J, Dickstein K, Lekakis J, McGregor K, Metra M, Morais J, Osterspey A, Tamargo J, Zamorano JL, Deckers JW, Bertrand M, Charbonnel B, Erdmann E, Ferrannini E, Flyvbjerg A, Gohlke H, Juanatey JR, Graham I, Monteiro PF, Parhofer K, Pyörälä K, Raz I, Schernthaner G, Volpe M, Wood D; Task Force on Diabetes and Cardiovascular Diseases of the European Society of Cardiology (ESC); European Association for the Study of Diabetes (EASD). Guidelines on diabetes, pre-diabetes and cardiovascular diseases: executive summary. The Task Force on Diabetes and Cardiovascular Diseases of the European Society of Cardiology (ESC) and the European Association for the Study of Diabetes (EASD). Eur Heart J 2007;28:88-136.

6. www.ehnheart.org.

7. Petersen S, Peto V, Rayner M. Leal J, Luengo-Fernández R, Gray A. European Cardiovascular Disease Statistics: 2005 edition. London: British Heart Foundation; 2005.

8. Leal J, Luengo-Fernández R, Gray A, Petersen S, Rayner M. Economic burden of cardiovascular diseases in the enlarged European Union. Eur Heart J 2006;27:1610-1619.

9. Kesteloot H, Sans S, Kromhout D. Dynamics of cardiovascular and allcause mortality in Western and Eastern Europe between 1970 and 2000. Eur Heart J 2006;27:107-113.

10. Tunstall-Pedoe H, Kulaasma K, Mahonen M, Tolonen H, Ruokokoski E. Contribution of trends in survival and coronary-event rates to changes in coronary heart disease mortality: 10 year results from 37 WHO
MONICA project populations. Monitoring trends and determinants in cardiovascular disease. Lancet 1999;353:1547-1557.

11. Vartiainen E, Puska P, Pekkanen J, Tuomilehto J, Jousilahti P. Changes in risk factors explain changes in mortality from ischemic heart disease in Finland. BMJ 1994;309:23-27.

12. Pyörälä K, Lehto S, De Bacquer D, De Sutter J, Sans S, Keil U, Wood D, De Backer G; EUROASPIRE I Group; EUROASPIRE II Group. Risk factor management in diabetic and non-diabetic coronary heart disease patients. Findings from Euroaspire | and || surveys. Diabetologia 2004;47: 1257-1265.

13. Levy D, Larson MG, Vasan RS, Kannel WB, Ho KKL. The progression from hypertension to congestive heart failure. JAMA 1996;275:1557-1562.

14. Filipovic M, Goldacre MJ, Roberts SE, Yeates D, Duncan ME, Cook-Mozaffari P. Trends in mortality and hospital admission rates for abdominal aortic aneurysm in England and Wales, 1979-99. Br J Surg 2005; 92:968-975.

15. MASS: Multicentre Aneurysm Screening Study Group. The Multicentre Aneurysm Screening Study (MASS) into the effect of abdominal aortic aneurysm screening on mortality in men: a randomised controlled trial. Lancet 2002;360:1531-1539.

16. Kroger K, Stang A, Kondratieva H. Prevalence of peripheral arterial disease-results of the Heinz Nixdorf recall study. Eur J Epidemiol 2006;21:279-285

17. Price J, Mowbray PI, Lee AJ, Rumley A, Lowe GD, Fowkes FG. Relationship between smoking and cardiovascular risk factors in the development of peripheral arterial disease and coronary artery disease: Edinburgh Artery Study. Eur Heart J 1999;20:344-353.

18. Hirsch A, Haskal ZJ, Hertzer NR, Bakal CW, Creager MA, Halperin JL, Hiratzka LF, Murphy WR, Olin JW, Puschett JB, Rosenfield KA, Sacks D, Stanley JC, Taylor LM, White CJ, White J, White RA, Antman EM, Smith SC, Adams CD, Anderson JL, Faxon DP, Fuster V, Gibbons RJ, Hunt SA, Jacobs AK, Nishimura R, Ornato JP, Page RL, Riegel B. American Association for Vascular Surgery; Society for Vascular Surgery; Society for Cardiovascular Angiography and Interventions; Society for Vascular Medicine and Biology; Society of Interventional Radiology; ACC/AHA Task Force on Practice Guidelines Writing Committee to Develop Guidelines for the Management of Patients With Peripheral Arterial Disease; American Association of Cardiovascular and Pulmonary Rehabilitation; National Heart, Lung, and Blood Institute; Society for Vascular Nursing; TransAtlantic Inter-Society Consensus; Vascular Disease Foundation. ACC/AHA 2005 Practice Guidelines for the management of patients with peripheral artery disease. Circulation 2006;113: e463-e654.

19. Bhatt D, Steg PG, Ohman EM, Hirsch AT, Ikeda Y, Mas JL, Goto S, Liau CS, Richard AJ, Röther J, Wilson PW; REACH Registry Investigators. International prevalence, recognition, and treatment of cardiovascular risk factors in outpatients with atherothrombosis. JAMA 2006;295:180-189.

20. Heart Protection Study Collaborative Group. MRC/BHF Heart Protection Study of cholesterol lowering with simvastatin in 20,536 high-risk individuals: a randomised placebo-controlled trial. Lancet 2002;360:7-22.

21. Henke P, Blackburn S, Proctor MC, Stevens J, Mukherjee D, Rajagopalin S, Upchurch GR, Stanley JC, Eagle KA. Patients undergoing infrainguinal bypass to treat atherosclerotic vascular disease are 
underprescribed cardioprotective medication: effect on graft patency, limb salvage, and mortality. J Vasc Surg 2004;39:357-365.

22. Adams H, Bendixen PH, Kappelle LJ, Biller J, Long BB, Gordon DL, Marsh EE. Classification of subtype of acute ischemic stroke: definitions for use in a multicenter clinical trial: TOAST: Trial of Org 10172 in acute stroke treatment. Stroke 1993;24:35-41.

23. European Stroke Initiative Executive Committee and the EUSI Writing Committee. European Stroke Initiative Recommendations for Stroke Management. Update 2003. Cerebrovasc Dis 2003;16:311-337.

24. WHO Framework Convention on Tobacco Control (WHO FCTC). www. who.int/tobacco/framework/. Geneva: WHO.

25. Commission of the European Communities. Green paper. Promoting healthy diets and physical activity: a European dimension for the prevention of overweight, obesity and chronic diseases. Int J Epidemiol 2005; 14: COM 637

26. WHO. Global Strategy on Diet, Physical Activity and Health. Geneva: WHO; 2004.

27. Clark A, Hartling L, Vandermeer B, McAlister FA. Meta-analysis: secondary prevention programs for patients with coronary heart disease. Ann Intern Med 2005;143:659-672.

28. Mc Alister F, Lawson FME, Teo KK, Arsmtrogg PW. Randomised trials of secondary prevention programmes in coronary heart disease: systematic review. BMJ 2001;323:957-962.

29. Sackett D, Richardson W, Rosenberg W, Haynes R. Evidence Based Medicine: How to Practice and Teach EBM. Edinburgh: Churchill Livingstone; 1996.

30. McColl A, Smith H, White P, Field J. General practitioner's perceptions of the route to evidence based medicine: a questionnaire survey. $B M J$ 1998; 316:361-365.

31. Woolf S, Grol R, Hutchinson A, Eccles M, Grimshaw J. Clinical guidelines: potential benefits, limitations, and harms of clinical guidelines. $B M J$ 1999;318:527-530.

32. Grol R, Dalhuijsen J, Thomas S, Veld C, Rutten G, Mokkink H. Attributes of clinical guidelines that influence use of guidelines in general practice: observational study. BMJ 1998;317:858-861.

33. GRADE Working Group. Grading quality of evidence and strength of recommendations. BMJ 2004;328:1490-1497.

34. Davey-Smith $G$, Egger $M$. Who benefits from medical interventions? BMJ 1994;308:72-74.

35. Egger M, Schneider M, Davey Smith G. Spurious precision? Meta-analysis of observational studies. BMJ 1998;316:140-144.

36. Hopper L, Ness A, Higgins JP, Moore T, Ebrahim S. GISSI-Prevenzione trial. Lancet 1999;354:1557.

37. Smeeth L, Haines A, Ebrahim S. Numbers needed to treat derived from meta-analyses-sometimes informative, usually misleading. BMJ 1999; 318:548-551.

38. EUROASPIRE I and II Group; European Action on Secondary Prevention by Intervention to Reduce Events. Clinical reality of coronary prevention programmes: a comparison of EUROASPIRE I \& II in 9 countries. EUROAS PIRE I \& II Group. European Action on Secondary prevention by Intervention to Reduce Events. Lancet 2001;357:995-1001.

39. EUROASPIRE Study Group: European Action on Secondary Prevention by Intervention to Reduce Events. EUROASPIRE. A European Society of Cardiology survey of secondary prevention of coronary heart disease: principal results. Eur Heart J 1997;18:1569-1582.

40. Rose $G$. The strategy of prevention: lessons from cardiovascular disease. BMJ 1981;282:1847-1851.

41. Anderson K, Wilson PW, Odell PM, Kannel WB. An updated coronary risk profile. A statement for health professionals. Circulation 1991;83 356-362.

42. Conroy R, Pyörälä K, Fitzgerald AP, Sans S, Menotti A, De Backer G, De Bacquer D, Ducimetière $P$, Jousilahti $P$, Keil U, Njølstad I, Oganov RG, Thomsen T, Tunstall-Pedoe H, Tverdal A, Wedel H, Whincup P, Wilhelmsen L, Graham IM; SCORE project group. Estimation of ten-year risk of fatal cardiovascular disease in Europe: the SCORE project. Eur Heart J 2003;24:987-1003.

43. Vartiainen E, Jousilahti P, Alfthan G, Sundvall J, Pietinen P, Puska P. Cardiovascular risk factor changes in Finland I 1972-1997. Int J Epidemio 2000;29:49-56.

44. Linden W, Stossel C, Maurice J. Psychosocial interventions for patients with coronary artery disease: a meta-analysis. Arch Intern Med 1996; 156:745-752.

45. Dusseldorp E, van Elderen T, Maes S, Meulman J, Kraaij V. A meta-analysis of psychoeduational programs for coronary heart disease patients. Health Psychol 1999;18:506-519.
46. Blumenthal J, Sherwood A, Babyak MA, Watkins LL, Waugh R, Georgiades A, Bacon SL, Hayano J, Coleman RE, Hinderliter A. Effects of exercise and stress management training on markers of cardiovascular risk in patients with ischemic heart disease: a randomized controlled trial. JAMA 2005;293:1626-1634.

47. US Department of Health and Human Services. The health consequences of smoking: a report of the Surgeon General. www.surgeongeneral.gov/ library/smokingconsequences/. Washington, DC; 2004.

48. Law M, Morris JK, Wald NJ. Environmental tobacco smoke exposure and ischaemic heart disease: an evaluation of the evidence. BMJ 1997;315: 973-980.

49. US Department of Health and Human Services. The Health Benefits of Smoking Cessation. Washington, DC: US Department of Health and Human Services; 1990.

50. McEwen A, Hajek P, McRobbic H, West R. Manual of Smoking Cessation. Oxford: Blackwell Publishers; 2006

51. Barth J, Bengel J. Smoking cessation in patients with coronary heart disease: risk reduction and an evaluation of the efficacy of interventions. In: Jordan J, Barde B, Zeiher AM eds. Contributions Toward Evidence-based Psychocardiology-A Systematic Review of the Literature. Washington, DC: American Psychological Association; 2007. p83-105.

52. Poirier P, Giles TD, Bray GA, Hong Y, Stern JS, Pi-Sunyer FX, Eckel RH. Obesity and cardiovascular disease: pathophysiology, evaluation, and effect of weight loss: an update of the 1997 American Heart Association Scientific Statement on Obesity and Heart Disease from the Obesity Committee of the Council on Nutrition, Physical Activity, and Metabolism. Circulation 2006;113:898-918.

53. Wajchenberg B. Subcutanuous and visceral adipose tissue: their relation to the metabolic syndrome. Endocr Rev 2000;21:697-738.

54. Carr M, Brunzell JD. Abdominal obesity and dyslipidemia in the metabolic syndrome: importance of type 2 diabetes and familial combined hyperlipidemia in coronary artery disease risk. J Clin Endocrinol Metab 2004;89:2601-2607.

55. Despres J, Moorjani S, Lupien PJ, Tremblay A, Nadeau A, Bouchard C. Regional distribution of body fat, plasma lipoprotein, and cardiovascular disease. Arteriosclerosis 1990;10:497-511.

56. Larsson B, Svardsudd K, Welin L, Wilhelmsen L, Bjorntorp P, Tibblin G. Abdominal adipose tissue distribution, obesity and risk of cardiovascular disease and death: 13 year follow up of participants in the study of men born in 1913. BMJ 1984;288:1401-1411.

57. Folsom A, Kushi LH, Anderson KE, Mink PJ, Olson JE, Hong C-P, Sellers TA, Lazovich D, Prineas RJ. Associations of general and abdominal obesity with multiple health outcomes in older women: the lowa Women's Health Study. Arch Intern Med 2000;160:2117-2128.

58. World Health Organization Consultation of Obesity. Obesity: Preventing and Managing the Global Epidemic. Geneva, Switzerland: Divison of Non-communicable Diseases, Programme of Nutrition, Family and Reproductive Health, WHO; 1998.

59. National Heart, Lung, and Blood Institute Obesity Education Initative Expert Panel. Clinical guidelines on the identification, evaluation, and treatment of overweight and obesity in adults. Obes Res 1998;6: 51S-209S.

60. Vikram N, Pandey RM, Misra A, Sharma R, Devi JR, Khanna N. Non-obese (body mass index $<25 \mathrm{~kg} / \mathrm{m}^{2}$ ) Asian Indians with normal waist circumference have high cardiovascular risk. Nutrition 2003;19:503-509.

61. Chowdbury B, Sjostrom L, Alpsten M, Kostanty J, Kvist H, Lofgren R. A multicompartment body composition technique based on computerized tomography. Int J Obes Relat Metab Disord 1994;18:219-234.

62. Ross R, Leger L, Morris D, de Guise J, Guardo R. Quantification of adipose tissue by MRI: relationship with anthropometric variables. J Appl Physiol 1992;72:787-795.

63. Tornaghi G, Raiteri R, Pozzato C, Rispoli A, Bramani M, Cipolat M, Craveri A. Anthropometric or ultrasonic measurements in assessment of visceral fat? A comparative study. Int J Obes Relat Metab Disord 1994; 18:771-775.

64. Armellini F, Zamboni M, Rigo L, Todesco T, Bergamo-Andreis IA, Procacci C, Bosello $\mathrm{O}$. The contribution of sonography to the measurement of intraabdominal fat. J Clin Ultrasound 1990;18:563-567.

65. Pouliot M, Despres JP, Lemieux S, Moorjani S, Bouchard C, Tremblay A, Nadeau A, Lupien PJ. Waist circumference and abdominal sagittal diameter: best simple anthropometric indexes of abdominal visceral adipose tissue accumulation and related cardiovascular risk in men and women. Am J Cardiol 1994;73:460-468.

66. Petersson H, Daryani A, Riserus U. Sagittal abdominal diameter as a marker of inflammation and insulin resistance among immigrant 
women from the Middle East and native Swedish women: a crosssectional study. Cardiovasc Diabetol 2007;6:10.

67. Kvist H, Chowdhury B, Grangard U, Tylen U, Sjostrom L. Total and visceral adipose-tissue volumes derived from measurements with computed tomography in adult men and women: predictive equations. Am J Clin Nutr 1988;48:1351-1361.

68. Martinez-Gonzalez M, Martinez JA, Hu FB, Gibney MJ, Kearney J. Physical inactivity, sedentary lifestyle and obesity in the European Union. Int J Obes Relat Metab Disord 1999;23:1192-1201.

69. Rejeski W, Brawley LR, Ambrosius WT, Brubaker PH, Focht BC, Foy CG, Fox LD. Older adults with chronic disease: benefits of group-mediated counseling in the promotion of physically active lifestyles. Health Physiol 2003;22:414-423.

70. Carlson J, Norman GJ, Feltz DL, Franklin BA, Johnson JA, Locke SK. Selfefficacy, psychosocial factors, and exercise behavior in traditional versus modified cardiac rehabilitation. J Cardiopulm Rehab 2001;21: 363-373.

71. Klein S, Burke LE, Bray GA, Blair S, Allison DB, Pi-Sunyer X, Hong $Y$, Eckel RH. Clinical implications of obesity with specific focus on cardiovascular disease: a statement for professionals from the American Heart Association Council on Nutrition, Physical Activity, and Metabolism: endorsed by the American College of Cardiology Foundation. Circulation 2004;110:2952-2967.

72. Howard B, Van Horn L, Hsia J, Manson JE, Stefanick ML, Wassertheil-Smoller S, Kuller LH, LaCroix AZ, Langer RD, Lasser NL, Lewis CE, Limacher MC, Margolis KL, Mysiw WJ, Ockene JK, Parker LM, Perri MG, Phillips L, Prentice RL, Robbins J, Rossouw JE, Sarto GE, Schatz IJ, Snetselaar LG, Stevens VJ, Tinker LF, Trevisan M, Vitolins MZ, Anderson GL, Assaf AR, Bassford T, Beresford SA, Black HR, Brunner RL, Brzyski RG, Caan B, Chlebowski RT, Gass M, Granek I, Greenland P, Hays J, Heber D, Heiss G, Hendrix SL, Hubell FA, Johnson KC, Kotehen JM. Low-fat dietary pattern and risk of cardiovascular disease: the Women's Health Initiative Randomized Controlled Dietary Modification Trial. JAMA 2006;295:655-666.

73. Nordmann A, Nordmann A, Briel M, Keller U, Yancy WS Jr, Brehm BJ, Bucher HC. Effects of low-carbohydrate vs low-fat diets on weight loss and cardiovascular risk factors: a meta-analysis of randomized controlled trials. Arch Intern Med 2006;166:285-293.

74. Shaw K, O’Rourke P, Del Mar C, Kenardy J. Psychological Interventions for Overweight or Obesity (Cochrane Review). Oxford: Update Software; 2005

75. Wing R, Tate DF, Gorin AA, Raynor HA, Fava JL. A self-regulation program for maintenance of weight loss. N Engl J Med 2006;355: 1563-1571.

76. Rosengren A, Wilhelmsen L. Physical activity protects against coronary death and deaths from all causes in middle aged men. Evidence from a 20 year follow up of primary prevention study in Goteburg. Ann Epidemiol 1997; 7:69-67.

77. Paffenbarger R, Hyde RT, Wing AL, Lee IM, Jung DL, Kampret JB. The association of changes in physical-activity level and other lifestyle characteristics with mortality amoung men. N Engl J Med 1993;328: 538-545.

78. Franco O, De Laet C, Peeters A, Jonker J, Mackenbach J, Nusselder W. Effects of physical activity on life expectancy with cardiovascular disease. Arch Intern Med 2005;165:2355-2360.

79. Taylor R, Brown A, Ebrahim S, Jolliffe J, Noorani H, Rees K, Skidmore B, Stone JA, Thompson DR, Oldridge N. Exercise-based rehabilitation for patients with coronary heart disease: systematic review and meta-analysis of randomized controlled trials. Am J Med 2004;116: 682-692.

80. Vanhees L, Lefevre J, Philippaerts R, Martens M, Huygens W, Troosters T, Beunen G. How to assess physical activity? How to assess physical fitness. Eur J Cardiovasc Prev Rehab 2005;12:102-114.

81. Börjesson M, Assanelli D, Carré F, Dugmore D, Panhuyzen-Goedkoop NM, Seiler C, Senden J, Solberg EE; ESC Study Group of Sports Cardiology. Position Paper ESC Study Group of Sports Cardiology: recommendations for participation in leisure-time physical activity and competitive sports for patients with ischaemic heart disease. Eur J Cardiovasc Prev Rehab 2006;13:137-149.

82. Kannel W, Kannel C, Paffenbarger RS, Cupples LA. Heart rate and cardiovascular mortality: the Framingham Study. Am Heart J 1987;113: 1489-1494.

83. Diaz A, Bourassa M, Guertin M, Tardiff J. Long-term prognostic value of resting heart rate in patients with suspected or proven coronary artery disease. Eur Heart J 2005;26:967-974.
84. Levine H. Rest heart rate and life expectancy. J Am Coll Cardiol 1997; 30:1104-1106.

85. Beere $P$, Glagov S, Zarins C. Retarding effect of lowered heart rate on coronary atherosclerosis. Science 1984;226:180-182.

86. Shaper A, Wannamethee G, Macfarlane P, Walker M. Heart rate, ischaemic heart disease and sudden death in middle-aged British men. $\mathrm{Br}$ Heart J 1993;70:49-55.

87. Freemantle N, Cleland J, Young P, Mason J, Harrison J. $\beta$ Blockade after myocardial infarction: systematic review and meta regression analysis. BMJ 1999;318:1730-1737.

88. Brophy J, Joseph L, Rouleau J. $\beta$-Blockers in congestive heart failure: a Bayesian meta-analysis. Ann Intern Med 2001;134:550-560.

89. Kjekshus J. Importance of heart rate in determining beta-blocker efficacy in acute and long-term acute myocardial infarction intervention trials. Am J Cardiol 1986;57:43F-49F.

90. Tardif J, Ford I, Tendera M, Bourassa M, Fox K. Efficacy of ivabradine, a new selective I(f) inhibitor, compared with atenolol in patients with chronic stable angina. Eur Heart J 2005;26:2529-2536.

91. Kannel W. Blood pressure as a cardiovascular risk factor: prevention and treatment. JAMA 1996;275:1571-1576.

92. Walker W, Neaton JD, Cutler JA, Neuwirth R, Cohen JD. Renal function change in hypertensive members of the Multiple Risk Factor Intervention Trial. Racial and treatment effects. The MRFIT Research Group. JAMA 1992;268:3085-3091.

93. Assmann G, Schulte $H$. The Prospective Cardiovascular Munster (PROCAM) study: prevalence of hyperlipidemia in persons with hypertension and/or diabetes mellitus and the relationship to coronary heart disease. Am Heart J 1988;116:1713-1724.

94. MacMahon S, Peto R, Cutler J, Collins R, Sorlie P, Neaton J, Abbott R, Godwin J, Dyer A, Stamler J. Blood pressure, stroke, and coronary heart disease. Part 1. Prolonged differences in blood pressure: prospective observational studies corrected for the regression dilution bias. Lancet 1990;335:765-774.

95. Skoog I, Lernfelt B, Landahl S, Palmertz B, Andreasson LA, Nilsson L, Persson G, Odén A, Svanborg A. 15-year longitudinal study of blood pressure and dementia. Lancet 1996;347:1141-1145.

96. Lewington S, Clarke R, Qizilbash N, Peto R, Collins R. Age-specific relevance of usual blood pressure to vascular mortality: A meta-analysis of individual data for one million adults in 61 prospective studies. Prospective Studies Collaboration. Lancet 2002;360:1903-1913.

97. Vasan R, Larson MG, Leip EP, Kannel WB, Levy D. Assessment of frequency of progression to hypertension in non-hypertensive participants in the Framingham Heart Study: a cohort study. Lancet 2001;358: $1682-1686$

98. Collins R, Peto R, MacMahon S, Hebert P, Fiebach NH, Eberlein KA, Godwin J, Qizilbash N, Taylor JO, Hennekens CH. Blood pressure, stroke, and coronary heart disease. Part 2. Short-term reductions in blood pressure: overview of randomised drug trials in their epidemiological context. Lancet 1990;335:827-838.

99. Staessen J, Gasowski J, Wang JG, Thijs L, Den Hond E, Boissel JP, Coope J, Ekbom T, Gueyffier F, Liu L, Kerlikowske K, Pocock S, Fagard RH. Risks of untreated and treated isolated systolic hypertension in the elderly: meta-analysis of outcome trials. Lancet 2000;355: 865-872.

100. Blood Pressure Lowering Treatment Trialists' Collaboration. Effects of different blood-pressure-lowering regimens on major cardiovascular events: results of prospectively-designed overviews of randomised trials. Lancet 2003;362:1527-1535.

101. Collins R, MacMahon S. Blood pressure, antihypertensive drug treatment and the risk of stroke and of coronary heart disease. Br Med Bull 1994; 50:272-298.

102. Zhang X, Attia J, D'Este C, Ma XY. The relationship between higher blood pressure and ischemic, haemorrhagic stroke among Chinese and Caucasians: meta-analyisis. Eur J Cardiovacular Prev Rehab 2006;13:429-437.

103. PROGRESS Collaborative Group. Randomised trial of a perindopril-based blood-pressure-lowering regimen among 6105 individuals with previous stroke or transient ischaemic attack. Lancet 2001;358:1033-1041.

104. Fox K, EURopean trial On reduction of cardiac events with Perindopril in stable coronary Artery disease Investigators. Efficacy of perindopril in reduction of cardiovascular events among patients with stable coronary artery disease: randomised, double-blind, placebo-controlled, multicentre trial (the EUROPA study). Lancet 2003;362:782-788.

105. Nissen S, Tuzcu EM, Schoenhagen P, Brown BG, Ganz P, Vogel RA, Crowe T, Howard G, Cooper CJ, Brodie B, Grines CL, DeMaria AN; REVER$\mathrm{SAL}$ Investigators. Effect of intensive compared with moderate 
lipid-lowering therapy on progression of coronary atherosclerosis: a randomized controlled trial. JAMA 2004;291:1071-1080.

106. HOPE: Heart Outcomes Prevntion Evaluation Study Investigators. Effects of ramipril on cardiovascular and microvascular outcomes in people with diabetes mellitus: results of the HOPE study and micro-HOPE substudy. Lancet 2000;355:253-259.

107. Schrier R, Estacio RO, Esler A, Mehler P. Effects of aggressive blood pressure control in normotensive type 2 diabetic patients on albuminuria, retinopathy and stroke. Kidney Int 2002;61:1086-1097.

108. Atkins R, Briganti EM, Lewis JB, Hunsicker LG, Braden G, Champion de Crespigny PJ, DeFerrari G, Drury P, Locatelli F, Wiegmann TB, Lewis EJ. Proteinuria reduction and progression to renal failure in patients with type 2 diabetes mellitus and overt nephropathy. Am J Kidney Dis 2005;45:281-287.

109. ACE Inhibitors in Diabetic Nephropathy Trialist Group. Should all patients with type 1 diabetes mellitus and microalbuminuria receive angiotensin-converting enzyme inhibitors? A meta-analysis of individual patient data. Ann Interm Med 2001;134:370-379.

110. Casas J, Chua W, Loukogeorgakis S, Vallance P, Smeeth L, Hingorani AR, Mac Alister RJ. Effects of inhibitors of the renin-angiotensin system and other antihypertensive drugs on renal outcomes: systematic review and meta-analysis. Lancet 2005;366:2026-2033.

111. Otten J, Pitzi Helliwig J, Meyers LD. The Dietary Reference Intakes: The Essential Guide to Nutrient Requirements. Washington, DC: National Academies Press; 2006.

112. Sacks F, Svetkey LP, Vollmer WM, Appel LJ, Bray GA, Harsha D, Obarzanek E, Conlin PR, Miller ER III, Simons-Morton DG, Karanja N, Liu PH. Effects on blood pressure of reduced dietary sodium and the Dietary Approaches to Stop Hypertension (DASH) diet. DASH-Sodium Collaborative Research Group. N Engl J Med 2001;344:3-10.

113. Dahlöf B, Devereux RB, Kjeldsen SE, Julius $S$, Beevers $G$, de Faire U, Fyhrquist $F$, Ibsen $H$, Kristiansson $K$, Lederballe-Pedersen $O$, Lindholm LH, Nieminen MS, Omvik P, Oparil S, Wedel H; LIFE Study Group. Cardiovascular morbidity and mortality in the Losartan Intervention For Endpoint reduction in hypertension study (LIFE): a randomised trial against atenolol. Lancet 2002;359:995-1003.

114. Lindholm L, Carlberg B, Samuelsson O. Should beta blockers remain first choice in the treatment of primary hypertension? A meta-analysis. Lancet 2005;366:1545-1553.

115. Dahlöf B, Sever PS, Poulter NR, Wedel H, Beevers DG, Caulfield M, Collins R, Kjeldsen SE, Kristinsson A, McInnes GT, Mehlsen J, Nieminen M, O'Brien E, Ostergren J; ASCOT Investigators. Prevention of cardiovascular events with an antihypertensive regimen of amlodipine adding perindopril as required versus atenolol adding bendoflumethiazide as required, in the Anglo-Scandinavian Cardiac Outcomes Trial-Blood Pressure Lowering Arm (ASCOT-BPLA): a multicentre randomized controlled trial. Lancet 2005;366:895-906.

116. Bradley H, Wiysonge CS, Volmink JA, Mayosi BM, Opie LH. How strong is the evidence for use of beta-blockers a first line therpay for hypertension? Systematic review and meta-analysis. J Hypertens 2006;24: 2131-2141.

117. Bonet S, Agusti A, Amau JM, Vidal X, Diogene E, Galve E, Laporte JR. Beta-adrenergic blocking agents in heart failure: benefits of vasodilating and non-vasodilating agents according to patients' characteristics: a meta-analysis of clinical trials. Arch Intern Med 2000;160:621-627.

118. Heidenreich P, McDonald KM, Hastie T, Fadel B, Hagan V, Lee BK, Hlatky MA. Meta-analysis of trials comparing beta-blockers, calcium antagonists, and nitrates for stable angina. JAMA 1999;281:1927-1936.

119. Sharma A, Pischon T, Hardt S, Kunz I, Luft FC. Beta-adrenergic receptor blockers and weight gain: a systematic analysis. Hypertension 2001;37: 250-254.

120. Mancia G, Grassi G, Zancheti A. New-onset diabetes and antihypertensive drugs. J Hypertens 2006;24:3-10.

121. Lindholm L, Ibsen H, Borch-Johnsen K, Olsen MH, Wachtell K, Dahlöf $B$, Devereux RB, Beevers G, de Faire U, Fyhrquist F, Julius S, Kjeldsen SE, Kristianson K, Lederballe-Pedersen O, Nieminen MS, Omvik P, Oparil S, Wedel $\mathrm{H}$, Aurup P, Edelman JM, Snapinn S; for the LIFE study group. Risk of new-onset diabetes in the Losartan Intervention For Endpoint reduction in hypertension study. J Hypertens 2002;20:1879-1886.

122. Kjeldsen S, Julius S, Mancia G, McInnes GT, Hua T, Weber MA, Coca A, Ekman S, Girerd X, Jamerson K, Larochelle P, MacDonald TM, Schmieder RE, Schork MA, Stolt P, Viskoper R, Widimský J, Zanchetti A; VALUE Trial Investigators. Effects of valsartan compared to amlodipine on preventing type 2 diabetes in high-risk hypertensive patients: the VALUE trial. J Hypertens 2006;24:1405-1412.
123. Torp-Pedersen C, Metra M, Charlesworth A, Spark P, Lukas MA, Poole-Wilson PA, Swedberg K, Cleland JG, Di Lenarda A, Remme W, Scherhaug A. Effects of metoprolol and carvedilol on preexisting and new on-set diabetes in patients with chronic heart failure sinverted exclamation\} $\vee$ data from the Carvedilol or metoprolol European Trial (COMET). Heart 2007:Jan 19 [Epub ahead of print].

124. Kaiser T, Heise T, Nosek L, Eckers U, Sawicki PT. Influence of nebivolol and enalapril on metabolic parameters and arterial stiffness in hypertensive type 2 diabetic patients. J Hypertens 2006;24:1397-1403.

125. Klingbeil J, Schneider $M$, Martus P, Messerli FH, Schmieder RE. A meta-analysis of the effects of treatment on left ventricular mass in essential hypertension. Am J Med 2003;115:41-46.

126. Ciulla M, Paliotti R, Esposito A, Diez J, López B, Dahlöf B, Nicholls MG, Smith RD, Gilles L, Magrini F, Zanchetti A. Different effects of antihypertensive therapies based on losartan or atenolol on ultrasound and biochemical markers of myocardial fibrosis: results of a randomized trial. Circulation 2004;110:552-557.

127. Ciulla M, Paliotti R, Esposito A, Cuspidi C, Muiesan ML, Salvetti M, Agabiti-Rosei E, Magrini F, Zanchetti A. Effects of the angiotension receptor antagonist candesartan and the ACE inhibitor enalapril on ultrasound markers of myocardial fibrosis in hypertensive patients with left ventricular hypertrophy. J Hypertens 2005;23(Suppl 2):S381.

128. GISEN, Gruppo Italiano di Studi Epidemiologici in Nefrologia. Randomised placebo-controlled trial of effect of ramipril on decline in glomerular filtration rate and risk of terminal renal failure in proteinuric, non-diabetic nephropathy. Lancet 1997;349:1857-1863.

129. Mann J, Gerstein HC, Yi QL, Franke J, Lonn EM, Hoogwerf BJ, Rashkow A, Yusuf S; HOPE Investigators. Progression of renal insufficiency in type 2 diabetes with and without microalbuminuria: results of the Heart Outcomes and Prevention Evaluation (HOPE) randomized study. Am J Kidney Dis 2003;42:936-942.

130. Ruggenenti P, Fassi A, llieva AP, Bruno S, lliev IP, Brusegan V, Rubis N, Gherardi G, Arnoldi F, Ganeva M, Ene-lordache B, Gaspari F, Perna A, Bossi A, Trevisan R, Dodesini AR, Remuzzi G; Bergamo Nephrologic Diabetes Complications Trial (BENEDICT) Investigators. Preventing microalbuminuria in type 2 diabetes. N Engl J Med 2004;351:1941-1951.

131. Brenner B, Cooper ME, de Zeeuw D, Keane WF, Mitch WE, Parving HH, Remuzzi G, Snapinn SM, Zhang Z, Shahinfar S; RENAAL Study Investigators. Effects of losartan on renal and cardiovascular outcomes in patients with type 2 diabetes and nephropathy. N Engl J Med 2001; 345:861-869.

132. Lewis E, Hunsicker LG, Clarke WR, Berl T, Pohl MA, Lewis JB, Ritz E, Atkins RC, Rohde R, Raz I; Collaborative Study Group. Renoprotective effect of the angiotensin-receptor antagonist irbesartan in patients with nephropathy due to type 2 diabetes. N Engl J Med 2001;345: 851-860.

133. Lewis E, Hunsicker LG, Bain RP, Rohde RD. The effect of angiotensin-converting-enzyme inhibition on diabetic nephropathy. The Collaborative Study Group. N Engl J Med 1993;329:1456-1462.

134. Zanchetti A, Bond MG, Hennig M, Neiss A, Mancia G, Dal Palù C, Hansson L, Magnani B, Rahn KH, Reid JL, Rodicio J, Safar M, Eckes L, Rizzini P; European Lacidipine Study on Atherosclerosis investigators. European Lacidipine Study on Atherosclerosis investigators. Calcium antagonist lacidipine slows down progression of asymptomatic carotid atherosclerosis: principal results of the European Lacidipine Study on Atherosclerosis (ELSA), a randomized, double-blind, long-term trial. Circulation 2002;106:2422-2427.

135. Zanchetti A, Agabiti Rosei E, Dal Palu C, Leonetti G, Magnani B, Pessina A. The Verapamil in Hypertension and Atherosclerosis Study (VHAS): results of long-term randomized treatment with either verapamil or chlorthalidone on carotid intima-media thickness. $J$ Hypertens 1998; 16:1667-1676.

136. Borhani N, Mercuri M, Borhani PA, Buckalew VM, Canossa-Terris M, Carr AA, Kappagoda T, Rocco MV, Schnaper HW, Sowers JR, Bond MG. Final outcome results of the Multicenter Isradipine Diuretic Atherosclerosis Study (MIDAS). A randomized controlled trial. JAMA 1996; 276:785-791.

137. Ruilope L, Rosei EA, Bakris GL, Mancia G, Poulter NR, Taddei S, Unger T, Volpe M, Waeber B, Zannad F. Angiotensin receptor blockers: therapeutic targets and cardiovascular protection. Blood Press 2005;14: 196-209.

138. Waeber B, Burnier M, Brunner HR. Compliance with antihypertensive therapy. Clin Exp Hypertens 1999;21:973-985.

139. Clement D, De Buyzere ML, De Bacquer DA, de Leeuw PW, Duprez DA, Fagard RH, Gheeraert PJ, Missault LH, Braun JJ, Six RO, Van Der Niepen P, O'Brien E; Office versus Ambulatory Pressure Study 
Investigators. Prognostic value of ambulatory blood pressure recordings in patients with treated hypertension. N Engl J Med 2003;348: 2407-2415.

140. Parati G, Pomidossi G, Albini F, Malaspina D, Mancia G. Relationship of 24-hour blood pressure mean and variability to severity of target-organ damage in hypertension. J Hypertens 1987;5:93-98.

141. Frattola A, Parati G, Cuspidi C, Albini F, Mancia G. Prognostic value of 24-hour blood pressure variability. J Hypertens 1993;11:1133-1137.

142. Sander D, Kukla C, Klingelhofer J, Winbeck K, Conrad B. Relationship between circadian blood pressure patterns and progression of early carotid atherosclerosis: a 3-year follow-up study. Circulation 2000; 102:1536-1541.

143. Mancia G, Sega R, Milesi C, Cesana G, Zanchetti A. Blood-pressure control in the hypertensive population. Lancet 1997;349:454-457.

144. Baigent C, Keech A, Kearney PM, Blackwell L, Buck G, Pollicino C, Kirby A, Sourjina T, Peto R, Collins R, Simes R; Cholesterol Treatment Trialists' (CTT) Collaborators. Efficacy and safety of cholesterollowering treatment: prospective meta-analysis of data from 90,056 participants in 14 randomised trials of statins. Lancet 2005;366:1267-1278.

145. Collins R, Armitage J, Parish S, Sleigh P, Peto R; Heart Protection Study Collaborative Group. MRC/BHF Heart Protection Study of cholesterollowering with simvastatin in 5963 people with diabetes: a randomised placebo-controlled trial. Lancet 2003;361:2005-2016.

146. Colhoun H, Betteridge DJ, Durrington PN, Hitman GA, Neil HA, Livingstone SJ, Thomason MJ, Mackness MI, Charlton-Menys V, Fuller JH; CARDS investigators. Primary prevention of cardiovascular disease with atorvastatin in type 2 diabetes in the Collaborative Atorvastatin Diabetes Study (CARDS): multicentre randomised placebocontrolled trial. Lancet 2004;364:685-696.

147. 4S Scandinavian Simvastatin Survival Study Group. Randomised trial of cholesterol lowering in 4444 patients with coronary heart disease: the Scandinavian Simvastatin Survival Study (4S). Lancet 1994;344: 1383-1389.

148. Shepherd J, Cobbe SM, Ford I, Isles CG, Lorimer AR, MacFarlane PW, McKillop JH, Packard CJ. Prevention of coronary heart disease with pravastatin in men with hypercholesterolemia. West of Scotland Coronary Prevention Study Group. N Engl J Med 1995;333:1301-1307.

149. Long-Term Intervention with Pravastatin in Ischaemic Disease (LIPID) Study Group. Prevention of cardiovascular events and death with pravastatin in patients with coronary heart disease and a broad range of initial cholesterol levels. N Engl J Med 1998;339:1349-1357.

150. Bucher H, Griffith LE, Guyatt GH. Effect of HMGcoA reductase inhibitors on stroke. A meta-analysis of randomized, controlled trials. Ann Intern Med 1998;128:89-95.

151. Schwartz G, Olsson AG, Ezekowitz MD, Ganz P, Oliver MF, Waters D, Zeiher A, Chaitman BR, Leslie S, Stern T; Myocardial Ischemia Reduction with Aggressive Cholesterol Lowering (MIRACL) Study Investigators. Effects of atorvastatin on early recurrent ischemic events in acute coronary syndromes: the MIRACL study: a randomized controlled trial. JAMA 2001;285:1711-1718.

152. Ray K, Cannon CP, McCabe CH, Cairns R, Tonkin AM, Sacks FM, Jackson G, Braunwald E; PROVE IT-TIMI 22 Investigators. Early and late benefit of high-dose atorvastatin in patients with acute coronary syndromes: results from the PROVE-IT-TIMI22 trial. J Am Coll Cardiol 2005;46: 1405-1410.

153. de Lemos J, Blazing MA, Wiviott SD, Lewis EF, Fox KA, White HD, Rouleau JL, Pedersen TR, Gardner LH, Mukherjee R, Ramsey KE, Palmisano J, Bilheimer DW, Pfeffer MA, Califf RM, Braunwald E; A to Z Investigators. Early intensive vs a delayed conservative simvastatin strategy in patients with acute coronary syndrome: phase $\mathrm{Z}$ of the $\mathrm{A}$ to Z trial. JAMA 2004;292:1307-1316.

154. Nissen S, Nicholls SJ, Sipahi I, Libby P, Raichlen JS, Ballantyne CM, Davignon J, Erbel R, Fruchart JC, Tardif JC, Schoenhagen P, Crowe T, Cain V, Wolski K, Goormastic M, Tuzcu EM. Effect of very high-intensity statin therapy on regression of coronary atherosclerosis: the ASTEROID trial. JAMA 2006;295:1556-1565.

155. Reiner Z, Galic M, Hanzevacki M, Tedeschi-Reiner E. Concomitant use of statins and cytochrome P 450 inhibitors. Lijec Vjesn 2005;127:65-68.

156. Grundy S, Brewer HB Jr, Cleeman JI, Smith SC Jr, Lenfant C. Definition of the metabolic syndrome. Report of the National Heart, Lung, and Blood Institute/American Heart Association conference on scientific issues related to definition. Circulation 2004;109:433-438.

157. Expert Panel on Detection, Evaluation, and Treatment of High Blood Cholesterol In Adults (Adult Treatment Panel III). Executive Summary of The Third Report of The National Cholesterol Education Program (NCEP). JAMA 2001;285:2486-2497.
158. Alberti K, Zimmet P, Shaw J, IDF Epidemiology Task Force Consensus Group. The metabolic syndrome-a new worldwide definition Lancet 2005;366:1059-1062.

159. Rozanski A, Blumenthal JA, Davidson KW, Saab PG, Kubzansky L. The epidemiology, pathophysiology, and management of psychosocial risk factors in cardiac practice: the emerging field of behavioral cardiology. J Am Coll Cardiol 2005;45:637-651.

160. Rees K, Bennett P, West R, Davey SG, Ebrahim S. Psychological Interventions for Coronary Heart Disease (Cochrane Review). Oxford: Update Software; 2004

161. Albus C, Jordan J, Herrmann-Lingen C. Screening for psychosocial risk factors in patients with coronary heart disease-recommendations for clinical practice. Eur J Cardiovasc Prev Rehabil 2004;11:75-79.

162. Ross R. Atherosclerosis-an inflammatory disease. N Engl J Med 1999; 340:115-126.

163. Libby P, Ridker PM, Maseri A. Inflammation and atherosclerosis. Circulation 2002; 105:1135-1143.

164. Ridker P, Hennekens $\mathrm{CH}$, Buring JE, Rifai N. C-reactive protein and other markers of inflammation in the prediction of cardiovascular disease in women. N Engl J Med 2000;342:836-843.

165. Scarabin P, Arveiler D, Amouyel P, Dos Santos C, Evans A, Luc G, Ferrières J, Juhan-Vague I; Prospective Epidemiological Study of Myocardial Infarction. Plasma fibrinogen explains much of the difference in risk of coronary heart disease between France and Northern Ireland. The PRIME Study. Atherosclerosis 2003;166:103-109.

166. Yarnell J, Patterson CC, Sweetnam PM, Lowe GDO. Haemostatic/inflammatory markers predict 10-year risk of IHD at least as well as lipids: the Caerphilly collaborative studies. Eur Heart J 2004;25:1049-1056.

167. Blankenberg $S$, Luc $G$, Ducimetière $P$, Arveiler $D$, Ferrières $J$, Amouyel $P$, Evans A, Cambien F, Tiret L; PRIME Study Group. Interleukin-18 and the risk of coronary heart disease in European men: the Prospective Epidemiological Study of Myocardial Infarction (PRIME). Circulation 2003; 108:2453-2459.

168. Smeeth L, Thomas SL, Hall AJ, Hubbard R, Farrington P, Vallance P. Risk of myocardial infarction and stroke after acute infection or vaccination. N Engl J Med 2004;351:2611-2618.

169. Pearson T, Mensah GA, Alexander RW, Anderson JL, Cannon RO, Criqui M, Fadl YY, Fortmann SP, Hong Y, Myers GL, Rifai N, Smith SC, Taubert K, Tracy RP, Vinicor F; Centers for Disease Control and Prevention; American Heart Association. Markers of inflammation and cardiovascular disease: application to clinical and public health practice: a statement for healthcare professionals from the Centers for Disease Control and Prevention and the American Heart Association. Circulation 2003;197: 499-551.

170. Lowe G. Can haematological tests predict cardiovascular risk? The 2005 Kettle Lecture. Br J Haematol 2006;133:232-250.

171. Lowe G. Circulating inflammatory markers and risks of cardiovascular and noncardiovascular disease. J Thromb Haemostasis 2005;3: 1618-1627.

172. Danesh J, Wheeler JG, Hirschfield GM, Eda S, Eiriksdottir G, Rumley A, Lowe GD, Pepys MB, Gudnason V. C-reactive protein and other circulating markers of inflammation in the prediction of coronary heart disease. N Engl J Med 2004;350:1387-1397.

173. Geelen A, Brouwer IA, Schouten EG, Maan AC, Katan MB, Zock PL. Effects of $\mathrm{n}-3$ fatty acids from fish on premature ventricular complexes and heart rate in humans. Am J Clin Nutr 2005;81:416-420.

174. Ye Z, Liu EH, Higgins JP, Keavney BD, Lowe GD, Collins R, Danesh J. Seven haemostatic gene polymorphisms in coronary disease: meta-analysis of 66,155 cases and 91,307 controls. Lancet 2006;367: 651-658.

175. Myers R, Kiely DK, Cupples LA, Kannel WB. Parental history is an independent risk factor for coronary artery disease: the Framingham Study. Am Heart J 1990;120:963-969.

176. Hawe E, Talmud PJ, Miller GJ, Humphries SE. Family history is a coronary heart disease risk factor in the Second Northwick Park Heart Study. Ann Hum Genet 2003;67:97-106.

177. Beekman M, Heijmans BT, Martin NG, Pedersen NL, Whitfield JB, DeFaire U, van Baal GC, Snieder H, Vogler GP, Slagboom PE, Boomsma DI. Heritabilities of apolipoprotein and lipid levels in three countries. Twin Res 2002;5:87-97.

178. Austin M, Sandholzer C, Selby JV, Newman B, Krauss RM, Utermann G. Lipoprotein(a) in women twins: heritability and relationship to apolipoprotein(a) phenotypes. Am J Hum Genet 1992;51:829-840.

179. Danesh J, Collins R, Peto R. Lipoprotein(a) and coronary heart disease. Meta-analysis of prospective studies. Circulation 2000;102:1082-1085. 
180. Pankow J, Folsom AR, Cushman M, Borecki IB, Hopkins PN, Eckfeldt JH, Tracy RP. Familial and genetic determinants of systemic markers of inflammation: the NHLBI family heart study. Atherosclerosis 2001;154: 681-689.

181. Worns M, Victor A, Galle PR, Hohler T. Genetic and environmental contributions to plasma C-reactive protein and interleukin-6 levels-a study in twins. Genes Immun 2006; 7:600-605.

182. Humphries S, Ridker PM, Talmud PJ. Genetic testing for cardiovascular disease susceptibility: a useful clinical management tool or possible misinformation? Arterioscler Thromb Vasc Biol 2004;24:628-636.

183. Redon R, Ishikawa S, Fitch KR, Feuk L, Perry GH, Andrews TD, Fiegler $H$, Shapero MH, Carson AR, Chen W, Cho EK, Dallaire S, Freeman JL, González JR, Gratacòs M, Huang J, Kalaitzopoulos D, Komura D, MacDonald JR, Marshall CR, Mei R, Montgomery L, Nishimura K, Okamura K, Shen F, Somerville MJ, Tchinda J, Valsesia A, Woodwark C, Yang F, Zhang J, Zerjal T, Zhang J, Armengol L, Conrad DF, Estivill X, Tyler-Smith C, Carter NP, Aburatani H, Lee C, Jones KW, Scherer SW, Hurles ME. Global variation in copy number in the human genome. Nature 2006;444:444-454.

184. Casas J, Cooper J, Miller GJ, Hingorani AD, Humphries SE. Investigating the genetic determinants of cardiovascular disease using candidate genes and meta-analysis of association studies. Ann Hum Genet 2006; 70:145-169.

185. Wilson P, D’Agostino RB, Levy D, Belanger AM, Silbershatz H, Kannel WB. Prediction of coronary heart disease using risk factor categories. Circulation 1997; 97:1837-1847.

186. Assmann G, Cullen P, Schulte H. Simple scoring scheme for calculating the risk of acute coronary events based on the 10-year follow-up of the prospective cardiovascular Munster (PROCAM) study. Circulation 2002; 105:310-315.

187. Cooper J, Miller GJ, Humphries SE. A comparison of the PROCAM and Framingham point-scoring systems for estimation of individual risk of coronary heart disease in the Second Northwick Park Heart Study. Atherosclerosis 2005;181:93-100.

188. Yang Q, Khoury MJ, Friedman JM, Little J, Flanders WD. How many genes underlie the occurrence of common complex diseases in the population? Int J Epidemiol 2005;34:1129-1137.

189. Goldstein J, Brown M. Familial hypercholesterolaemia. In: Scriver C, Beaudet A, Sly W, Valle D eds. The Metabolic Basis of Inherited Disease. New York: McGraw Hill; 1995. p1215-1245.

190. Patterson D, Slack J. Lipid abnormalities in male and female survivors of myocardial infarction and their first-degree relatives. Lancet 1972;1: 393-399.

191. Scientific Steering Committee on behalf of Simon Broome Register Group. The risk of fatal coronary heart disease in familial hypercholesterolaemia. BMJ 1991;303:893-896.

192. Williams R, Hunt SC, Schumacher MC, Hegele RA, Leppert MF, Ludwig EH, Hopkins PN. Diagnosing heterozygous familial hypercholesterolaemia using new practical criteria validated by molecular genetics. Am J Cardiol 1993;72:171-176.

193. Umans-Eckenhausen M, Defesche JC, Sijbrands EJ, Scheerder RL, Kastelein JJ. Review of first 5 years of screening for familial hypercholesterolaemia in the Netherlands. Lancet 2001;357:165-168.

194. Heath K, Humphries SE, Middleton-Price H, Boxer M. A molecular genetic service for diagnosing individuals with familial hypercholesterolaemia (FH) in the United Kingdom. Eur J Hum Genet 2001;9:244-252.

195. Fouchier S, Defesche JC, Umans-Eckenhausen MW, Kastelein JP. The molecular basis of familial hypercholesterolemia in The Netherlands. Hum Genet 2001;109:602-615.

196. Holla O, Teie C, Berge KE, Leren TP. Identification of deletions and duplications in the low density lipoprotein receptor gene by MLPA. Clin Chim Acta 2005;356:164-171.

197. Heath K, Gahan M, Whittall RA, Humphries SE. Low-density lipoprotein receptor gene (LDLR) world-wide website in familial hypercholesterolaemia: update, new features and mutation analysis. Atherosclerosis 2001; 154:243-246.

198. Myant N. Familial defective apolipoprotein B-100: a review, including some comparisons with familial hypercholesterolaemia. Atherosclerosis 1993;104:1-18.

199. Abifadel M, Varret M, Rabès JP, Allard D, Ouguerram K, Devillers $M$, Cruaud $C$, Benjannet $S$, Wickham L, Erlich $D$, Derré A, Villéger $L$, Farnier M, Beucler I, Bruckert E, Chambaz J, Chanu B, Lecerf JM, Luc G, Moulin P, Weissenbach J, Prat A, Krempf $M$, Junien $C$, Seidah NG, Boileau C. Mutations in PCSK9 cause autosomal dominant hypercholesterolemia. Nat Genet 2003;34:154-156.
200. Familial hypercholesterolemia in Spain: case-finding program clinical genetic aspects. Semin Vasc Med 2004;4:67-74.

201. Marks D, Thorogood M, Neil SM, Humphries SE, Neil HA. Cascade screening for familial hypercholesterolaemia: implications of a pilot study for national screening programmes. J Med Screen 2006;13:156-159.

202. Thorsson B, Sigurdsson G, Gudnason V. Systematic family screening for familial hypercholesterolemia in Iceland. Arterioscler Thromb Vasc Biol 2003;23:335-338.

203. Leren T, Manshaus T, Skovholt U, Skodje T, Nossen IE, Teie C, Sorensen S, Bakken KS. Application of molecular genetics for diagnosing familial hypercholesterolemia in Norway: results from a family-based screening program. Semin Vasc Med 2004;4:75-85.

204. Hadfield S, Humphries SE. Implementation of cascade testing for the detection of familial hypercholesterolaemia. Curr Opin Lipidol 2005; 16:428-433.

205. Goldstein J, Hazzard WR, Schrott HG, Bierman EL, Motulsky AG. Hyperlipidemia in coronary heart disease. I. Lipid levels in 500 survivors of myocardial infarction. J Clin Invest 1973;52:1533-1543.

206. Pajukanta P, Lilja HE, Sinsheimer JS, Cantor RM, Lusis AJ, Gentile M, Duan XJ, Soro-Paavonen A, Naukkarinen J, Saarela J, Laakso M, Ehnholm C, Taskinen MR, Peltonen L. Familial combined hyperlipidemia is associated with upstream transcription factor 1 (USF1). Nat Genet 2004; 36:371-376.

207. Naukkarinen J, Gentile M, Soro-Paavonen A, Saarela J, Koistinen HA, Pajukanta P, Taskinen MR, Peltonen L. USF1 and dyslipidemias: converging evidence for a functional intronic variant. Hum Mol Genet 2005; 14:2595-2605.

208. von Eckardstein A. Differential diagnosis of familial high density lipoprotein deficiency syndromes. Atherosclerosis 2006;186:231-239.

209. Stramba-Badiale M, Fox KM, Priori SG, Collins P, Daly C, Graham I, Jonsson B, Schenk-Gustafsson K, Tendera M. Cardiovascular disease in women: a statement from the policy conference of the European Society of Cardiology. Eur Heart J 2006;27:994-1005.

210. Mosca L, Appel LJ, Benjamin EJ, Berra K, Chandra-Strobos N, Fabunmi RP, Grady D, Haan CK, Hayes SN, Judelson SR, Keenan NL, McBride P, Oraril S, Ouyang P, Oz MC, Mendelsohn SC, Pasternak RC, Pinn VW, Robertson RM, Schenk-Gustafsson K, Sila CA, Smith SC Jr, Sopko G, Taylor AL, Walsh BW, Wenger NK, Williams CL; American Heart Association. Evidence-based guidelines for cardiovascular disease prevention in women. Circulation 2004;109:672-693.

211. Manolio T, Pearson T, Wenger NH, Barrett-Connor E, Payne GH. Cholesterol and heart disease in older persons and women. Ann Epidemiol 1992;2:161-176.

212. Jacobs A, Kelsey SF, Brooks MM, Faxon DP, Chaitman BR, Bittner V, Mock MB, Weiner BH, Dean L, Winston C, Drew L, Sopko G. Better outcome for women compared with men undergoing coronary revascularization: a report from the bypass angioplasty revascularization investigation (BARI). Circulation 1998;98:1279-1285.

213. Stramba-Badiale M, Priori SG. Gender-specific prescription for cardiovascular diseases? Eur Heart J 2005;26:1571-1572.

214. Ridker P, Cook NR, Lee IM. A randomized trial of low-dose aspirin in the primary prevention of cardiovascular disease in women. $N$ Engl J Med 2005;352:1293-1304.

215. Kachelriess M, Kalender WA. Electrocardiogram-correlated image reconstruction from subsecond spiral computed tomography scans of the heart. Med Phys 1998;25:2417-2431.

216. Tedeschi-Reiner E, Reiner Z, Sonicki Z. Atherosclerosis of retinal arteries in men: Role of serum lipoproteins and apoproteins. Croat Med J 2004; 45:333-337.

217. Tedeschi-Reiner E, Strozzi M, Skoric B, Reiner Z. Relation of atherosclerotic changes in retinal arteries to the extent of coronary artery disease. Am J Cardiol 2005;96:1107-1109.

218. Berl T, Henrich W. Kidney-heart interactions: epidemiology, pathogenesis, and treatment. Clin J Am Soc Nephrol 2006;1:8-18.

219. Fox C, Larson MG, Leip EP, Culleton B, Wilson PWF, Levy D. Predictors of new-onset kidney disease in a community-based population. JAMA 2004; 291:844-850.

220. Sarafidis P, Whaley-Connell, Sowers J, Bakris GL. Cardiometabolic syndrome and chronic kidney disease: what is the link? JCMS 2006;1:58-65.

221. Cozzolino M, Brancaccio D, Gallieni M, Slatopolsky E. Pathogenesis of vascular calcification in chronic kidney disease. Kidney Int 2005;68: 429-436.

222. Strippoli G, Craig JC, Manno C, Schena FP. Hemoglobin targets for the anemia of chronic kidney disease: a meta-analysis of randomized controlled trials. J Am Soc Nephrol 2004;15:3154-3165. 
223. Segura J, Gracia-Donaire JA, Praga M, Ruilope LM. Chronic kidney disease as a situation of high added risk in hypertensive patients. J Am Soc Nephrol 2006;17(4 Suppl 2):S136-S140.

224. Ezekowitz J, McAlister FA, Humphries KH, Norris CM, Tonelli $M$, Ghali WA, Knudson ML. The association among renal insufficiency, pharmacotherapy and outcomes in 6247 patients with heart failure and coronary artery disease. J Am Coll Cardiol 2004;44: 1587-1592.

225. Antithrombotic Trialists' Collaboration. Collaborative meta-analysis of randomised trials of antiplatelet therapy for prevention of death, myocardial infarction, and stroke in high risk people. BMJ 2002;324: 71-86.

226. CURE Trial Investigators. Effects of clopidogrel in addition to aspirin in patients with acute coronary syndromes without ST-segment elevation. N Engl J Med 2001;345:494-502.

227. Bonarjee V, Carstensen S, Caidahl K, Nilsen DW, Edner M, Berning J. Attenuation of left ventricular dilatation after acute myocardial infarction by early initiation of enalapril therapy. CONSENSUS II Multi-Echo Study Group. Am J Cardiol 1993;72:1004-1009.
228. Hurlen $M$, Abdelnoor M, Smith P, Erikssen J, Arnesen H. Warfarin, aspirin, or both after myocardial infarction. N Eng J Med 2002;347: 969-974.

229. Fuster V, Rydén LE, Cannom DS, Crijns HJ, Curtis AB, Ellenbogen KA, Halperin JL, Le Heuzey JY, Kay GN, Lowe JE, Olsson SB, Prystowsky EN, Tamargo JL, Wann S, Smith SC, Jacobs AK, Adams CD, Anderson JL, Antman EM, Halperin JL, Hunt SA, Nishimura R, Ornato JP, Page RL, Riegel B, Priori SG, Blanc JJ, Budaj A, Camm AJ, Dean V, Deckers JW, Despres C, Dickstein K, Lekakis J, McGregor K, Metra M, Morais J, Osterspey A, Tamargo JL, Zamorano JL; American College of Cardiology; American Heart Association Task Force; European Society of Cardiology Committee for Practice Guidelines; European Heart Rhythm Association; Heart Rhythm Society. ACC/AHA/ESC 2006 guidelines for the management of patients with atrial fibrillation: executive summary. Eur Heart J 2006;27:1979-2030.

230. Getz L, Sigurdsson JA, Hetlevik I, Kirkengen AL, Romundstad S, Holmen J. Estimating the high risk group for cardiovascular disease in the Norwegian HUNT 2 population according to the 2003 European guidelines: modelling study. BMJ 2005;331:551. 